Elsevier Editorial System(tm) for

Experimental Thermal and Fluid Science

Manuscript Draft

Manuscript Number: ETFS-D-17-00122R1

Title: An experimental investigation on the evaporation and condensation heat transfer of two-phase closed thermosyphons

Article Type: Research paper

Keywords: thermosyphon,

pool boiling,

liquid film evaporation,

condensation

Corresponding Author: Dr. Davoud jafari, Ph.D.

Corresponding Author's Institution: University of Twente

First Author: Davoud jafari, Ph.D.

Order of Authors: Davoud jafari, Ph.D.; Paolo Di Marco, Associate professor; Sauro Filippeschi, Assistance professor; Alessandro Franco, Professor

Abstract: Two-phase closed thermosyphons (TPCTs) are excellent thermal transfer devices that their integration into heat exchangers has been shown a strong potential for energy savings. The scope of this study is an experimental evaluation of the evaporation and condensation heat transfer of a TPCT for uniformly heated evaporator surface. Water as the working fluid is charged in a TPCT with a length of $500 \mathrm{~mm}$ and an inner diameter of $33 \mathrm{~mm}$ at different filling ratios (8\%-100\%). The performance of the thermosyphon with predictions of the pool boiling (filling ratio of $100 \%$ ) and a combination of the pool boiling and film evaporation models in the evaporator section (filling ratio<100\%) are compared with available predictive correlations and theories. The experimentally obtained condensation heat transfers also evaluate by available filmwise condensation model in the condenser section. Results show an agreement with the most of the selected correlations with tolerance $\pm 30 \%$ and the appropriate set of correlations are introduced within an accuracy of $\pm 10 \%$. 


\section{UNIVERSITY \\ OF TWENTE.}

Object: Submission of revision paper (ETFS-D-17-00122)

Dear Professor Cornelis W.M. van der Geld,

Please find enclosed the revised version of our manuscript (ETFS-D-17-00122).

We greatly appreciate the opportunity that we have been given to further revise the manuscript. We have considered and re-reviewed the revised manuscript submitted on 9 February 2017. We answered to the reviewer comment and we hope that the clarity of the manuscript is improved.

We would like to express our gratitude to you and reviewers for the extremely helpful comments and guidance in the revision. We hope that our efforts have succeeded in addressing yours and reviewers concerns. We look forward to your decision.

Sincerely yours,

Davoud Jafari

Davoud Jafari

Faculty of Engineering Technology

University of Twente

P.O. Box 217, 7500 AE Enschede

The Netherlands,

e-mail: davoud.jafari@utwente.nl, j.davoud@yahoo.com
Engineering Technology Faculty

Department of Design,

Production and Management

P.0. Box 217,

7500 AE Enschede,

The Netherlands

23 March 2017 


\section{Highlights for:}

\section{An experimental investigation on the evaporation and condensation heat transfer of thermosyphons}

- The heat transfer characteristics of thermosyphons are experimentally examined.

- The evaporation and the condensation heat transfers of a thermosyphon are proposed.

- Sensitivity of evaporation heat transfer correlations to filling ratio and heat flux is described.

- The most appropriate sets of correlations are suggested. 


\title{
An experimental investigation on the evaporation and condensation heat transfer of two-phase closed thermosyphons
}

\author{
Davoud Jafari $^{1, *}$, Paolo Di Marco ${ }^{2}$, Sauro Filippeschi $^{2}$, Alessandro Franco ${ }^{2}$ \\ ${ }^{1}$ Faculty of Engineering Technology, University of Twente, P.O. Box 217, 7500 AE Enschede, The \\ Netherlands \\ ${ }^{2}$ Department of Energy, Systems, Territory and Constructions Engineering (DESTEC), \\ University of Pisa, Italy
}

Corresponding Author:

Davoud Jafari

University of Twente

Faculty of Engineering Technology, P.O. Box 217, 7500 AE Enschede, The Netherlands

Email: davoud.jafari@utwente.nl, j.davoud@yahoo.com

\begin{abstract}
Two-phase closed thermosyphons (TPCTs) are excellent thermal transfer devices that their integration into heat exchangers has been shown a strong potential for energy savings. The scope of this study is an experimental evaluation of the evaporation and condensation heat transfer of a TPCT for uniformly heated evaporator surface. Water as the working fluid is charged in a TPCT with a length of $500 \mathrm{~mm}$ and an inner diameter of $33 \mathrm{~mm}$ at different filling ratios (8\%-100\%). The performance of the thermosyphon with predictions of the pool boiling (filling ratio of 100\%) and a combination of the pool boiling and film evaporation models in the evaporator section (filling ratio<100\%) are compared with available predictive correlations and theories. The experimentally obtained condensation heat transfers also evaluate by available filmwise condensation model in the condenser section. Results show an agreement with the most of the selected correlations with tolerance $\pm 30 \%$ and the appropriate set of correlations are introduced within an accuracy of $\pm 10 \%$.
\end{abstract}

Keywords: thermosyphon, pool boiling, liquid film evaporation, condensation 


\section{Nomenclature}

Bo $\quad$ Bond number, $d_{i} / L_{b}$

c Specific heat $\left(\mathrm{J} \mathrm{kg}^{-1} \mathrm{~K}^{-1}\right)$

D Diameter (m)

$d_{b} \quad$ Bubble departure diameter (m)

FR Filling ratio

$g \quad$ Gravitational acceleration $\left(\mathrm{m} \mathrm{s}^{-2}\right)$

$h \quad$ Heat transfer coefficient $\left(\mathrm{W} \mathrm{m}^{-2} \mathrm{~K}^{-1}\right)$

$h_{f g} \quad$ Heat of vaporization $\left(\mathrm{J} \mathrm{kg}^{-1}\right)$

$K \quad$ Thermal conductivity $\left(\mathrm{W} \mathrm{m} \mathrm{m}^{-1} \mathrm{~K}^{-1}\right)$

L $\quad$ Length (m)

$L_{b} \quad$ Bubble length scale $(\mathrm{m}),\left[\sigma / g\left(\rho_{l}-\rho_{v}\right)\right]^{1 / 2}$

$\dot{m} \quad$ Mass flow rate $\left(\mathrm{kg} \mathrm{s}^{-1}\right)$

$\mathrm{Nu} \quad$ Nusselt number, $h L / k$

$P \quad$ Pressure $(\mathrm{Pa})$

Pr Prandtl number, $v / \alpha$

Q Heat transfer rate (W)

$q \quad$ Heat flux $\left(\mathrm{W} \mathrm{m}^{-2}\right)$

$R \quad$ Thermal resistance $\left({ }^{\circ} \mathrm{K} \mathrm{W}^{-1}\right)$

$r \quad$ Radius (m)

Re Reynolds number, $4 Q / \pi D h_{f g} \pi$

$T \quad$ Temperature $\left({ }^{\circ} \mathrm{K}\right)$

\section{Greek symbols}

$\begin{array}{ll}v & \text { Kinematic viscosity }\left(\mathrm{m}^{2} \mathrm{~s}^{-1}\right) \\ \rho & \text { Density }\left(\mathrm{kg} \mathrm{m}^{-3}\right) \\ \mu & \text { Dynamic viscosity }(\mathrm{Pa} \mathrm{s}) \\ \sigma & \text { Surface tension }\left(\mathrm{N} \mathrm{m}^{-1}\right) \\ \theta & \text { Contact angle }\left(^{\circ}\right)\end{array}$

Subscripts

\begin{tabular}{cl} 
a & Adiabatic \\
atm & Atmospheric \\
$\mathrm{c}$ & Condenser \\
$\mathrm{e}$ & Evaporator \\
film & Liquid film \\
$\mathrm{i}$ & Inner \\
$\mathrm{l}$ & Liquid \\
$\mathrm{o}$ & Outer \\
$\mathrm{p}$ & Pool \\
$\mathrm{sat}$ & Saturation \\
$\mathrm{t}$ & Total \\
$\mathrm{v}$ & Vapor \\
& \\
& \\
\hline
\end{tabular}

\section{Introduction}

A continuous cycle of the evaporation and the condensation processes is encountered in many energy and thermal processing applications. The example includes, but not limited, two-phase devices. A twophase closed thermosyphon (TPCT) or a gravity-assisted wickless heat pipe is one of the two-phase passive devices which work on the mechanisms of evaporation and condensation to transfer large amounts of heat with a minimal temperature difference [1]. A TPCT operates when heat is applied to the evaporator section, causes evaporation of the working fluid. The vapor flows to the condenser section, where the fluid condenses. Then, the condensate returns to the evaporator section along the 
wall by the action of gravity, closing the cycle. Given the advantages of the TPCT, heat transfer predictions in its uniformly heated are of interest in many industrial and energy applications. Examples of these applications include heating, ventilation and air conditioning, residential and commercial refrigeration, data center cooling, solar water heating and geothermal energy recovery [2-6].

The challenges of prediction of the heat transfer process in two-phase devices to be integrated into many industrial thermal controls have been raised. The heat and mass transfer processes inside a TPCT include convection, pool boiling, thin liquid film evaporation, countercurrent two-phase flow and filmwise condensation. In the evaporator section, the falling liquid film and the liquid pool in the bottom of the device are occurred participating in the phase change and heat transfer simultaneously. As various heat transfer regimes can be observed in the evaporator section include natural convection, mixed convection and the nucleate boiling (at high heat fluxes), its heat transfer mechanism is complex [7]. Recent studies considered the nucleate pool boiling regime to predict the heat transfer coefficients within the evaporator section: Rohsenow [8], Labuntsov [9], Imura et al. [10], Shiraishi et al. [11], Kutateladze [12] and Chowdhury et al. [13]. For a relatively small heat flux, Nusselt theory for filmwise evaporation is suggested [7, 14] while Shiraishi et al. [11] suggested a modification of Nusselt theory when nucleate boiling within the liquid film is dominant. Among others, Kiatsiriroat et al. [15] reported the use of a modified Rohsenow [8] correlation to predict the boiling heat transfer coefficient inside the thermosyphon for different working fluid. Park et al. [16], Noie [17] and Guo and Nutter [18] showed a good agreement with the Imura [10] using FC-72, water and R134a as a working fluid, respectively. Jouhara and Robinson [14] experimentally investigated a thermosyphons charged with water at filling ratios of $50 \%$ and $160 \%$. They compared the evaporation heat transfer with available predictive correlations and theories with a good agreement; however, they have not analyzed the combination of correlation in the case of low filling ratio. 
A Nusselt analysis for filmwise condensation has been used to predict condensation heat transfer coefficient. To predict the filmwise condensation heat transfer, Rohsenow [8] modified Nusselt correlation which is applicable when Reynolds film number is in the range of 30-1600. Hashimoto and Kaminaga [19] provided a correlation considering the effect of entrainment which latter modified by Jouhara and Robinson [14]. Different approaches for defining the condensation heat transfer is defined by Wang and Ma [20] applicable for vertical and inclined TPCTs. Hussein et al. [21] presented a correlation to predict condensation heat transfer a wide range of inclination angles. The majority of studies to analyze evaporation and condensation heat transfer have been recently discussed by Jafari et al. [2]. They have made a comparative analysis of the heat transfer correlations with the experimental data in the literature. They showed that the results appear to be dispersed both for condenser and evaporator sections.

The thermal characteristics of TPCTs have been investigated in recent years [22-25]. There still exists, however, uncertainty in the description of heat transfer characteristics. Previous studies on the investigation of evaporation heat transfer focused on pool boiling or film evaporation heat transfer. There is limited open literature on the combination of pool boiling and film evaporation heat transfer on TPCTs. The selection of appropriate heat transfer correlation would be resulted in prediction thermal performance of two-phase closed thermosyphon and also their integration into lots of practical applications. The authors of present study [26], recently, experimentally and numerically investigated the transient behavior of TPCTs at different filling ratios. They showed that the Imura [10] correlation is able to accurately predict the pool boiling heat transfer as expected from the literature for high filling ratios (filling ratio of 135\%), but comparable agreement observed at low filling ratios (filling ratio of $16 \%$ and $35 \%)$. Therefore, there is a need to evaluate the reported heat transfer correlations for thermosyphons to present more accurate heat transfer correlations as well as their combination. This paper is the second part of the recent paper [26]. In current document, the experimental data of a thermosyphon with $500 \mathrm{~mm}$ 
length and $33 \mathrm{~mm}$ internal diameter charging with water is presented. Water tests are performed with different filling ratios range from $8 \%$ to $100 \%$; to have a combination of the liquid pool and liquid film region and also to have only pool boiling. The experimental measurements are compared with those of a model that is based on existing correlations of the literature basing on evaporation and condensation heat transfer.

\section{Methods for prediction of condensation and evaporation heat transfer in a TPCT}

A TPCT is divided into three sections: an evaporator, an adiabatic and a condenser, as shown in Fig. 1. The thermosyphon operates when heat is supplied to the evaporator section. The working fluid in the evaporator section is vaporized and transfers heat from the evaporator section (heat source) to the condenser section (heat sink), where condensation of the working fluid occurs. Then, a countercurrent (the liquid and the vapor flow in opposite directions) thin liquid film is flow backed to the evaporator section under the gravitational force which the liquid is evenly distributed around the thermosyphon wall. The thermal resistances of a thermosyphon are illustrated in Fig. 1.

The two major contributors to the total thermal resistance of a thermosyphon are the thermal resistances in the liquid film in both the condenser $\left(R_{c}\right)$ and the evaporator $\left(R_{e, f i l m}\right)$. The condensation thermal resistance of the thermosyphon is verified by

$R_{c}=\frac{1}{h_{c} A_{c}}$

where $h_{c}$ is the heat transfer coefficient of the liquid film in the condenser section of a thermosyphon, and $A_{c}$ is the inner surface area of the liquid film. There are some parameters that affect the condensation heat transfer: thermal and hydrodynamic properties of the working fluid, local flow velocity, orientation and operating temperature. A Nusselt analysis for condensation on a vertical flat plate is the first basic approach and commonly used to evaluate the condensation heat transfer 
coefficient, considering the filmwise condensation within the laminar regime, Eq. 3 (see Table 1). Where $\rho_{l}$ and $\rho_{v}$ are the density of the liquid and vapor, $k_{l}$ is the thermal conductivity of the liquid, $\mu_{l}$ is the liquid viscosity. The film Reynolds number $\left(R e_{f}\right)$ for this study is defined as

$\operatorname{Re}_{f}=\frac{4 Q}{\pi D h_{f g} \mu_{l}}$

where $h_{f g}$ is the latent heat of vaporization and $D$ is pipe diameter. It is worth noticing that all fluid properties are evaluated at the saturation temperature corresponding to the pressure in the thermosyphon. An approach to predicting condensation heat transfer of TPCTs is presented by Hashimoto and Kaminaga [19], considering the fluid entrainment in a TPCT which later modified by Jouhara and Robinson (Eq. 5). Table 1 lists the selected correlations to predict condensation heat transfer.

The evaporation in the evaporator section is another important thermal resistance. Of the various heat transfer regimes may exist in the liquid pool (natural convection, mixed convection and the nucleate boiling), nucleate boiling is the most desirable regime in practice because of high heat transfer rates. A nucleate boiling heat transfer correlation contains a heat flux, a temperature term, a density and a fluid property dependent factor (Prandtl number, surface tension and heat capacity) [28]. The main available correlations for the pool boiling regime in this paper include Rohsenow [8], Labuntsov [9], Imura et al. [10], Shiraishi et al. [11], Kutateladze [12] and Chowdhury et al. [13], as summarized in Table 2. Where $h_{e, p}$ is the heat transfer coefficient for the internal evaporation from the liquid pool, $g$ is gravitational acceleration, $h_{f g}$ is latent heat of vaporization, $q$ is heat flux to the liquid pool region, $P_{a t m}$ is atmospheric pressure, $\rho_{l}$ and $\rho_{v}$ are liquid and vapor phase densities, $c_{p, l}$ is specific heat of liquid, $k_{l}$ is liquid thermal conductivity, $\mu_{l}$ is liquid dynamic viscosity and $L_{b}$ is the bubble departure diameter given by $\left[\sigma / g\left(\rho_{l}-\rho_{v}\right)\right]^{1 / 2}$. The correlation of Imura et al. [10] was developed specifically for pool boiling in thermosyphons; however, it can cover also the natural convection and combined convection 
regimes [7]. Shiraishi et al. [11] modified Imura [10] correlation by changing the exponent of the pressure term from 0.3 to 0.23 for water, ethanol and R-1 13. The proposed correlation by Rohsenow [8] is independent of the geometry and orientation of the heater surface while includes an adjustable constant that depended upon the nature of the surface-fluid combination. The Kutateladze correlation [12] was also developed for different working fluids which make them more general at the expense of accuracy due to constants and powers of the correlation.

Nusselt theory for filmwise evaporation is applicable for a relatively small heat flux (Eq. 3). For the heat transfer coefficient related to the liquid film in the upper region of the evaporator section, $h_{e, \text { film }}$. Shiraishi et al. [11] used to estimate the liquid film heat transfer coefficient. The thermal resistance of the evaporator part is defined by the heat transfer coefficients associated with an only liquid pool when evaporator section filled with the working fluid (filling ratio is 100\%) $\left(R_{e, p}\right)$ and liquid pool and liquid film when filling ratio is less than $100 \%\left(R_{e, p+f i l m}\right)$ :

$$
\begin{aligned}
& R_{e, p}=\frac{1}{h_{e, p} A_{e}} \\
& R_{e, P+f i l m}=\frac{1}{h_{e, P} A_{e}+h_{e, f i l m}\left(A_{e}-A_{P}\right)}
\end{aligned}
$$

where $h_{e, p}$ is obtained from pool boiling correlations summarize in Table 2 and $h_{e, f i l m}$ is determined by applying Shiraishi et al. [11] correlation. The variables $A_{e}$ and $A_{p}$ are the inner surface area of the evaporator section and the evaporator inner surface area in contact with the liquid pool, respectively.

\section{Experimental setup and procedure}

An experimental apparatus is designed, as illustrated schematically in Fig. 2, consists of a thermosyphon, heater, cooling water flow circuit and instrumentation. The envelope of the TPCT is 
manufactured by copper, with a $35 \mathrm{~mm}$ outside diameter, $1 \mathrm{~mm}$ thickness and $500 \mathrm{~mm}$ length. The volume of the evaporator, $V_{e}$, is defined as the inner volume of that part of the evaporator section of the TPCT where is in contact with electrical heaters. It is quantified as the volume $\pi r_{i}^{2} L_{e}$ with evaporator length $\left(L_{e}\right)$ of $150 \mathrm{~mm}$. To reduce the consequences of non-condensable gas generation inside the thermosyphon, the pipe and the working fluid are degassed under vacuum before charging, different filling ratios of water are examined: $8 \%, 16 \%, 35 \%, 50 \%$ and $100 \%,\left(F R=V_{\text {fluid }} / V_{e}\right)$ where $V_{\text {fluid }}$ is the volume of used water as a working fluid in the TPCT. Heat is applied to the thermosyphon at the evaporator section by using silicon thermofoil heater (model MINCO HK5488R17.2L12A) clamped to the external evaporator wall surface. The electrical power input to the heater is controlled and supplied by a DC Power supply (Agilent DC6575A) which has an accuracy of \pm 1 percent of reading. The condenser section of the thermosyphon is cooled by a flow of water through a $150 \mathrm{~mm}$ long and with an inside diameter of $39 \mathrm{~mm}$. Condenser water is supplied via a cooling bath (HAKKE F-3C DIN 58966). An electromagnetic flow meter (Siemens SITRANS F M MAGFLO5000) is used to measure the mass flow rate of the cooling water. The temperature distribution along the thermosyphon is measured using T-type thermocouples, as shown schematically in Fig. 2. To obtain the input and the output water temperatures from the water jacket, two thermocouples are used. More details of experimental facilities describe in [26]. Table 3 lists the detailed specifications and operating parameters of the TPCT.

The experiments are performed with a TPCT in the vertical orientation. During the tests, the heat input to the evaporator and the temperatures are monitored. An energy balance is performed to obtain a confidence in the measured values of heat transfer rate. Energy balances between the applied heat flux in the evaporator section (the electrical heaters, $Q_{i n}=V I$ ) and the removed heat flux (the heat sink, $\left.Q_{\text {out }}=\dot{m} C_{p}\left(T_{\text {out }}-T_{\text {in }}\right)\right)$ are monitored to ensure an energy balance of at least 90 percent at steady state 
operation, as evidenced in Fig. 3. Where $T_{\text {in }}$ is the temperature of the inlet and $T_{\text {out }}$ is the outlet temperature of cooling water and $\dot{\mathrm{m}}$ is cooling mass flow rate.

The heat transfer capacity of evaporator section is determined by the evaporation heat transfer coefficient $\left(h_{e}\right)$ of the TPCT. From the measured data of wall temperature and vapor temperature (equivalent to the wall temperature of the adiabatic section), the heat transfer coefficient in the evaporator can be evaluated using the following equation:

$h_{e}=\frac{Q_{a v}}{\pi D_{i} L_{e}\left(T_{e, a v e}-T_{v}\right)}$

Where

$Q_{a v}=\frac{Q_{i n}+Q_{o u t}}{2}$

The heat transfer capacity of the condenser section is also reflected through condensation heat transfer coefficient $\left(h_{c}\right)$ for TPCTs. This is associated with conduction through the liquid film inside the thermosyphon and related to the average wall temperature of condenser section which can be evaluated using the following equation:

$h_{c}=\frac{Q_{a v}}{\pi D_{i} L_{c}\left(T_{v}-T_{c, a v e}\right)}$

In the evaporator and condenser regions, respectively, thermal resistances is calculated by

$R_{e}=\frac{T_{e, a v e}-T_{v}}{Q_{a v}}$

$R_{c}=\frac{T_{v}-T_{c, a v e}}{Q_{a v}}$

where $T_{e, a v e}$ and $T_{c, \text { ave }}$ are the average wall temperatures in the evaporator and condenser, respectively, and $T_{v}$ is the saturated vapor temperature taken here as the adiabatic wall temperature. The experimental uncertainty of the measurement is calculated by the uncertainty in the temperature 
measurements at different applied powers, increasing from a higher power to lower one as indicated for total thermal resistance in Table 4.

\section{Results and discussion}

The purpose of experimental results is to understand the condensation and evaporation heat transfer of TPCTs. The performance of the thermosyphon is examined in detail to understand how the system operates in pool boiling mode at a high filling ratio $(\mathrm{FR}=100 \%)$ and how to operate under a combination of film convection and pool boiling $(\mathrm{FR}<100 \%)$. Before discussion on the evaporation and the condensation heat transfer, a sample of steady state and transient operation of thermosyphon is presented.

\subsection{Temperature distribution analysis}

A typical example of external wall temperature distributions along the thermosyphon at heat transfer rates of $30 \mathrm{~W}, 100 \mathrm{~W}$ and $200 \mathrm{~W}$ for filling ratios of $35 \%$ and $100 \%$ under steady state operation is shown in Fig. 4. Obviously, the wall temperatures and the total temperature differences increase with increasing input powers and the wall temperature of the evaporator and condenser sections are approximately uniform for each respective power level tested. The temperature rise of the evaporator section in the filling ratio of $100 \%$ is more than the filling ratio of $35 \%$. The temperature of lower part of the evaporator section in the filling ratio of $35 \%$ is similar to that of filled evaporator (filling ratio of $100 \%$ ) where the maximum temperature is observed as occupied by the liquid pool. The maximum wall temperature is approximately equal to $39{ }^{\circ} \mathrm{C}$ and $41{ }^{\circ} \mathrm{C}$ for filling ratio of $35 \%$ and $100 \%$, respectively at heat transfer rate of $200 \mathrm{~W}$.

In some cases the heat flow rate is high, the thermosyphon can dry out. Fig. 5 shows the transient wall temperature variation for filling ratio of $16 \%$ at the heat flux ranged: $350 \mathrm{~W}$ to $900 \mathrm{~W}$ which the 
maximum heat transfer rate is detected. It is found that the normal operation continues up to heat transfer rate of $800 \mathrm{~W}$. Another observation is local dryout at first stage of operation in which evaporator temperature sharply increases to about $140^{\circ} \mathrm{C}$, and then decreases, much more than steady state operation which is about $43{ }^{\circ} \mathrm{C}$. This phenomenon can be explained by considering the condensate film response. This observation strongly recommends that to avoid an excessive temperature rise in the evaporator section for small filling ratios the input heat should be applied gradually. It should be noticed that when dryout occurs, the measurement is skipped from the heat transfer analysis described in following sections.

\subsection{Heat transfer analysis of the TPCT}

To evaluate the condensation and the evaporation heat transfer, different filling ratios of $16 \%, 35 \%$, $50 \%$ and $100 \%$ is tested. Fig. 6 shows the relationship between experimentally obtained evaporation and condensation heat transfers for filling ratio of $100 \%$ and lower than $100 \%(16 \%, 35 \%$ and $50 \%)$. As it appears, a general trend of both is increasing together with the inlet cooling temperature of $25^{\circ} \mathrm{C}$, at reasonably similar values. However, for the inlet cooling temperature of $55^{\circ} \mathrm{C}$ the results are less clear.

Based on applied filling ratios, the evaporator section divides a region of the liquid pool $\left(L_{p}\right)$ in which nucleate pool boiling is occurring as well a region of the liquid film where evaporation is occurring across a thin liquid film. The evaporation and condensation heat transfers are predicted by the correlations listed in Table 1 and Table 2. Accordingly, the thermal resistance of the evaporator section obtains by Eq. 12 and Eq. 13 based on filling ratio and condenser section thermal resistance obtains by Eq. 1.

\subsubsection{Condensation heat transfer}


Dimensionless numbers are often used for a general characterization of heat transfer. The heat transfer in the condenser section is verified by a relation between Nusselt number, $N u$, and the film Reynolds number, $\operatorname{Re}_{f}\left(N u=h_{c} L_{c} / k_{l}\right)$. In Fig. 7, the experimental Nusselt numbers are presented as a function of the Reynolds number by the models of Nusselt, Hashimoto and Kaminaga [19] and Jouhara and Robinson [14] at filling ratios of $16 \%$ and $100 \%$. The Nusselt equation shows over prediction of experimental data at different heat fluxes; however, for the higher Reynolds numbers (higher heat transfer rates) a comparable agreement with the experimental data is observed. The similar agreement is observed at filling ratios of $35 \%$ and $50 \%$ (not shown). As it is evidenced in Fig. 7, the experimental results show a comparable agreement with the Hashimoto and Kaminaga [19] correlation while the best agreement with the experimental data is observed with Jouhara and Robinson [14] modification.

The variations of the thermal resistance in the condenser section with heat input power difference is shown in Fig. 8. As it is evidenced, the condenser thermal resistance remains constant over heat transfer rate of $400 \mathrm{~W}$ (see Fig. 8a). A very good agreement is observed in the comparison of experimentally thermal resistance in the condenser section and the correlation modified by (Jouhara and Robinson [14]).

\subsubsection{Evaporation heat transfer}

Complex fluid flow and heat transfer behaviors occur in the evaporator of TPCTs, as described in section 2; however, nucleate boiling could be dominant mechanism in the evaporator section $[7,16]$. The selected nucleate boiling correlations lists in Table 2 are chosen to compare with experimental data. Fig. 9 shows the evaporation heat transfer predictions by Rohsenow [8], Labuntsov [9], Imura et al. [10], Shiraishi et al. [11], Kutateladze [12] and Chowdhury et al. [13] correlations versus the experimental evaporation heat transfers at both filling ratio of $100 \%$ and lowers than $100 \%$. The most 
proposed correlations give similar results with the experimental evaporation heat transfer within a deviation of $\pm 30 \%$. As it is evidenced, the experimental data for filling ratio of $100 \%$ are in a good agreement with Rohsenow [8], Imura et al. [10] and Shiraishi et al. [11] correlations while underprediction of Labuntsov [9], Kutateladze [12] and Chowdhury [13] is observed. For filling ratio of $<100 \%$ there is a worse agreement between the sets of values. The Imura et al. [10], Shiraishi et al. [11] and Rohsenow [8] correlations show a better agreement for filling ratio of <100\% and underprediction of the experimental data at higher values for Imura [10] correlation while over-predict for Rohsenow [8] correlation. Agreement worsens for Kutateladze [12], Chowdhury et al. [13] and Labuntsov [9]. This suggests a combination of the liquid pool boiling and the film evaporation which would result in a better agreement.

The variations of the thermal resistance in the evaporator section with heat input power to compare the predicted and experimental thermal resistance values for filling ratio less than $100 \%$ (a combination of pool boiling and film evaporation occurs) are shown in Fig. 10. The lines indicate correlations for Shiraishi et al. [11], unfilled markers represent correlations for pool boiling correlations (Eq. 12, see Table 2) and filled markers represents the combination of pool boiling and film evaporation developed by Shiraishi et al. [11] (Eq. 13). As it is evidenced, the experiments and predictions show reasonable agreement with correlations of Imura [10], Shiraishi [11] and Rohsenow [8], together with the combination of nucleate pool boiling correlation of Imura [10], Kutateladze [12], Rohsenow [8], Labuntsov [9] and Chowdhury [13] with Shiraishi [11] for film evaporation, expect filling ratio of $8 \%$. At filling ratio of $8 \%$ dryout occurs due to a very low filling ratio (skipped from the following analysis). A general observation is that with increasing filling ratio the combination of pool boiling correlations and film evaporation [11] behaves as over/under-prediction of experimental measurements, thus this combination recommended for a low filling ratio. It is also noticed that 
applying the proposed correlation by Kutateladze [12], Labuntsov [9] and Chowdhury [13] yields poor results while its combination with film evaporation provides a very good prediction in comparison of experimental data. The proposed correlation by Shiraishi [11] and Rohsenow [8] show similar results with the experimental heat transfer within a deviation of $\pm 10 \%$ at filling ratio of $16 \%$ and high heat flux while applying these correlations at higher filling ratios (35\% and 50\%) yields comparable/underpredicted results in comparison of experimental data. The proposed correlation by Chowdhury [13] shows similar results at filling ratio and high heat flux, but at higher filling ratios Chowdhury [13] correlation gives comparable/over-predicted results in comparison of experimental data. Applying the proposed correlation by Labuntsov [9] and Kutateladze [12] yields worse results, over-prediction of experimentally obtained evaporation heat transfer. The combination of correlation proposed by Labuntsov [9] and Kutateladze [12] with Shiraishi [11] give a very good agreement in comparison of the experimental heat transfer within a deviation of $\pm 10 \%$ at filling ratio from $16 \%$ to $50 \%$ while the combination of Imura [10] and Rohsenow [8] with proposed film evaporation correlation provide a compare bale/under-prediction of experimental data within a deviation of $\pm 30 \%$.

Fig. 11 shows the variations of the thermal resistance in the evaporator section with heat input power to compare the predicted and measured thermal resistance values for filling ratio of $100 \%$ which the thermosyphon experience pool boiling. The thermal resistance is determined by calculating the heat transfer coefficient and then using Eq. 12. The proposed correlation by Imura [10] and Rohsenow [8] correlations give a good agreement in comparison of the experimental heat transfer within a deviation of $\pm 15 \%$. It is noticed that applying the proposed correlation by Shiraishi [11] yields comparable/under-prediction of experimental results at the inlet cooling temperature of $25^{\circ} \mathrm{C}$ (within a deviation of $\pm 30 \%$ ) while its prediction at the inlet cooling temperature of $55{ }^{\circ} \mathrm{C}$ shows a good agreement within a deviation of $\pm 10 \%$. The proposed correlation by Labuntsov [9] and Kutateladze 
[12] results in over-prediction of experimental results while applying the proposed correlation by Chowdhury [13] gives comparable/over-prediction of experimental data within a deviation of $30 \%$ at higher heat flux at both cooling temperatures. In all above correlation, it is observed that the proposed correlation by Shiraishi [11] seems to be sensitive to operating temperature. Based on the above presented results on evaporation and condensation heat transfers following a guideline to select appropriate heat transfer coefficients at different filling ratios and heat fluxes is presented.

\section{Summary of results and discussion}

In this section first the evaporation correlation is discussed in detail in comparison also with small tested thermosyphon $(6 \mathrm{~mm})$ using water as a working fluid at filling ratio of $135 \%$ in [14] to have a clear perspective for selection of appropriate heat transfer correlation for a particular application depending, diameter, filling ratio and applied heat input. Afterward, total thermal resistance is evaluated and discussed. Table 5 summarizes the agreement of selected nucleate pool boiling correlation at filling ratio of $100 \%$, together with their combination with film evaporation correlation [11] at filling ratios of $16 \%, 35 \%$ and $50 \%$. It is obvious that the proposed correlation by Shiraishi [11], Rohsenow [8], Kutateladze [12] and Chowdhury [13] gives almost similar results with the experimental heat transfer within a deviation of $\pm 20 \%$ at both small and large diameter thermosyphon at the inlet cooling temperature of $25{ }^{\circ} \mathrm{C}$, however, these correlations show a better agreement at the inlet cooling temperature of $55^{\circ} \mathrm{C}$. Applying the proposed correlation by Imura [10] yields a deviation of $\pm 10 \%$ at large diameter thermosyphon while comparable/under-prediction of experimental results observes at small diameter thermosyphon (a deviation of $\pm 30 \%$ ). A discrepancy in experimental and predicted evaporation heat transfer proposed by Labuntsov [9] is observed in a comparison of small and large diameter thermosyphons. Applying the proposed correlation by Labuntsov [9] yields poor (over-prediction) results in present study for large diameter thermosyphon while at small diameter 
thermosyphon, Jouhara and Robinson [14] observed a good prediction in the comparison of experimental data within a deviation of $\pm 10 \%$ at low heat flux while comparable/under-prediction of experimental results at high heat fluxes within a deviation of $\pm 30 \%$.

Table 5 also illustrates the agreement between the experimental values of the evaporation heat transfer coefficient and the prediction values of the correlation proposed by Imura [10], Rohsenow [8], Kutateladze [12], Chowdhury [13], Labuntsov [9] in combination of Shiraishi [11] to consider the effect of film evaporation at filling ratios of $16 \%, 35 \%$ and $50 \%$.

Imura [10] correlation- Based on presented results on evaporation heat transfer, the Imura [10] correlation can predict the pool boiling regime with a very good accuracy at filling ratios of more than $35 \%$ within a deviation of $\pm 10 \%$ while its combination with Shiraishi [11] correlation to consider film evaporation shows under-prediction of experimental data. A good agreement with the experimental heat transfer at filling ratio of $16 \%$ only observes at high heat fluxes. Therefore, the proposed correlation by Imura [10] is suggested to predict the thermal performance of thermosyphons at filling ratio of more than $30 \%$.

Shiraishi [11] correlation- Applying the proposed correlation by Shiraishi [11] yields comparable/under-prediction of experimental results at different filling ratios and the inlet cooling temperature of $25{ }^{\circ} \mathrm{C}$ (within a deviation of $\pm 30 \%$ ) while good agreement observes at inlet cooling temperature of $55^{\circ} \mathrm{C}$. Among them, the prediction result of filling ratio of $16 \%$ at high heat flux is the best with an error of lower than $10 \%$.

Rohsenow [8] correlation- From the analysis of data, it is observed that the proposed correlation by Rohsenow [8] is sensitive to both filling ratio and cooling temperature. As of filling ratio increases, the agreement of experimental evaporation improves from a deviation of $\pm 30 \%$ at a lower filling ratio to a deviation of $\pm 10 \%$ for the higher filling at low heat fluxes. However, a comparable/under-prediction of 
experimental results observes for higher filling ratios at higher heat fluxes while as the inlet cooling temperature increases from $25^{\circ} \mathrm{C}$ to $55^{\circ} \mathrm{C}$, an agreement within a deviation of $\pm 10 \%$ is observed. The combination of nucleate pool boiling correlation of Rohsenow [8] and Shiraishi et al. [11] correlation for film evaporation shows a better agreement only at low fillings ratio and higher heat fluxes. Therefore, the combination of Rohsenow [8] and Shiraishi et al. [11] correlation is not suggested.

Kutateladze [12] correlation- Applying the proposed correlation by Kutateladze [12] to predict pool boiling heat transfer regime yields poor results (over-predicted) at different filling ratios while its combination with film evaporation (Shiraishi et al. [11] correlation) provides a very good prediction (within a deviation of $\pm 10 \%$ ) at filling ratio of $16 \%$ and $35 \%$ and a comparable/cover-prediction of experimental data at filling ratio of $50 \%$. It seems that for a thin film region it would be reasonable to apply Shiraishi [11] correlation for evaporation, thus, a combination of Kutateladze [12] and Shiraishi [11] correlations is suggested to predict evaporation heat transfer at filling ratios of lower than $35 \%$ within an accuracy of $\pm 10 \%$.

Labuntsov [9] correlation- The proposed pool boiling correlation by Labuntsov [9] gives overprediction of experimental heat transfer at different filling ratios, similar to that of Kutateladze [12] correlation. A combination of Labuntsov [9] and Shiraishi [11] correlations improves the prediction of evaporation heat transfer at filling ratios of $16 \%, 35 \%$ and $50 \%$ within an accuracy of $\pm 10 \%$ at high heat transfer rates, $\pm 10 \%$ and $\pm 20 \%$, respectively. Thus, applying Labuntsov [9] correlation is not suggested to predict pool boiling heat regime in large diameter thermosyphon application while the combination of this correlation with Shiraishi [11] is suggested at filling ratio ranges from $15 \%$ to $50 \%$.

Chowdhury [13] correlation- The experimental evaporation heat transfers and predictions show good agreement with the correlation of Chowdhury [13] at filling ratio of $16 \%$ (within an accuracy of $\pm 20 \%$ ) while as the filling ratio increases the predictions give over-prediction of experimental heat transfer. 
However, comparable/over-prediction of experimental results observes at filling ratio of $100 \%$ at high heat flux within an accuracy of $\pm 30 \%$. Its combination with film evaporation correlation of Shiraishi [11] provides a good prediction in comparison of experimental data at filling ratio of $16 \%-50 \%$ within a deviation of $\pm 10 \%$. Therefore, the combination of Chowdhury [13] and Shiraishi [11] correlations is suggested to predict evaporation heat transfer of thermosyphons at low filling ratios $(15 \%-50 \%)$. The above suggestion would help modeling and prediction of the heat transfer process in TPCTs as well as their integration in industrial applications.

The total thermal resistance of the thermosyphon is determined by a combination of the evaporation and condensation thermal resistance $\left(\mathrm{R}_{\mathrm{t}}=\mathrm{R}_{\mathrm{e}}+\mathrm{R}_{\mathrm{c}}\right)$. Fig. 12 shows comparisons of the experimental and predicted overall thermal resistance at different filling ratios $(16 \%, 35 \%, 50 \%$ and 100\%). The most appropriate pool boiling correlations as well as their combinations is applied to predict evaporation heat transfer and modified correlation by Jouhara and Robinson [14] is used to predict heat transfer in the condenser section. The measured and predicted thermal resistance curves agree well. Therefore the applied set of correlations recommends predicting heat transfer in a TPCT for a wide range of filling ratios and heat fluxes.

At the end, it worth to notice that there is an interest to approximate the heat transfer capacity of a heat exchanger systems incorporating two-phase closed thermosyphons in various industrial applications (e.g. a simple thermal network approach). Therefore, the results of this study describe the most accurate evaporation and condensation heat transfer coefficients to characterize and analyze two-phase closed thermosyphons to be applied in a real system.

\section{Conclusions}

Experiments on the evaporation and condensation heat transfer of a two-phase closed thermosyphon (TPCT) are carried to have a clear perspective for selection of appropriate heat transfer correlation for 
a particular application depending filling ratio and applied heat input. The thermosyphon with an inner diameter of $33 \mathrm{~mm}$ is tested at heat transfer rate of $30 \mathrm{~W}$ to $900 \mathrm{~W}$. The pure water is used as the working fluid at filling ratios of $8 \%, 16 \%, 35 \%, 50 \%$ and $100 \%$. The filmwise model containing liquid entrainment affects in the condenser section shows good agreement with experimental results to predict condensation heat transfer. The available nucleate boiling correlations, together with their combination with a film evaporation correlation are evaluated to predict the evaporation heat transfer. From the analysis of data, the sensitivity of the pool boiling correlation as well as their combination to the heat flux, filling ratio and cooling temperature is described in details. The experimental results show an agreement with the most of the selected correlations with tolerance $\pm 30 \%$ and the proper sets of correlations are suggested to predict the heat transfer in the evaporator section as well as condensation heat within a deviation of $\pm 10 \%$. The applied approach is found to predict evaporation and condensation heat transfer of thermosyphons with a good agreement with experimental results. A join of our recent paper [26] and current study would enable the readers to design a TPCT for a specific application at different operating parameters, specifically, when a low filling ratio, a low heat flux and a low to medium temperature is a matter of interest (e.g. solar applications).

\section{References}

[1] A. Faghri, Heat Pipe Science and Technology, Philadelphia, PA: Taylor \& Francis, (1995).

[2] D. Jafari, A. Franco, S. Filippeschi, P. Di Marco, Two-phase closed thermosyphons: A review of studies and solar applications, Renewable \& Sustainable Energy Reviews 53 (2016) 575-93.

[3] H. Shabgard, M.J. Allen, N. Sharifi, S.P. Benn, A. Faghri, Bergman TL, Heat pipe heat exchangers and heat sinks: Opportunities, challenges, applications, analysis, and state of the art, International Journal of Heat and Mass Transfer 89 (2015) 138-58. 
[4] L.L. Vasiliev, S. Kakaç, Heat Pipes and solid sorption transformations Fundamentals and Practical Applications, Ed. CRC Press- Taylor \& Francis Group (2013).

[5] T. He, C. Mei, J.P. Longtin, Thermosyphon-assisted cooling system for refrigeration applications, International Journal of Refrigeration (2016), http://dx.doi.org/doi: 10.1016/j.ijrefrig.2016.10.012.

[6] A.A. Eidan, S.E. Najim, J.M. Jalil, Experimental and numerical investigation of thermosyphone performance in HVAC system applications, Heat Mass Transfer 52 (2016) 2879-93.

[7] M.S. EL-Genk, H H. Saber, Heat transfer correlations for small, uniformly heated liquid pools, International Journal of Heat and Mass Transfer 41 (1998) 261-74.

[8] W.M. Rohsenow, A method of correlating heat transfer data for surface boiling of liquids, Transactions of the ASME 74 (1952) 969-976.

[9] D.A. Labuntsov, Heat transfer problems with nucleate boiling of liquids, Thermal Engineering 19 (1972) 21-28.

[10] H. Imura, H. Kusada, J. Oyata, T. Miyazaki, N. Sakamoto, Heat transfer in two-phase closed-type thermosyphons, Transactions of Japan Society of Mechanical Engineers 22 (1977) 485-493.

[11] M. Shiraishi, K. Kikuchi, T. Yamanishi, Investigation of heat transfer characteristics of a twophase closed thermosyphon, Heat Recovery Systems 1 (1981) 287-297.

[12] Kutateladze, Heat Transfer and Hydrodynamic Resistance, Energoatomizdat Publishing House, Moscow, Russia, 1990.

[13] F.Md. Chowdhury, F. Kaminaga, K. Goto, K. Matsumura, Boiling heat transfer in a small diameter tube below atmospheric pressure on a natural circulation condition, Journal of Japan Association for Heat Pipe 16 (1997) 14-16.

[14] H. Jouhara, A.J. Robinson. Experimental investigation of small diameter two phase closed thermosyphons charged with water, FC-84, FC-77 and FC-3283, Applied Thermal Engineering 30 (2010) 201-11. 
[15] T. Kiatsiriroat, A. Nuntaphan, J. Tiansuwan, Thermal performance enhancement of thermosyphon heat pipe with binary working fluids, Experimental Heat Transfer 13(2) (2000) 137-52.

[16] Y.J. Park, H.K. Kang, C.J. Kim, Heat transfer characteristics of a two phase closed thermosyphon to fill charge ratio, International Journal of Heat and Mass Transfer 45 (2002) 4655-61.

[17] S. H. Noie, Heat transfer characteristics of a two-phase closed thermosyphon, Applied Thermal Engineering 25(4) (2005) 495-506.

[18] W. Guo, D.W. Nutter, An experimental study of axial conduction through a thermosyphon pipe wall, Applied Thermal Engineering 29 (2009) 3536-41.

[19] H. Hashimoto, F. Kaminaga, Heat transfer characteristics in a condenser of closed two-phase thermosyphon: effect of entrainment on heat transfer deterioration, Heat Transfer-Asian Res 31(3) (2002) 212-25.

[20] J.C.Y. Wang, Y. Ma, Condensation heat transfer inside vertical and inclined thermosyphons, Journal of Heat Transfer 113 (1991) 777-80.

[21] H.M.S. Hussein, M.A. Mohamad, A.S. El-Asfouri, Theoretical analysis of laminar-film condensation heat transfer inside inclined wickless heat pipes flat-plate solar collector, Renewable Energy 23 (2001) 525-35.

[22] M. H. M. Grooten, C. W. M. van der Geld, Predicting Heat Transfer in Long R-134a Filled Thermosyphons, Journal of Heat Transfer 131 (2009) 51501.

[23] M. Shanbedi, S. Z. Heris, M. Baniadam, A. Amiri, M. Maghrebi, Investigation of Heat-Transfer Characterization of EDA-MWCNT/DI-Water Nanofluid in a Two-Phase Closed Thermosyphon, Industrial \& Engineering Chemistry Research 51 (2012) 1423-8.

[24] S. Z. Heris, M. Fallahi, M. Shanbedi, A. Amiri, Heat transfer performance of two-phase closed thermosyphon with oxidized CNT/water nanofluids, Heat Mass Transfer 10 (2015) 1007. 
[25] E. Gedik, Experimental investigation of the thermal performance of a two-phase closed thermosyphon at different operating conditions, Energy and Buildings (127) 2016 1096-107.

[26] D. Jafari, S. Filippeschi, A. Franco, P. Di Marco, Unsteady experimental and numerical analysis of a two-phase closed thermosyphon at different filling ratios, Experimental Thermal and Fluid Science 81 (2017) 164-74.

[27] W.M. Rohsenow, J.P. Harnett, E.N. Ganic, Handbook of Heat Transfer Fundamentals. $2^{\text {nd }}$ ed. New York: McGraw-Hill (1985).

[28] I.L. Pioro, W. Rohsenow, S.S. Doerffer, Nucleate pool-boiling heat transfer II: assessment of prediction methods, International Journal of Heat and Mass Transfer 23 (2004) 5045-57.

\section{Figures}

Fig. 1 Schematic view of a TPCT at filling ratio of (a) $100 \%$ and (b) $<100 \%$ and (c) its thermal resistances as well as highlighted major ones

Fig. 2 schematic view of experimental apparatus as well as locations of thermocouples [26]

Fig. 3 Comparison of measured heat flow rates at evaporator and condenser side of the TPCT

Fig. 4 Axial wall temperature distribution for filling ratio of (a) $35 \%$ and (b) $100 \%$

Fig. 5 Transient wall temperature variation

Fig. 6 Experimental condensation and evaporation heat transfer coefficients

Fig. 7 Predicted and experimentally determined Nusselt number $(\mathrm{Nu})$ versus the film Reynolds number $\left(R e_{f i l m}\right)$ values for the condenser section of the thermosyphon at filling ratio of (a) $16 \%$ and (b) $100 \%$

Fig. 8 Predicted and experimentally determined thermal resistance of the condenser section of the thermosyphon at filling ratio of (a) $16 \%$ and (b) $100 \%$ 
Fig. 9 Predicted evaporation heat transfer coefficients versus the experimental evaporation heat transfer coefficient values at the filling ratio of (a) $<100 \%(16 \%, 35 \%$ and $50 \%)$ and (b) $100 \%$

Fig. 10 Predicted and experimentally determined thermal resistances of the evaporator section of the thermosyphon (combination of pool boiling and film evaporation)

Fig. 11 Predicted and experimentally determined thermal resistances of the evaporator section of the thermosyphon (pool boiling)

Fig. 12 Predicted and experimentally determined total thermal resistances of the thermosyphon for filling ratios of (a) $16 \%$, (b) $35 \%$, (c) $50 \%$ and (d) $100 \%$.

(a)

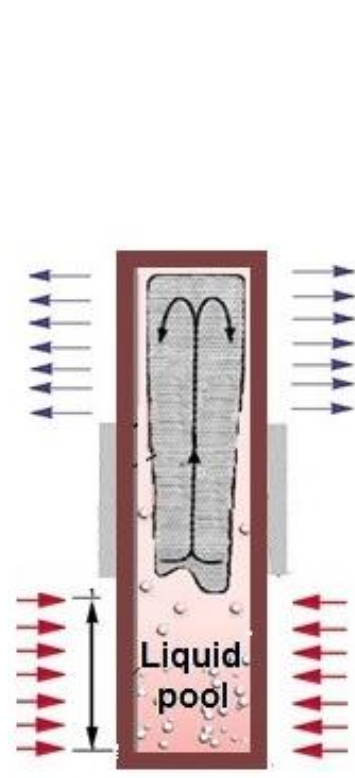

(b)

(c)

Thermal resistances in the condenser

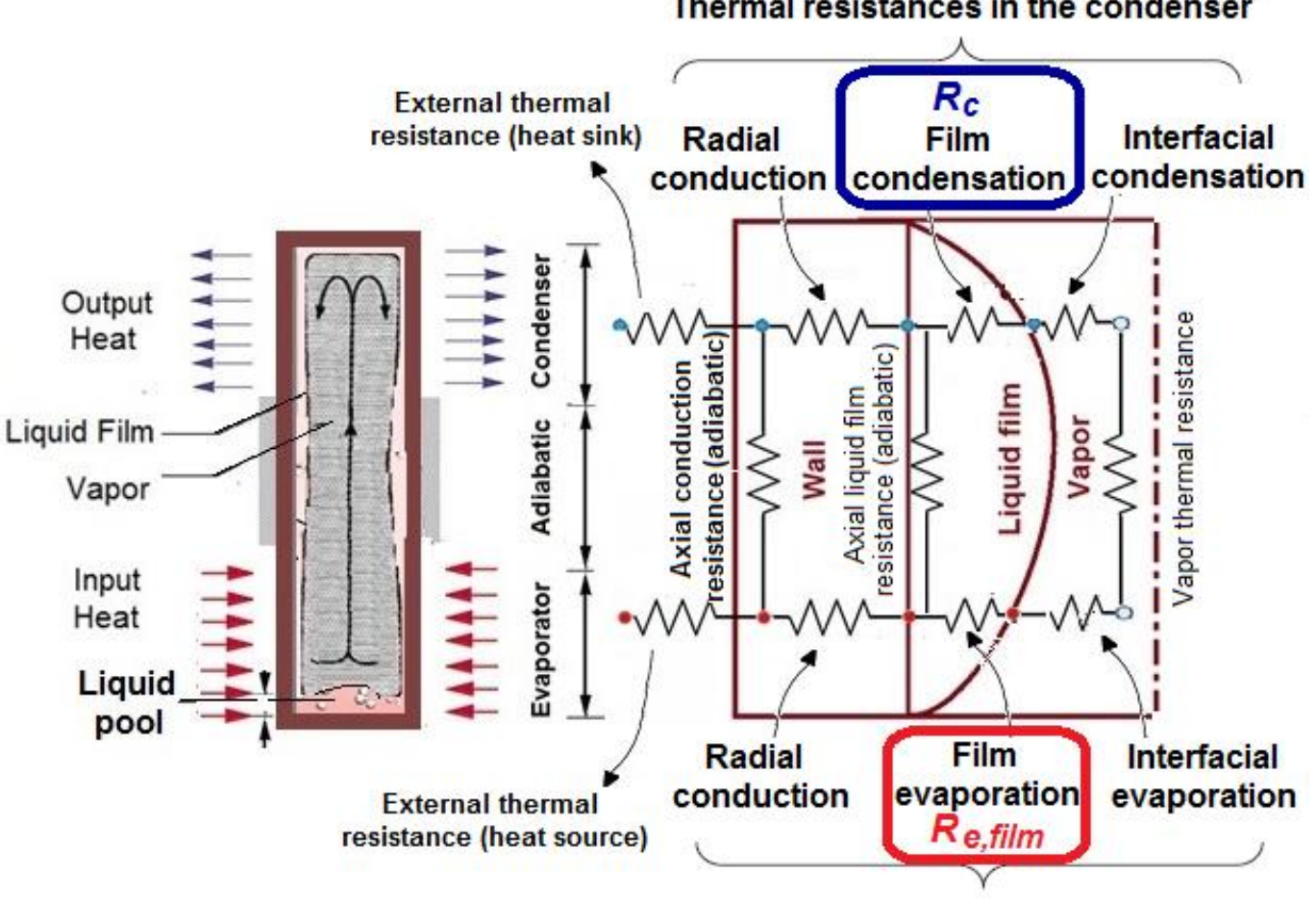

Thermal resistances in the evaporator 
Fig. 1

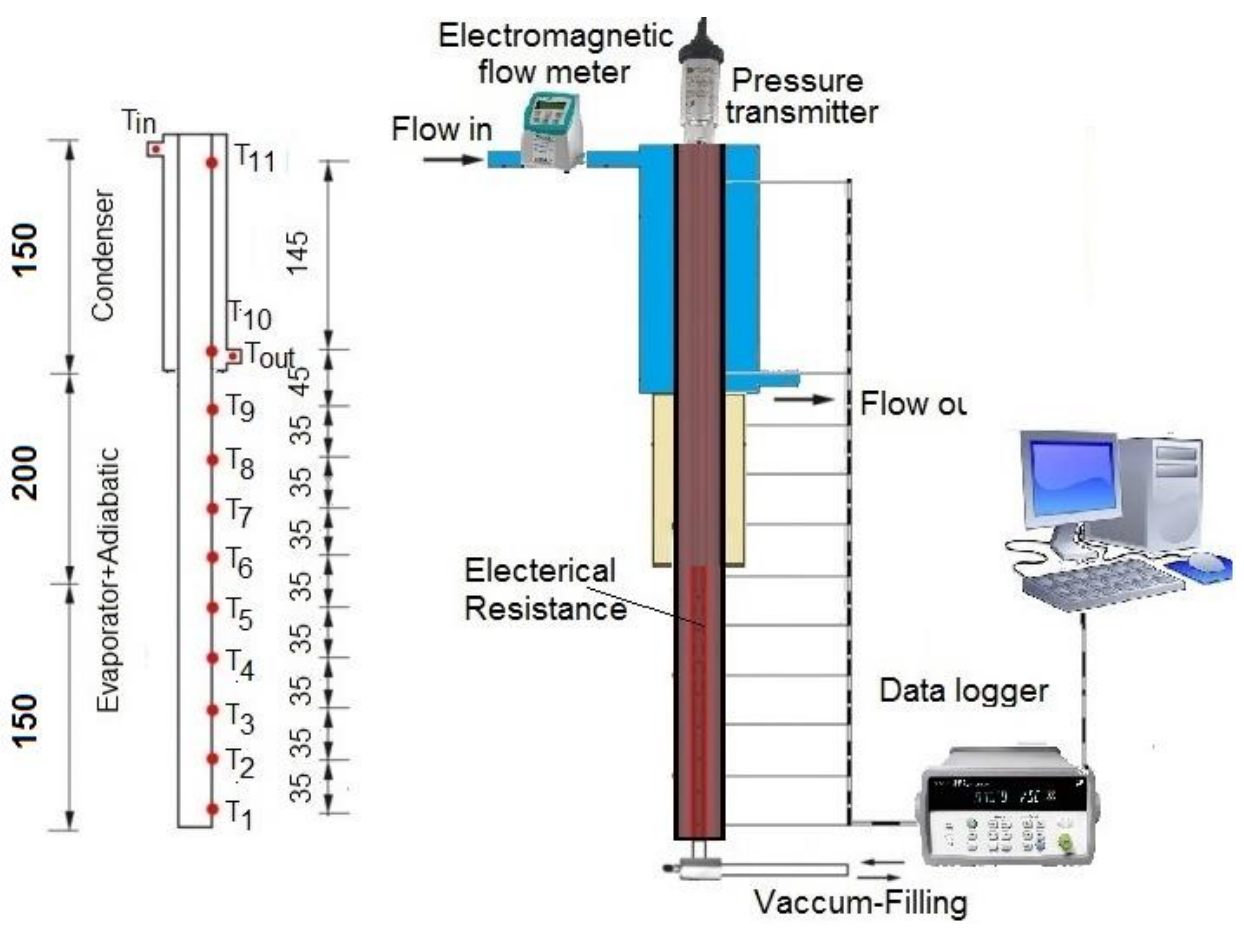

Fig. 2

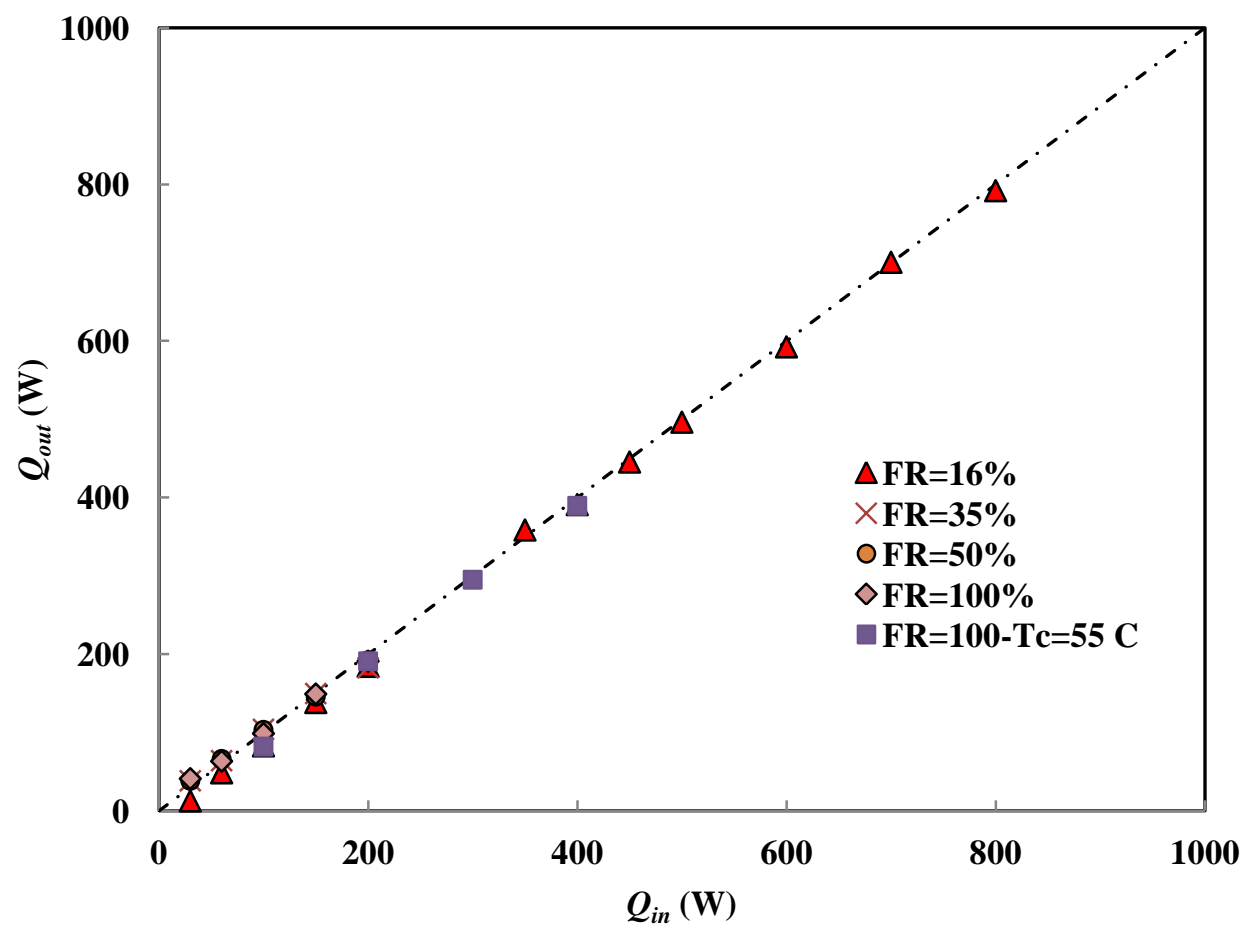

Fig. 3 


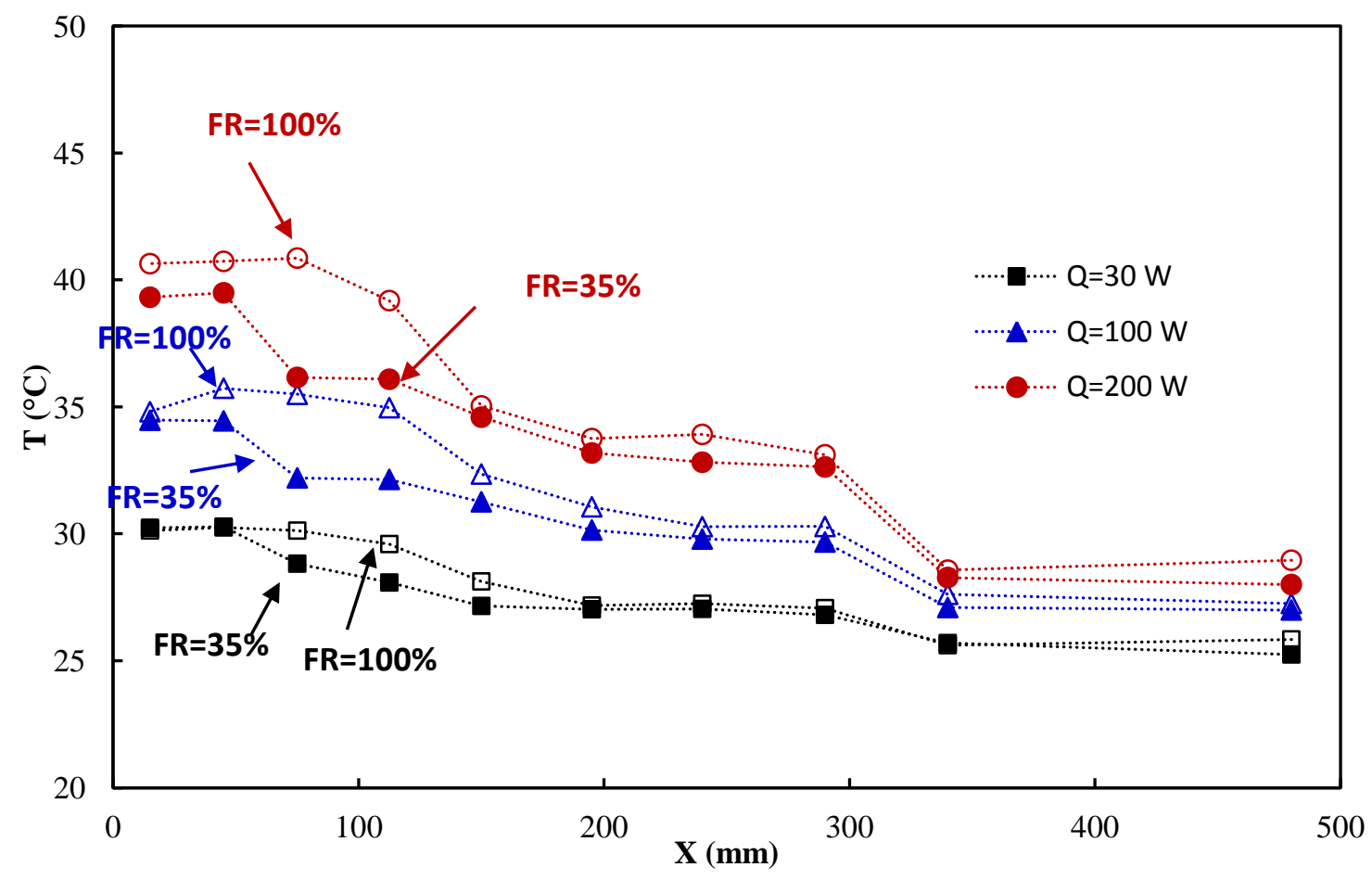

Fig. 4

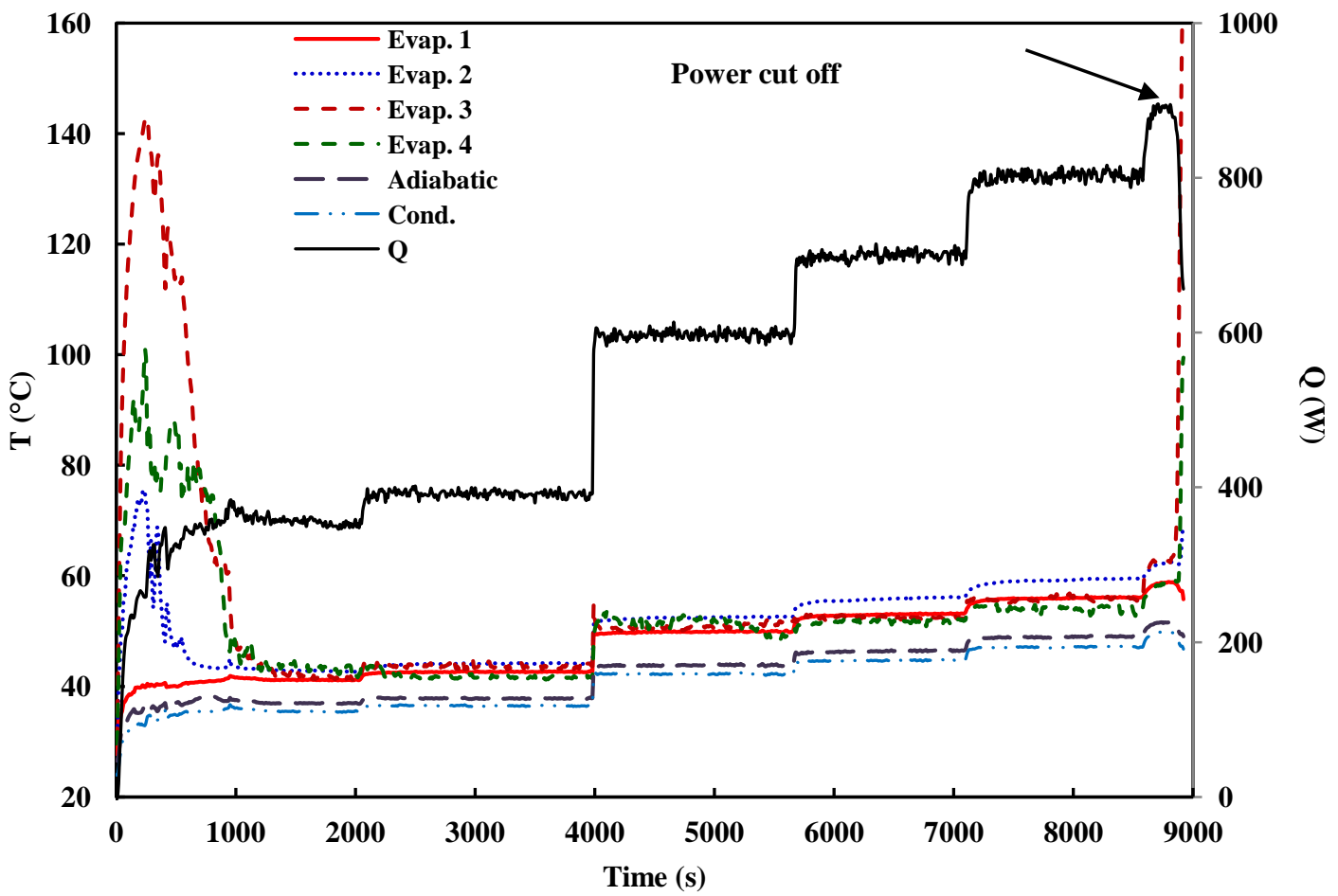

Fig. 5 


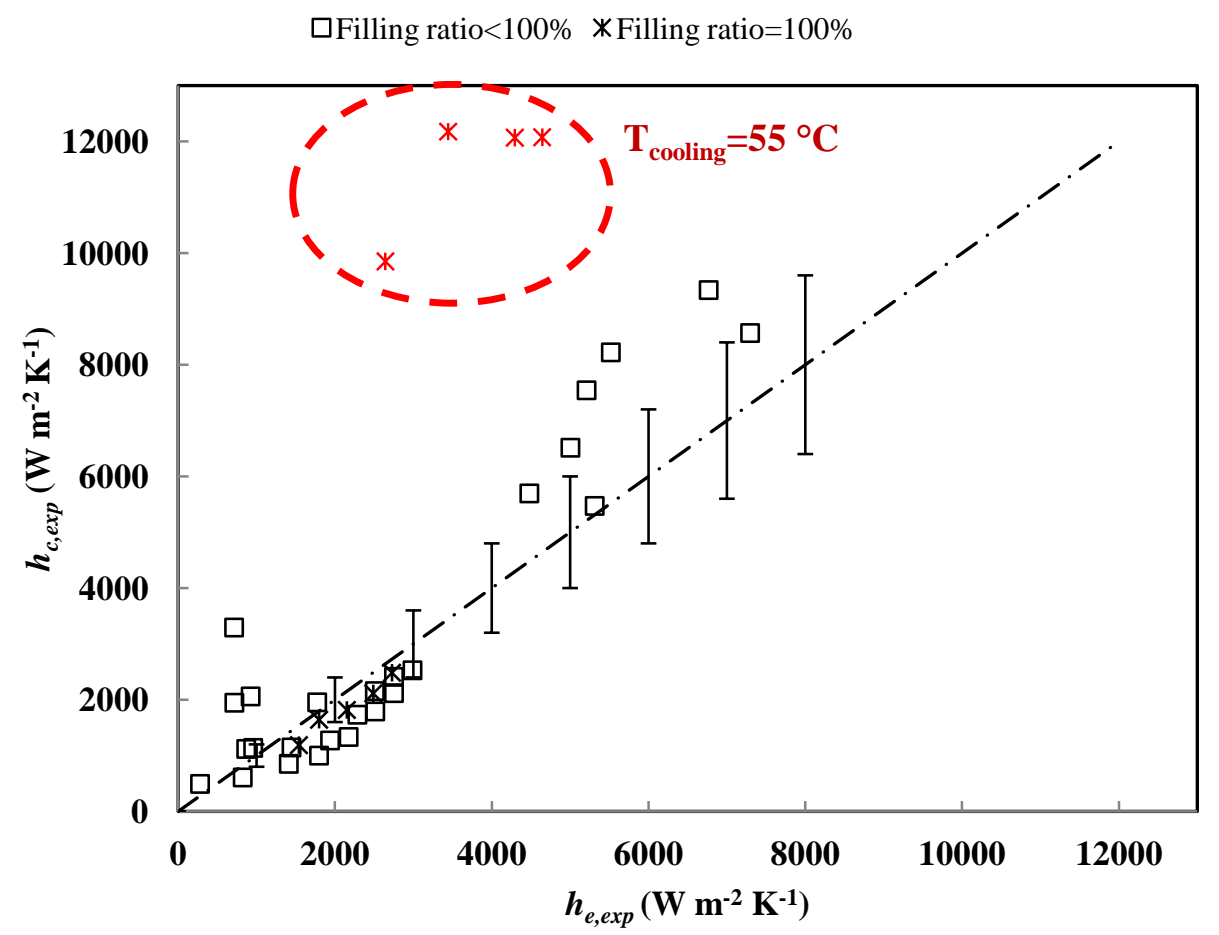

Fig. 6

(a)
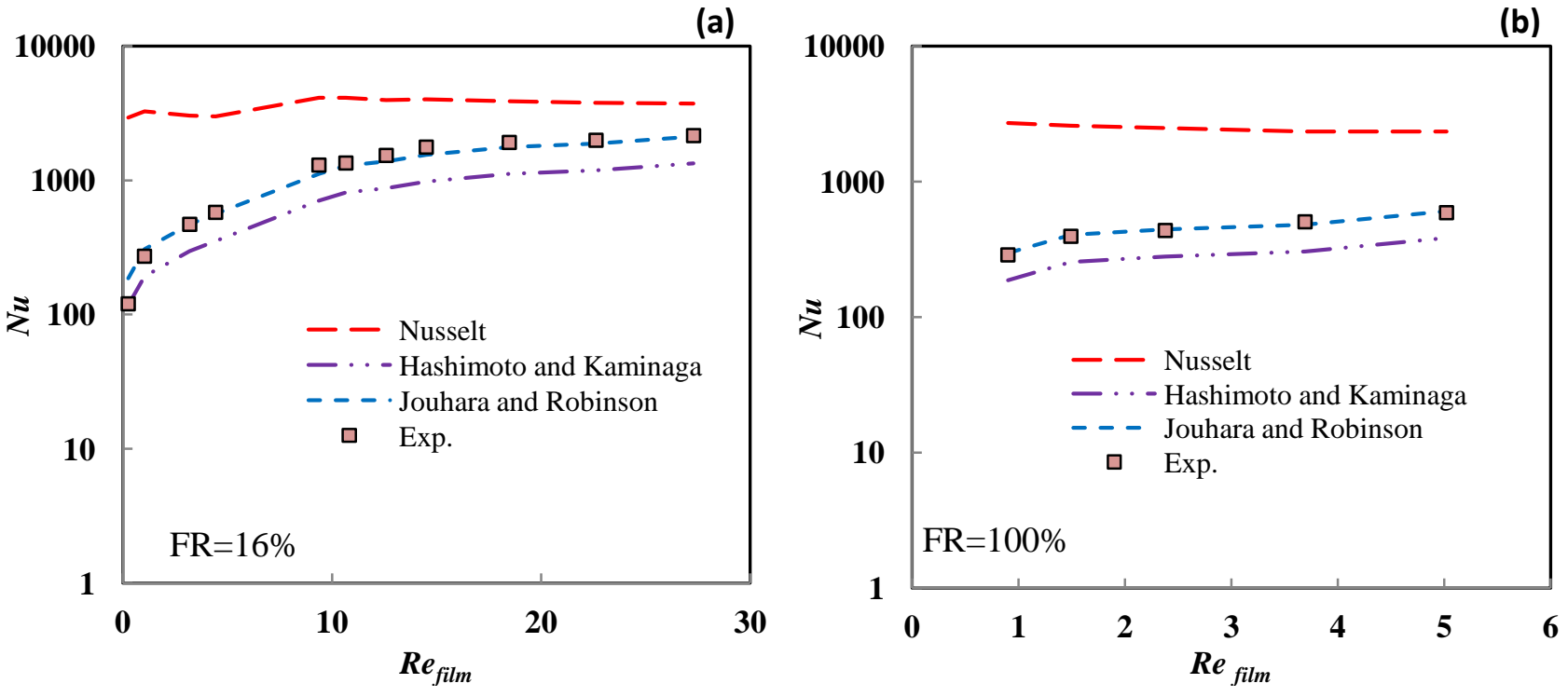

Fig. 7 
(a)

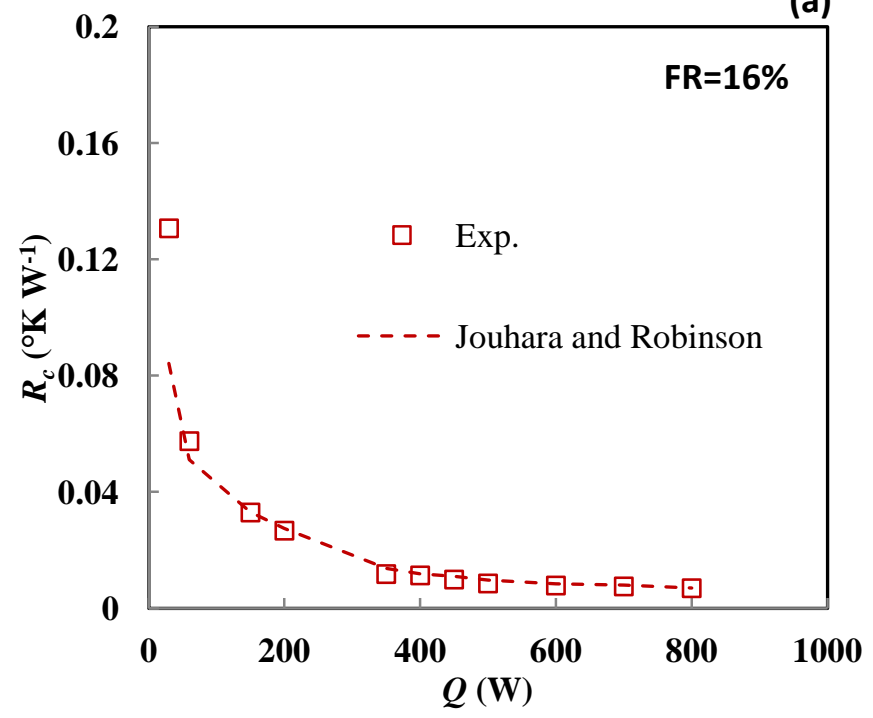

(b)

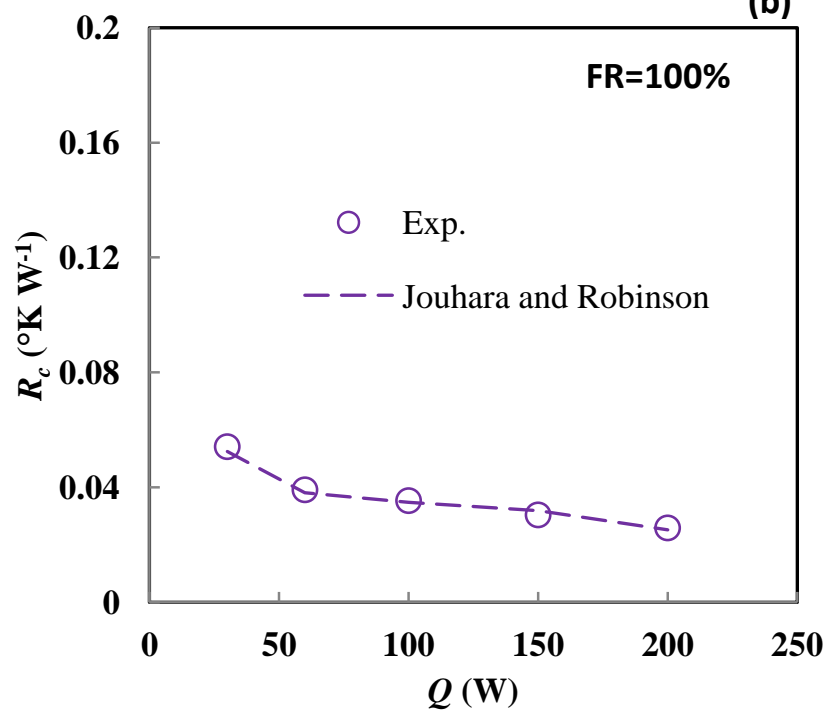

Fig. 8

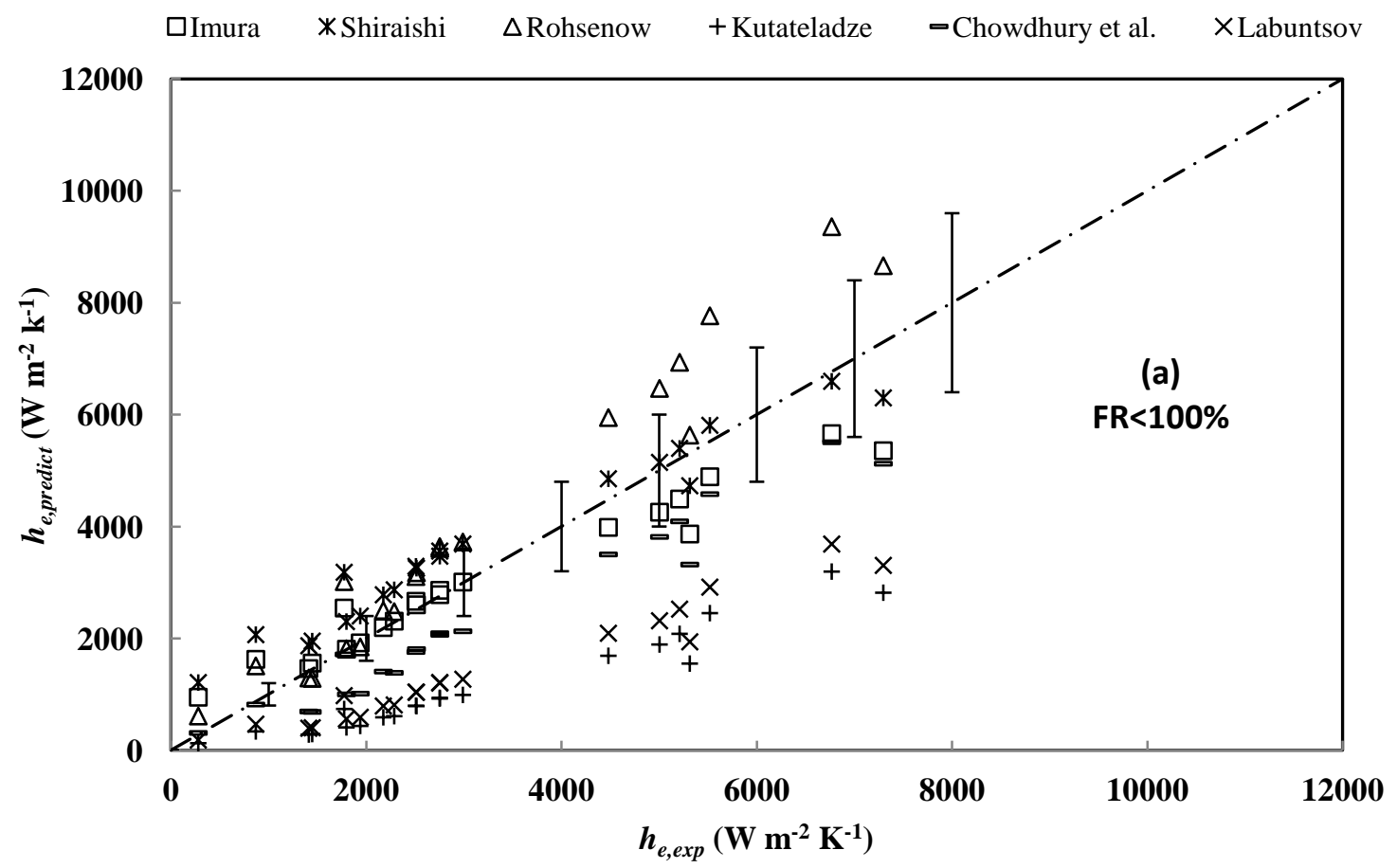




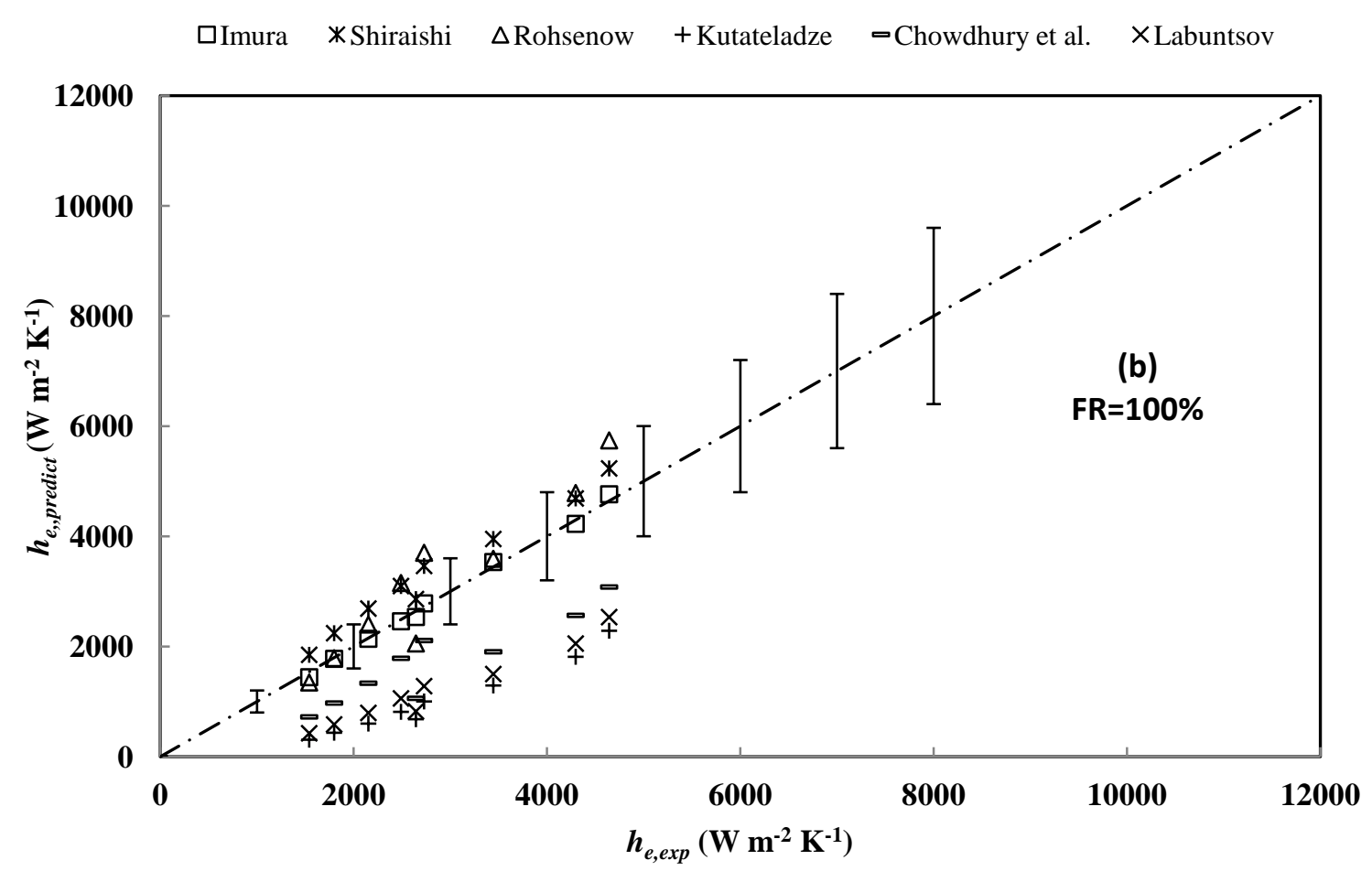

Fig. 9

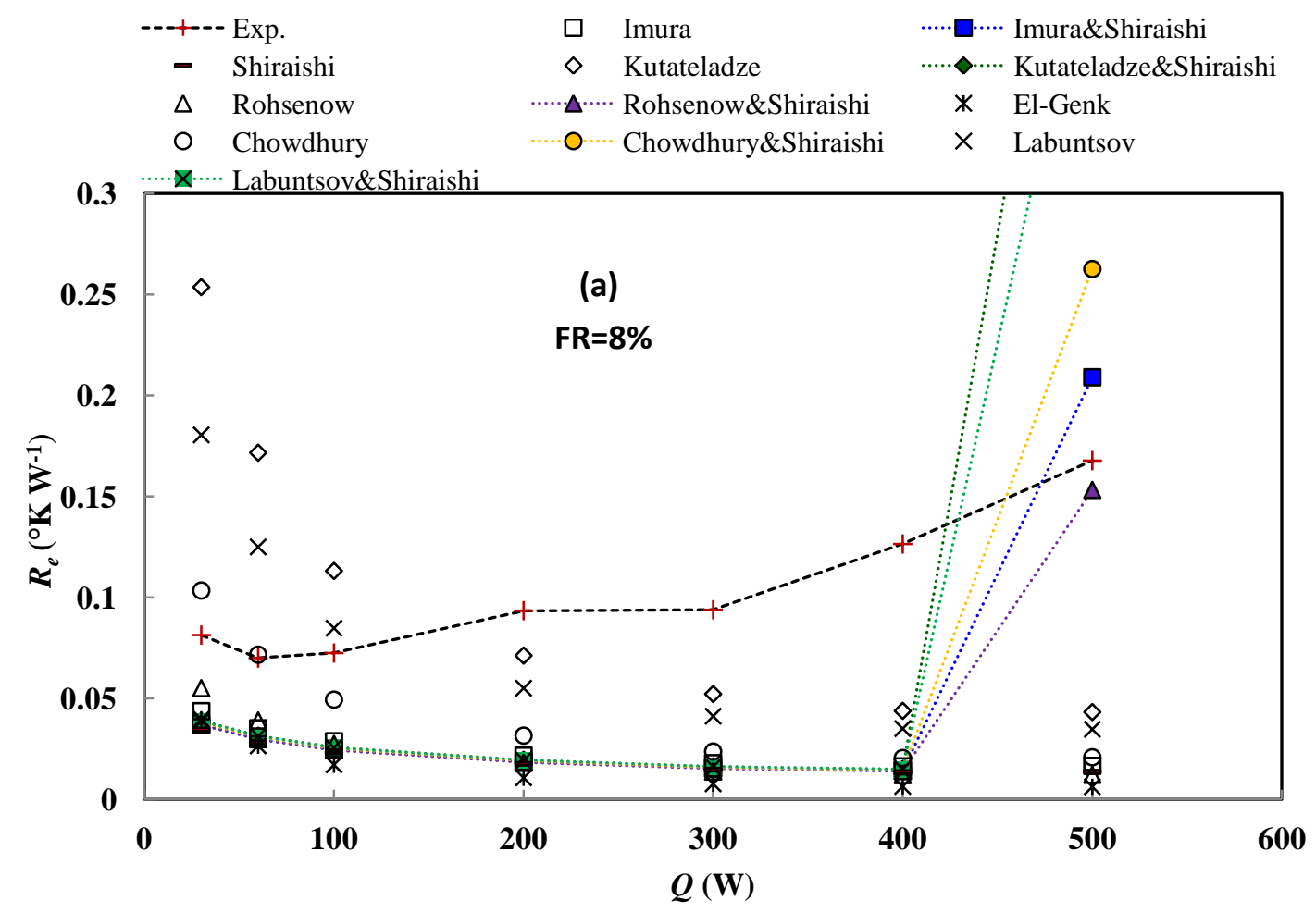



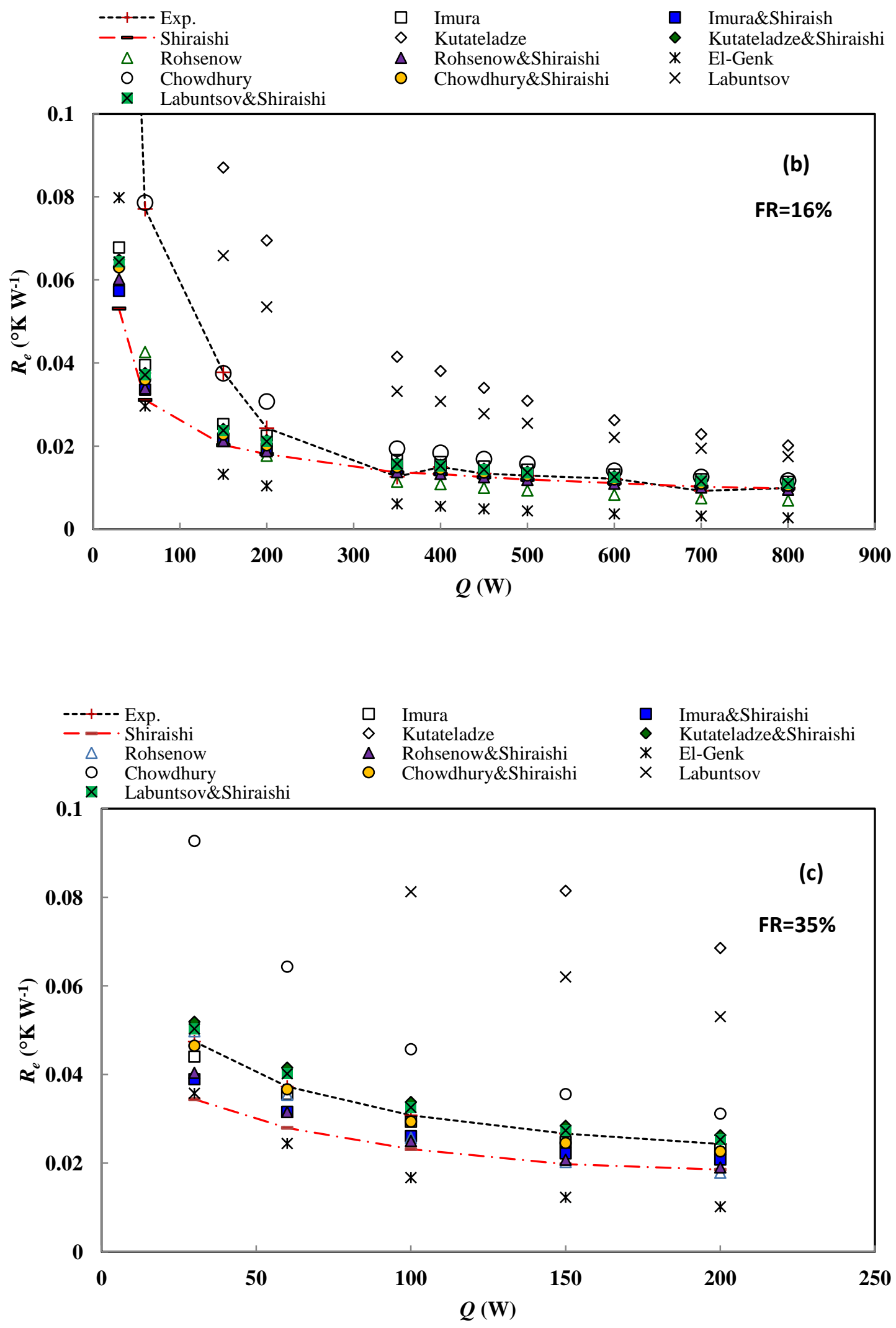


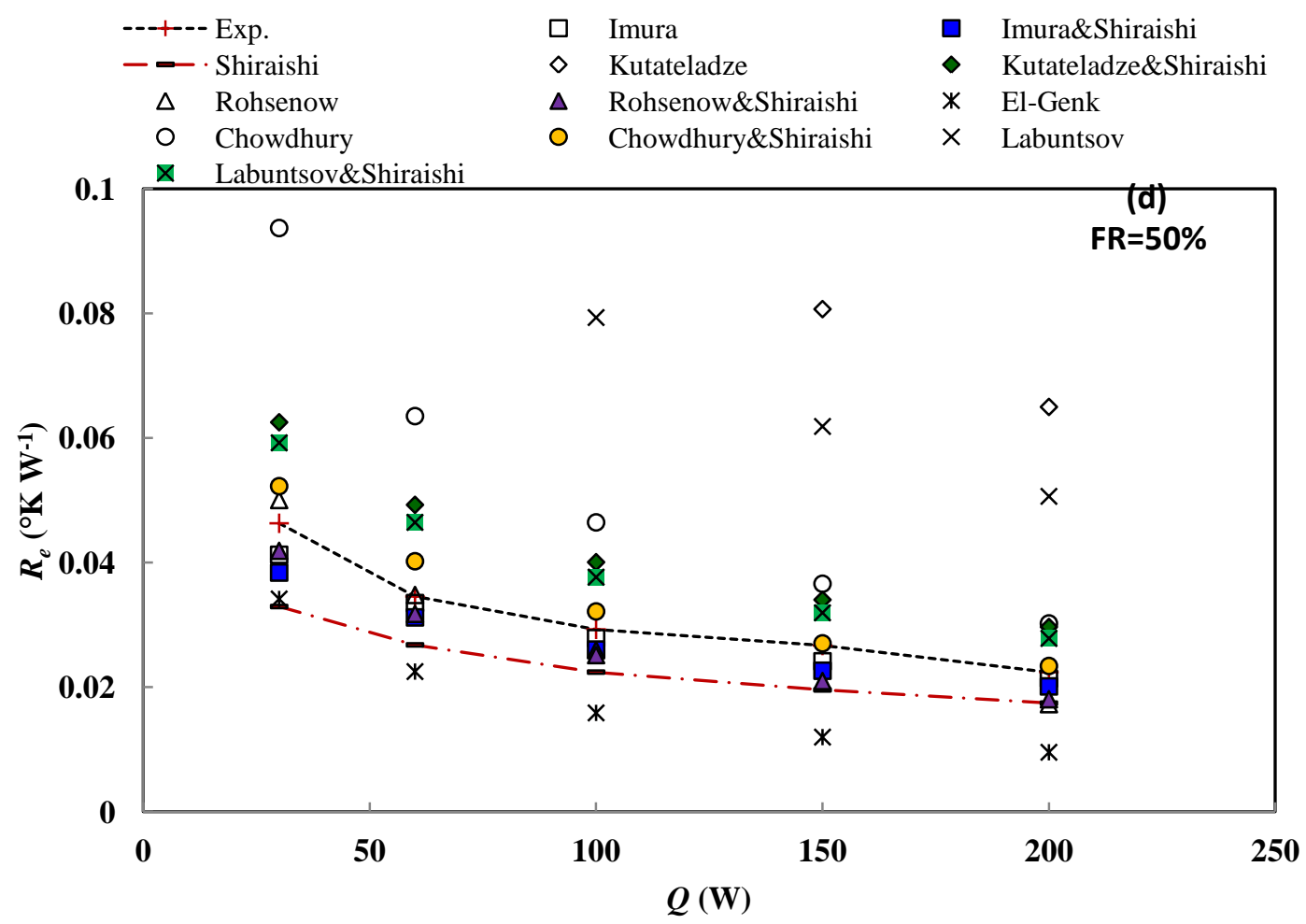

Fig. 10

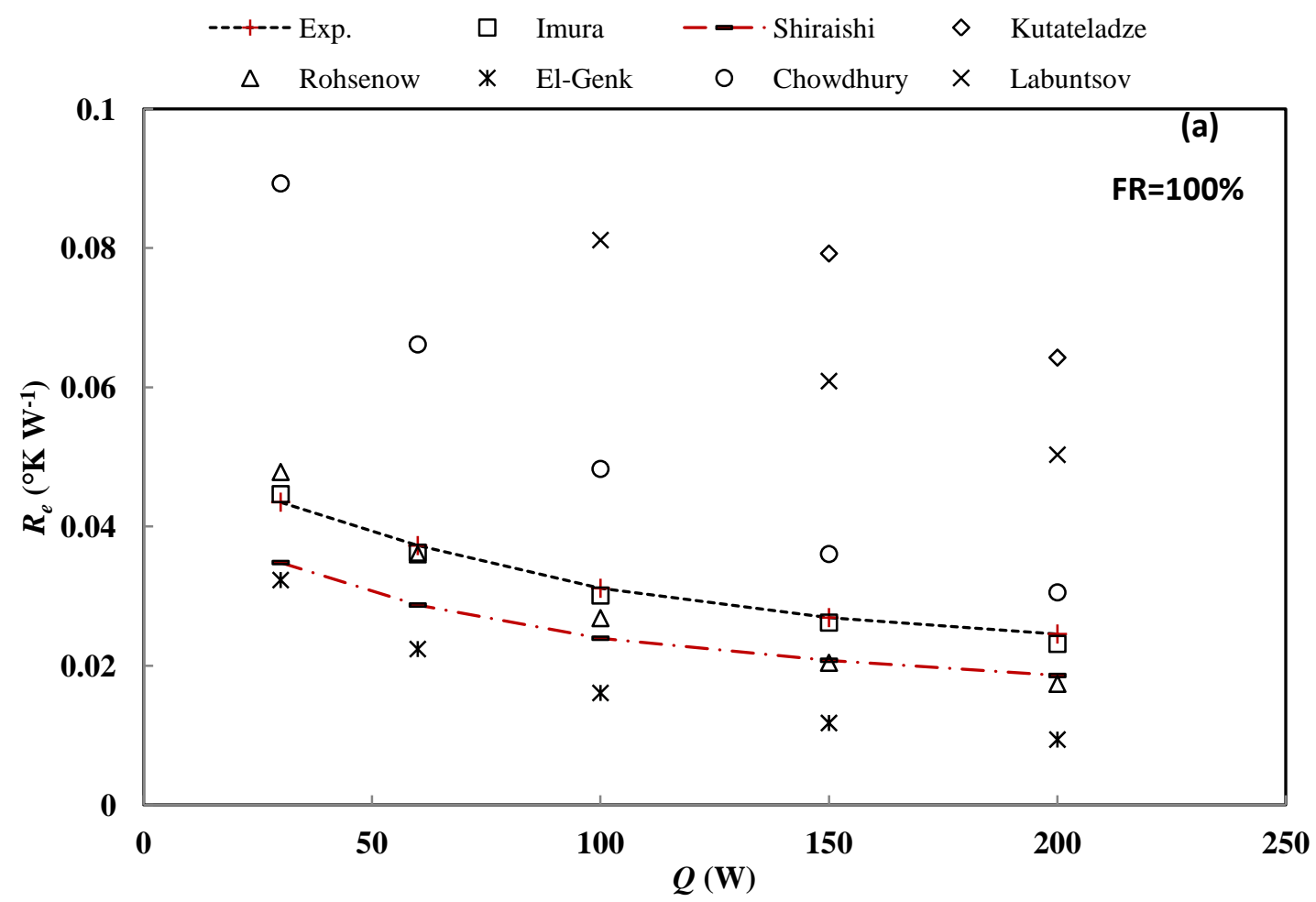




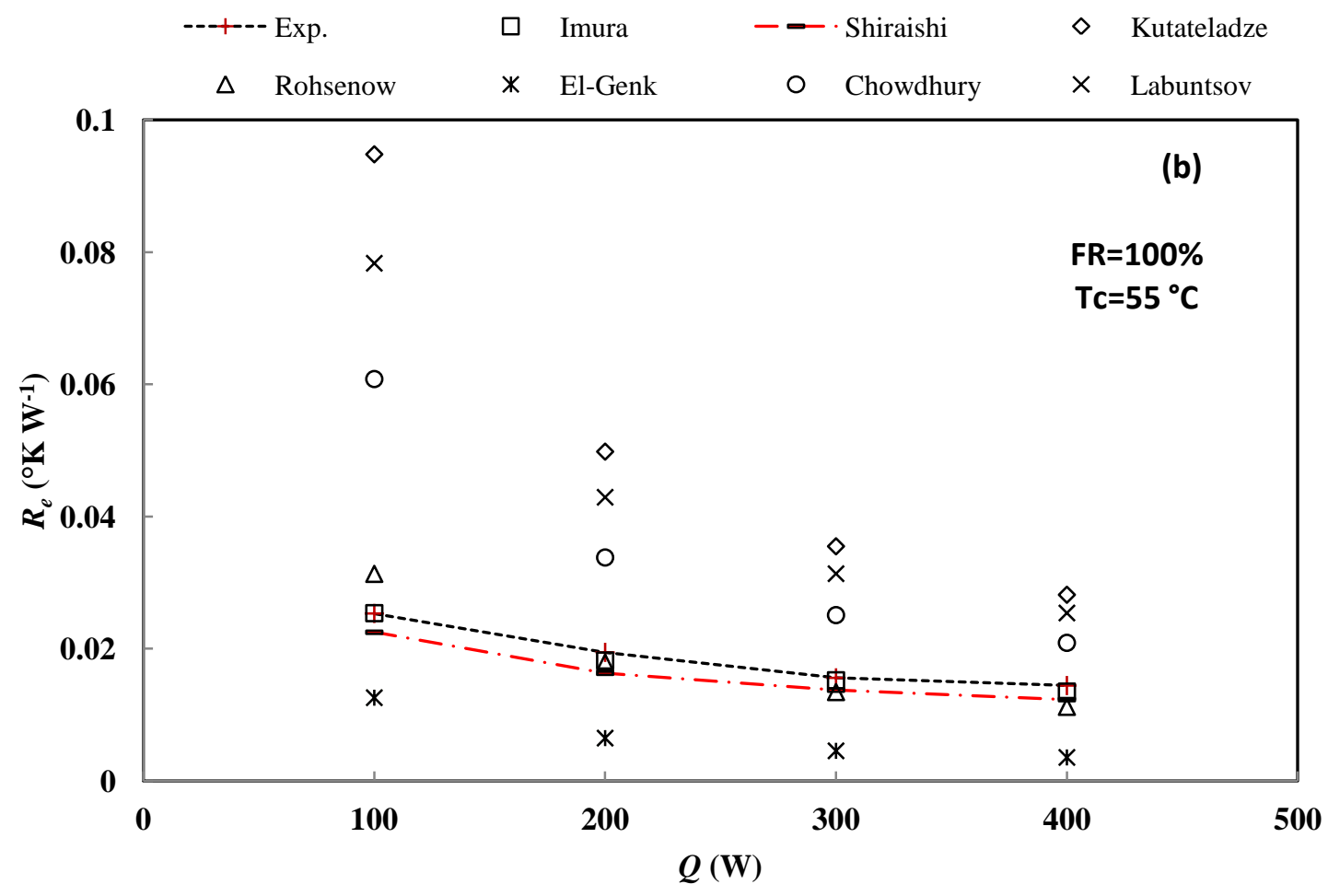

Fig. 11
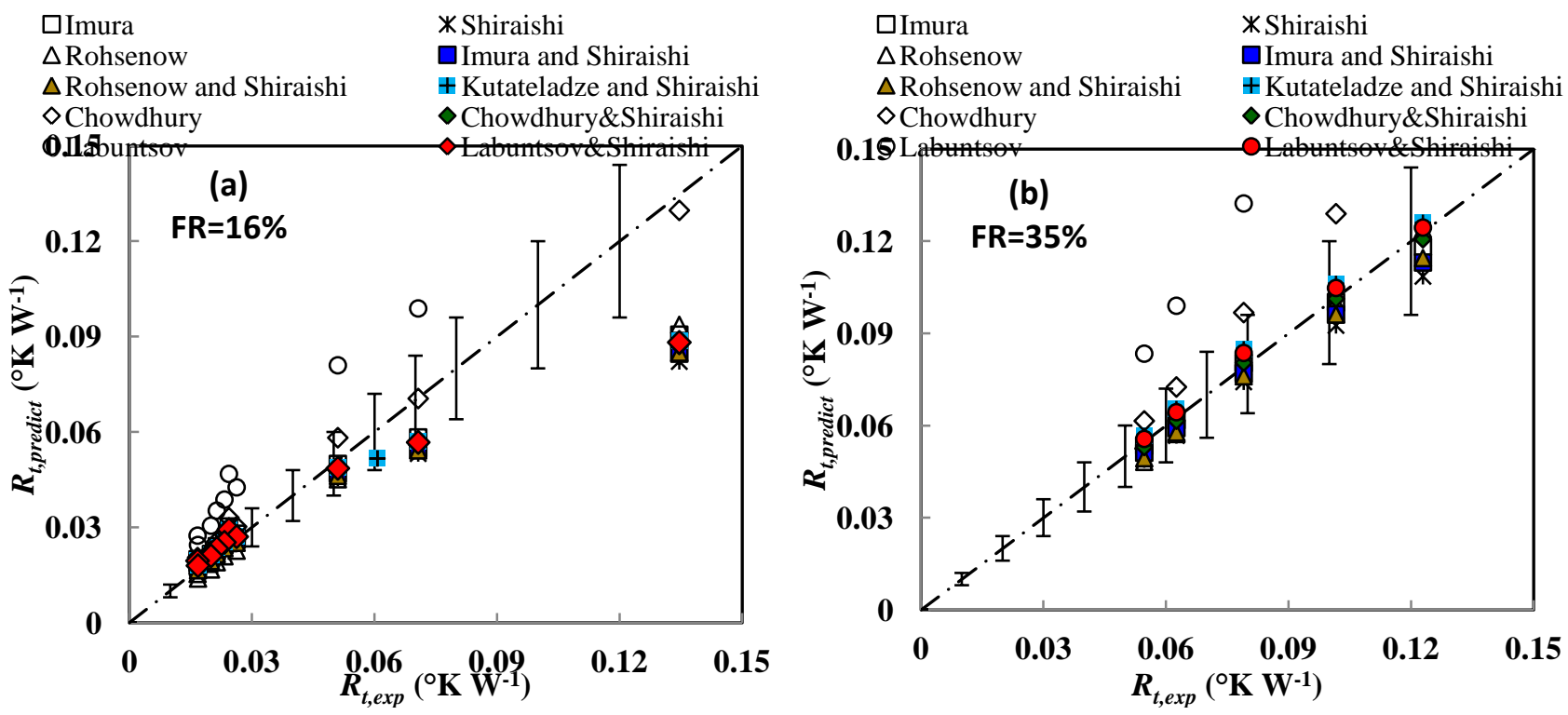

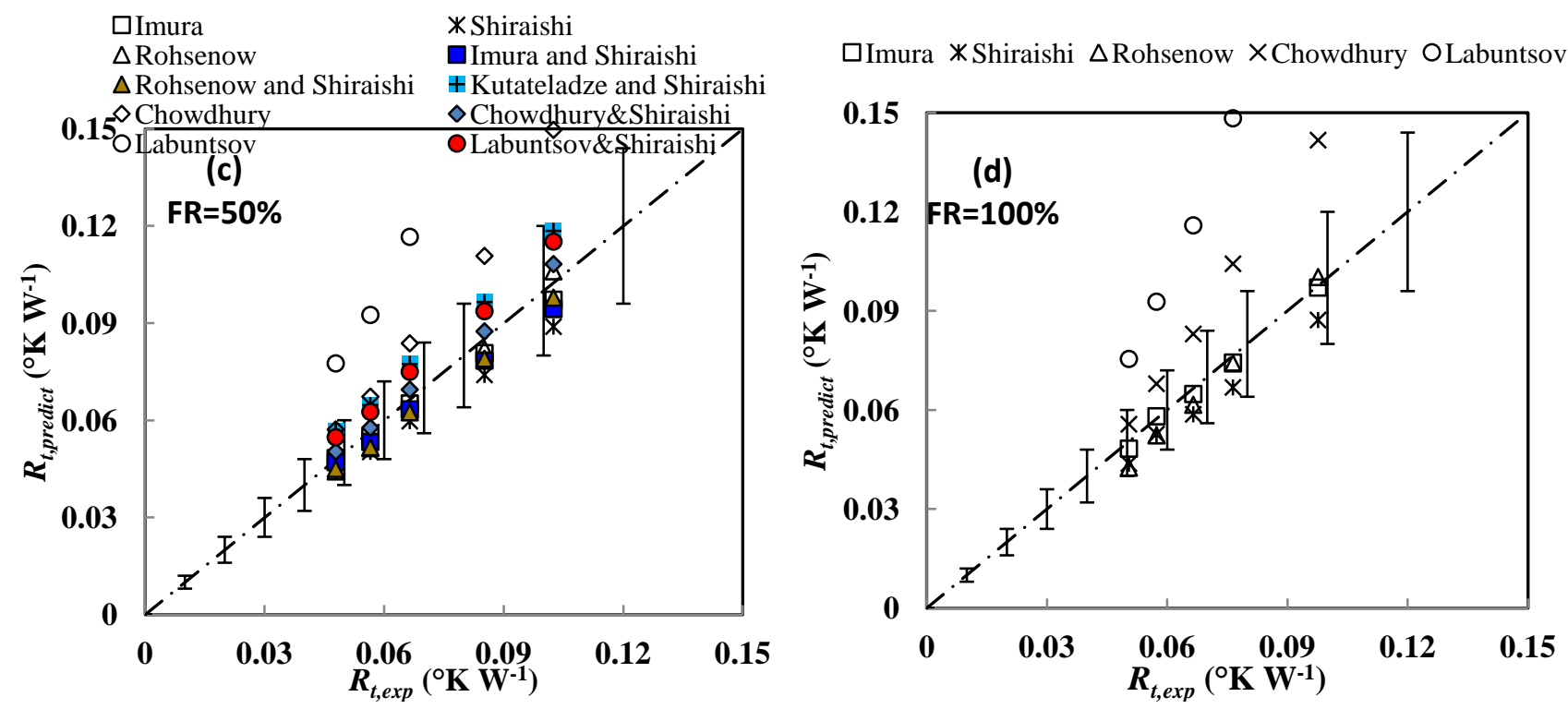

Fig. 12 


\section{$\underline{\text { Tables }}$}

Table 1 A list of some correlations provided for the calculation of condensation heat transfer

Table 2 A list of some correlations provided for the calculation of the evaporation heat transfer

Table 3 Design summery of the TPCT

Table Uncertainty of experimentally measured total thermal resistance (filling ratio of 50\%)

Table 5 The agreement of nucleate pool boiling correlations and their combination with film evaporation correlation [11] with experimental data

\section{Table 1}

\begin{tabular}{lll}
\hline Correlations & & References \\
\hline$h_{\text {Nusselt }}=1.47 \operatorname{Re}_{f}{ }^{-1 / 3}\left[\frac{\rho_{l}\left(\rho_{l}-\rho_{v}\right) g k_{l}^{3}}{\mu_{l}^{2}}\right]^{1 / 3}$ & (3) & Rohsenow [27] \\
$h_{c}=0.85 \operatorname{Re}_{f}^{0.1} \exp \left(-0.000067 \frac{\rho_{l}}{\rho_{v}}-0.6\right) h_{\text {Nusselt }}$ & (4) & Hashimoto and Kaminaga [19] \\
$h_{c}=0.85 \operatorname{Re}_{f}^{0.1} \exp \left(-0.000067 \frac{\rho_{l}}{\rho_{v}}-0.14\right) h_{\text {Nusselt }}$ & (5) & Jouhara and Robinson [14] \\
\hline
\end{tabular}


Table 2

\begin{tabular}{lll}
\hline Correlations & References \\
$h_{e, p}=$ & $q^{2 / 3} \operatorname{Pr}_{l}^{1.7}\left(\frac{C_{s, f} h_{f g}}{C p}\right)\left(\frac{d_{b}}{h_{f g} \mu_{l}}\right)^{0.33}$ & Rohsenow [8] \\
$h_{e, p}=$ & $\left.0.075 q^{0.67}\left[1+10\left(\frac{\rho_{v}}{\rho_{l}-\rho_{v}}\right)^{0.67}\right] \frac{k_{l}^{2}}{v_{l} \sigma(T+273.15)}\right]^{0.33}$ \\
$h_{e, p}=$ & $0.32\left(\frac{\rho_{l}^{0.65} k_{l}^{0.3} C_{p l}^{0.7} g^{0.2}}{\rho_{v}^{0.25} h_{f g}^{0.4} \mu_{l}^{0.1}}\right)\left(\frac{P_{v}}{P_{a t m}}\right)^{0.3} q^{0.4}$
\end{tabular}


Table 3

\begin{tabular}{ll}
\hline Parameters & \\
\hline Wall Material & Copper \\
Outer radius, $(\mathrm{mm})$ & 35 \\
Thickness, $(\mathrm{mm})$ & 1 \\
Total length, $(\mathrm{mm})$ & 500 \\
Evaporator length, $(\mathrm{mm})$ & 150 \\
Condenser length, $(\mathrm{mm})$ & 150 \\
Cooling mass flow meter, $\left(\mathrm{kg} \mathrm{s}^{-1}\right)$ & 0.038 \\
Inlet cooling temperature, $\left({ }^{\circ} \mathrm{C}\right)$ & 25 and 55 \\
Input heat flux, $(\mathrm{W})$ & $30-900$ \\
Filling ratio $($ working fluid volume/evaporator volume), $(\%)$ & $8,16,35,50$ and 100 \\
\hline
\end{tabular}

\section{Table 4}

\begin{tabular}{llllll}
\hline Heat transfer rate $(\mathbf{W})$ & $\mathbf{3 0}$ & $\mathbf{6 0}$ & $\mathbf{1 0 0}$ & $\mathbf{1 5 0}$ & $\mathbf{2 0 0}$ \\
\hline Uncertainty in overal thermal resistance $(\%)$ & 7.2 & 6.5 & 5.9 & 5.8 & 5.4 \\
\hline
\end{tabular}


Table 5

\begin{tabular}{|c|c|c|c|c|c|c|}
\hline \multirow[t]{2}{*}{ Correlations } & \multicolumn{5}{|c|}{ Present study } & \multirow{2}{*}{$\begin{array}{l}\text { Jouhara and } \\
\text { Robinson [14] } \\
\text { FR } \approx 130 \% \\
T_{C}=25^{\circ} \mathrm{C}\end{array}$} \\
\hline & $\begin{array}{l}\mathrm{FR}=16 \% \\
T_{c}=25^{\circ} \mathrm{C}\end{array}$ & $\begin{array}{l}\mathrm{FR}=35 \% \\
T_{c}=25^{\circ} \mathrm{C}\end{array}$ & $\begin{array}{l}\mathrm{FR}=50 \% \\
T_{c}=25^{\circ} \mathrm{C}\end{array}$ & $\begin{array}{l}\mathrm{FR}=100 \% \\
T_{c}=25^{\circ} \mathrm{C}\end{array}$ & $\begin{array}{l}\mathrm{FR}=100 \% \\
T_{c}=55^{\circ} \mathrm{C}\end{array}$ & \\
\hline Imura [10] & $\begin{array}{l}\text { Very Good } \\
\text { at high HF, } \\
\text { UP low }\end{array}$ & Good & Very Good & Very Good & Very good & $\begin{array}{l}\text { Co/UP at high } \\
\text { heat Flux }\end{array}$ \\
\hline Shiraishi [11] & $\begin{array}{l}\text { Very Good } \\
\text { at high HF, } \\
\text { UP at low } \\
\text { HF }\end{array}$ & $\mathrm{Co} / \mathrm{UP}$ & $\mathrm{Co} / \mathrm{UP}$ & $\mathrm{Co} / \mathrm{UP}$ & Good & $\begin{array}{l}\mathrm{Co} / \mathrm{UP} \text { at high } \\
\text { heat Flux }\end{array}$ \\
\hline Rohsenow [8] & $\begin{array}{l}\mathrm{Co} / \mathrm{UP} \text { at } \\
\text { high } \mathrm{HF}, \\
\mathrm{UP} \text { at low } \\
\mathrm{HF}\end{array}$ & $\mathrm{Co} / \mathrm{UP}$ & $\begin{array}{l}\text { Very Good } \\
\text { at low HF; } \\
\text { Co/UP at } \\
\text { high HF }\end{array}$ & $\begin{array}{l}\text { Very Good } \\
\text { at low HF; } \\
\text { Co/UP at } \\
\text { high HF }\end{array}$ & Very good & $\begin{array}{l}\text { Co/UP at high } \\
\text { heat flux; good } \\
\text { at low heat flux. }\end{array}$ \\
\hline Kutateladze [12] & OP & OP & $\mathrm{OP}$ & $\mathrm{OP}$ & OP & $\begin{array}{l}\text { Good at high } \\
\text { heat flux, OP at } \\
\text { low heat flux }\end{array}$ \\
\hline Chowdhury [13] & Good & $\begin{array}{l}\mathrm{OP} \text { at low } \\
\mathrm{HF}, \mathrm{Co} / \mathrm{OP} \\
\text { at high } \mathrm{HF}\end{array}$ & $\mathrm{OP}$ & $\begin{array}{l}\mathrm{OP} \text { at low } \\
\mathrm{HF}, \mathrm{Co} / \mathrm{OP} \\
\text { at high } \mathrm{HF}\end{array}$ & $\begin{array}{l}\mathrm{OP} \text { at low } \\
\mathrm{HF} \text {, } \\
\mathrm{Co} / \mathrm{OP} \text { at } \\
\text { high } \mathrm{HF}\end{array}$ & $\mathrm{Co} / \mathrm{OP}$ \\
\hline Labuntsov [9] & OP & OP & $\mathrm{OP}$ & OP & OP & $\begin{array}{l}\begin{array}{l}\text { Good at low } \\
\text { heat } \\
\text { CO/UP } \\
\text { heat flux. }\end{array} \\
\text { high } \\
\end{array}$ \\
\hline $\begin{array}{l}\text { Imura }[10] \& \\
\text { Shiraishi [11] }\end{array}$ & $\begin{array}{l}\text { Very Good } \\
\text { at high HF; } \\
\text { UP at low } \\
\text { HF }\end{array}$ & $\mathrm{Co} / \mathrm{UP}$ & $\mathrm{Co} / \mathrm{UP}$ & - & - & \\
\hline $\begin{array}{l}\text { Rohsenow [8]\& } \\
\text { Shiraishi [11] }\end{array}$ & $\begin{array}{l}\text { Very Good } \\
\text { at high HF, } \\
\text { UP at low } \\
\text { HF }\end{array}$ & $\mathrm{Co} / \mathrm{UP}$ & $\mathrm{Co} / \mathrm{UP}$ & - & - & \\
\hline $\begin{array}{l}\text { Kutateladze [12]\& } \\
\text { Shiraishi [11] }\end{array}$ & $\begin{array}{l}\text { Very Good } \\
\text { at high HF }\end{array}$ & Very Good & $\mathrm{Co} / \mathrm{OP}$ & - & - & \\
\hline $\begin{array}{l}\text { Chowdhury [13]\& } \\
\text { Shiraishi [11] }\end{array}$ & $\begin{array}{l}\text { Very Good } \\
\text { at high HF }\end{array}$ & Very Good & Good & - & - & \\
\hline $\begin{array}{l}\text { Labuntsov }[9] \& \\
\text { Shiraishi [11] }\end{array}$ & $\begin{array}{l}\text { Very Good } \\
\text { at high HF }\end{array}$ & Very Good & Good & - & - & \\
\hline
\end{tabular}

$\boldsymbol{H F}$ : heat flux; $\boldsymbol{U P}$ : Under-Predict, $\boldsymbol{O P}$ : Over-Predict, $\boldsymbol{C o}$ : comparable,

Comparable: when experiments and predictions in an agreement of $\pm 20 \%- \pm 30 \%$

Good: when experiments and predictions in an agreement of $\pm 10 \%-20 \%$

Very Good: when experiments and predictions in an agreement of lower than $\pm 10 \%$ 


\title{
An experimental investigation on the evaporation and condensation heat transfer of two-phase closed thermosyphons
}

\author{
Davoud Jafari ${ }^{1, *}$, Paolo Di Marco ${ }^{2}$, Sauro Filippeschi $^{2}$, Alessandro Franco ${ }^{2}$ \\ ${ }^{1}$ Faculty of Engineering Technology, University of Twente, P.O. Box 217, 7500 AE Enschede, The Netherlands \\ ${ }^{2}$ Department of Energy, Systems, Territory and Constructions Engineering (DESTEC), \\ University of Pisa, Italy
}

Corresponding Author:

Davoud Jafari

University of Twente

Faculty of Engineering Technology, P.O. Box 217, 7500 AE Enschede, The Netherlands

Email: jafariidavoud@gmail.com,j.davoud@yahoo.com

\begin{abstract}
Two-phase closed thermosyphons (TPCTs) are excellent thermal transfer devices that their integration into heat exchangers has been shown a strong potential for energy savings. The scope of this study is an experimental evaluation of the evaporation and condensation heat transfer of a TPCT for uniformly heated evaporator surface. Water as the working fluid is charged in a TPCT with a length of $500 \mathrm{~mm}$ and an inner diameter of $33 \mathrm{~mm}$ at different filling ratios (8\%-100\%). The performance of the thermosyphon with predictions of the pool boiling (filling ratio of 100\%) and a combination of the pool boiling and film evaporation models in the evaporator section (filling ratio<100\%) and alse filmwise condensation model in the condenser section-are compared with available predictive correlations and theories. The experimentally obtained condensation heat transfers also evaluate by available filmwise condensation model in the condenser section. Results show an agreement with the most of the selected correlations with tolerance $\pm 30 \%$ and the appropriate set of correlations are introduced within an accuracy of $\pm 10 \%$.
\end{abstract}


Keywords: thermosyphon, pool boiling, liquid film evaporation, condensation

\section{Nomenclature}

Bo $\quad$ Bond number, $d_{i} / L_{b}$

$C \quad$ Specific heat $\left(\mathrm{J} \mathrm{kg}^{-1} \mathrm{~K}^{-1}\right)$

D Diameter (m)

$d_{b} \quad$ Bubble departure diameter (m)

FR Filling ratio

$G \quad$ Gravitational acceleration $\left(\mathrm{m} \mathrm{s}^{-2}\right)$

$H \quad$ Heat transfer coefficient $\left(\mathrm{W} \mathrm{m}^{-2} \mathrm{~K}^{-1}\right)$

$h_{f g} \quad$ Heat of vaporization $\left(\mathrm{J} \mathrm{kg}^{-1}\right)$

$K \quad$ Thermal conductivity $\left(\mathrm{W} \mathrm{m}^{-1} \mathrm{~K}^{-1}\right)$

L $\quad$ Length (m)

$L_{b} \quad$ Bubble length scale $(\mathrm{m}),\left[\sigma / g\left(\rho_{l}-\rho_{v}\right)\right]^{1 / 2}$

$\dot{m} \quad$ Mass flow rate $\left(\mathrm{kg} \mathrm{s}^{-1}\right)$

$\mathrm{Nu} \quad$ Nusselt number, $h L / k$

$P \quad$ Pressure $(\mathrm{Pa})$

$\operatorname{Pr} \quad$ Prandtl number, $v / \alpha$

Q Heat transfer rate (W)

$Q \quad$ Heat flux $\left(\mathrm{W} \mathrm{m}^{-2}\right)$

$R \quad$ Thermal resistance $\left({ }^{\circ} \mathrm{K} \mathrm{W}^{-1}\right)$

$R \quad$ Radius (m)

Re Reynolds number, $4 Q / \pi D h_{f g} \pi$

$T \quad$ Temperature $\left({ }^{\circ} \mathrm{K}\right)$

\section{Greek symbols}

Kinematic viscosity $\left(\mathrm{m}^{2} \mathrm{~s}^{-1}\right)$

Density $\left(\mathrm{kg} \mathrm{m}^{-3}\right)$

Dynamic viscosity (Pa s)

Surface tension $\left(\mathrm{N} \mathrm{m}^{-1}\right)$

Contact angle $\left({ }^{\circ}\right)$

Subscripts

a Adiabatic

atm Atmospheric

c Condenser

e Evaporator

film Liquid film

i Inner

$1 \quad$ Liquid

o Outer

p Pool

sat Saturation

$\mathrm{t}$ Total

v Vapor

\section{Introduction}

A continuous cycle of the evaporation and the condensation processes is encountered in many energy and thermal processing applications. The example includes, but not limited, two-phase devices. A twophase closed thermosyphon (TPCT) or a gravity-assisted wickless heat pipe is one of the two-phase passive devices which work on the mechanisms of evaporation and condensation to transfer large amounts of heat with a minimal temperature difference [1]. A TPCT operates when heat is applied to 
the evaporator section, causes evaporation of the working fluid. The vapor flows to the condenser section, where the fluid condenses. Then, the condensate returns to the evaporator section along the wall by the action of gravity, closing the cycle. Given the advantages of the TPCT, heat transfer predictions in its uniformly heated are of interest in many industrial and energy applications. Examples of these applications include heating, ventilation and air conditioning, residential and commercial refrigeration, data center cooling, solar water heating and geothermal energy recovery [2-6].

The challenges of prediction of the heat transfer process in two-phase devices to be integrated into many industrial thermal controls have been raised. The heat and mass transfer processes inside a TPCT include convection, pool boiling, thin liquid film evaporation, countercurrent two-phase flow and filmwise condensation. In the evaporator section, the falling liquid film and the liquid pool in the bottom of the device are occurred participating in the phase change and heat transfer simultaneously. As various heat transfer regimes can be observed in the evaporator section include natural convection, mixed convection and the nucleate boiling (at high heat fluxes), its heat transfer mechanism is complex [7]. Recent studies considered the nucleate pool boiling regime to predict the heat transfer coefficients within the evaporator section: Rohsenow [8], Labuntsov [9], Imura et al. [10], Shiraishi et al. [11], Kutateladze [12] and Chowdhury et al. [13]. For a relatively small heat flux, Nusselt theory for filmwise evaporation is suggested [7, 14] while Shiraishi et al. [11] suggested a modification of Nusselt theory when nucleate boiling within the liquid film is dominant. Among others, Kiatsiriroat et al. [15] reported the use of a modified Rohsenow [8] correlation to predict the boiling heat transfer coefficient inside the thermosyphon for different working fluid. Park et al. [16], Noie [17] and Guo and Nutter [18] showed a good agreement with the Imura [10] using FC-72, water and R134a as a working fluid, respectively. Jouhara and Robinson [14] experimentally investigated a thermosyphons charged with water at filling ratios of $50 \%$ and $160 \%$. They compared the evaporation heat transfer with 
available predictive correlations and theories with a good agreement; however, they have not analyzed the combination of correlation in the case of low filling ratio.

A Nusselt analysis for filmwise condensation has been used to predict condensation heat transfer coefficient. To predict the filmwise condensation heat transfer, Rohsenow [8] modified Nusselt correlation which is applicable when Reynolds film number is in the range of 30-1600. Hashimoto and Kaminaga [19] provided a correlation considering the effect of entrainment which latter modified by Jouhara and Robinson [14]. Different approaches for defining the condensation heat transfer is defined by Wang and Ma [20] applicable for vertical and inclined TPCTs. Hussein et al. [21] presented a correlation to predict condensation heat transfer a wide range of inclination angles. The majority of studies to analyze evaporation and condensation heat transfer have been recently discussed by Jafari et al. [2]. They have made a comparative analysis of the heat transfer correlations with the experimental data in the literature. They showed that the results appear to be dispersed both for condenser and evaporator sections.

The thermal characteristics of TPCTs have been investigated in recent years [22-25]. There still exists, however, uncertainty in the description of heat transfer characteristics. Previous studies on the investigation of evaporation heat transfer focused on pool boiling or film evaporation heat transfer. There is limited open literature on the combination of pool boiling and film evaporation heat transfer on TPCTs. The selection of appropriate heat transfer correlation would be resulted in prediction thermal performance of two-phase closed thermosyphon and also their integration into lots of practical applications. The authors of present study [26], recently, experimentally and numerically investigated the transient behavior of TPCTs at different filling ratios. They showed that the Imura [10] correlation is able to accurately predict the pool boiling heat transfer as expected from the literature for high filling ratios (filling ratio of $135 \%$ ), but comparable agreement observed at low filling ratios (filling ratio of $16 \%$ and $35 \%)$. Therefore, there is a need to evaluate the reported heat transfer correlations for thermosyphons to 
present more accurate heat transfer correlations as well as their combination. This paper is the second part of the recent paper [26]. In current document, in which, the experimental data of a thermosyphon with $500 \mathrm{~mm}$ length and $33 \mathrm{~mm}$ internal diameter charging with water is presented. Water tests are performed with different filling ratios range from $8 \%$ to $100 \%$; to have a combination of the liquid pool and liquid film region and also to have only pool boiling. The experimental measurements are compared with those of a model that is based on existing correlations of the literature basing on evaporation and condensation heat transfer.

\section{Deseribing prediction methods Methods for prediction of condensation and} evaporation heat transfer in a TPCT

A TPCT is divided into three sections: an evaporator, an adiabatic and a condenser, as shown in Fig. 1. The thermosyphon operates when heat is supplied to the evaporator section. The working fluid in the evaporator section is vaporized and transfers heat from the evaporator section (heat source) to the condenser section (heat sink), where condensation of the working fluid occurs. Then, a countercurrent (the liquid and the vapor flow in opposite directions) thin liquid film is flow backed to the evaporator section under the gravitational force which the liquid is evenly distributed around the thermosyphon wall. The thermal resistances of a thermosyphon are illustrated in Fig. 1.

The two major contributors to the total thermal resistance of a thermosyphon are the thermal resistances in the liquid film in both the condenser $\left(R_{c}\right)$ and the evaporator $\left(R_{e, f i m}\right)$. The condensation thermal resistance of the thermosyphon is verified by

$R_{c}=\frac{1}{h_{c} A_{c}}$

where $h_{c}$ is the heat transfer coefficient of the liquid film in the condenser section of a thermosyphon, and $A_{c}$ is the inner surface area of the liquid film. There are some parameters that affect the 
condensation heat transfer: thermal and hydrodynamic properties of the working fluid, local flow velocity, orientation and operating temperature. A Nusselt analysis for condensation on a vertical flat plate is the first basic approach and commonly used to evaluate the condensation heat transfer coefficient, considering the filmwise condensation within the laminar regime, Eq. $z-3$ (see Table 1). Where $\rho_{l}$ and $\rho_{v}$ are the density of the liquid and vapor, $k_{l}$ is the thermal conductivity of the liquid, $\mu_{l}$ is the liquid viscosity. and $\mathrm{tThe}$ film Reynolds number $\left(R e_{f}\right)$ for this study is defined as

$$
\operatorname{Re}_{f}=\frac{4 Q}{\pi D h_{f g} \mu_{l}}
$$

where $h_{f g}$ is the latent heat of vaporization and $D$ is pipe diameter. It is worth noticing that all fluid properties are evaluated at the saturation temperature corresponding to the pressure in the thermosyphon. An approach to predicting condensation heat transfer of TPCTs is presented by Hashimoto and Kaminaga [19], considering the fluid entrainment in a TPCT which later modified by Jouhara and Robinson (Eq. 5). Table 1 lists the selected correlations to predict condensation heat transfer.

The evaporation in the evaporator section is another important thermal resistance. Of the various heat transfer regimes may exist in the liquid pool (natural convection, mixed convection and the nucleate boiling), nucleate boiling is the most desirable regime in practice because of high heat transfer rates. A nucleate boiling heat transfer correlation contains a heat flux, a temperature term, a density and a fluid property dependent factor (Prandtl number, surface tension and heat capacity) [28]. The main available correlations for the pool boiling regime in this paper include Rohsenow [8], Labuntsov [9], Imura et al. [10], Shiraishi et al. [11], Kutateladze [12] and Chowdhury et al. [13], as summarized in Table 2. Where $h_{e, p}$ is the heat transfer coefficient for the internal evaporation from the liquid pool, $g$ is gravitational acceleration, $h_{f g}$ is latent heat of vaporization, $q$ is heat flux to the liquid pool region, $P_{a t m}$ is atmospheric pressure, $\rho_{l}$ and $\rho_{v}$ are liquid and vapor phase densities, $c_{p, l}$ is specific heat of liquid, $k_{l}$ is 
liquid thermal conductivity, $\mu_{l}$ is liquid dynamic viscosity and $L_{b}$ is the bubble departure diameter given by $\left[\sigma / g\left(\rho_{l}-\rho_{v}\right)\right]^{1 / 2}$. The correlation of Imura et al. [10] was developed specifically for pool boiling in thermosyphons; however, it can cover also the natural convection and combined convection regimes [7]. Shiraishi et al. [11] modified Imura [10] correlation by changing the exponent of the pressure term from 0.3 to 0.23 for water, ethanol and R-1 13. The proposed correlation by Rohsenow [8] is independent of the geometry and orientation of the heater surface while includes an adjustable constant that depended upon the nature of the surface-fluid combination. The Kutateladze correlation [12] was also developed for different working fluids which make them more general at the expense of accuracy due to constants and powers of the correlation.

Nusselt theory for filmwise evaporation is applicable for a relatively small heat flux (Eq. 3). For the heat transfer coefficient related to the liquid film in the upper region of the evaporator section, $h_{e, f i l m}$. Shiraishi et al. [11] used to estimate the liquid film heat transfer coefficient. The thermal resistance of the evaporator part is defined by the heat transfer coefficients associated with an only liquid pool when evaporator section filled with the working fluid (filling ratio is $100 \%)\left(R_{e, p}\right)$ and liquid pool and liquid film when filling ratio is less than $100 \%\left(R_{e, p+f i l m}\right)$ :

$$
\begin{aligned}
& R_{e, p}=\frac{1}{h_{e, p} A_{e}} \\
& R_{e, P+f i l m}=\frac{1}{h_{e, P} A_{e}+h_{e, f i l m}\left(A_{e}-A_{P}\right)}
\end{aligned}
$$

where $h_{e, p}$ is obtained from pool boiling correlations summarize in Table 2 and $h_{e, f i l m}$ is determined by applying Shiraishi et al. [11] correlation. The variables $A_{e}$ and $A_{p}$ are the inner surface area of the evaporator section and the evaporator inner surface area in contact with the liquid pool, respectively. 


\section{Experimental setup and procedure}

An experimental apparatus is designed, as illustrated schematically in Fig. 2, consists of a thermosyphon, heater, cooling water flow circuit and instrumentation. The envelope of the TPCT is manufactured by copper, with a $35 \mathrm{~mm}$ outside diameter, $1 \mathrm{~mm}$ thickness and $500 \mathrm{~mm}$ length. The volume of the evaporator, $V_{e}$, is defined as the inner volume of that part of the evaporator section of the TPCT where is in contact with electrical heaters. It is quantified as the volume $\pi r_{i}^{2} L_{e}$ with evaporator length $\left(L_{e}\right)$ of $150 \mathrm{~mm}$. To reduce the consequences of non-condensable gas generation inside the thermosyphon, the pipe and the working fluid are degassed under vacuum before charging-, different filling ratios of water are examined: $8 \%, 16 \%, 35 \%, 50 \%$ and $100 \%,\left(F R=V_{\text {fluid }} / V_{e}\right)$ where $V_{\text {fluid }}$ is the volume of used water as a working fluid in the TPCT. Heat is applied to the thermosyphon at the evaporator section by using silicon thermofoil heater (model MINCO HK5488R17.2L12A) clamped to the external evaporator wall surface. The electrical power input to the heater is controlled and supplied by a DC Power supply (Agilent DC6575A) which has an accuracy of \pm 1 percent of reading. The condenser section of the thermosyphon is cooled by a flow of water through a $150 \mathrm{~mm}$ long and with an inside diameter of $39 \mathrm{~mm}$. Condenser water is supplied via a cooling bath (HAKKE F-3C DIN 58966). An electromagnetic flow meter (Siemens SITRANS F M MAGFLO5000) is used to measure the mass flow rate of the cooling water. The temperature distribution along the thermosyphon is measured using T-type thermocouples, as shown schematically in Fig. 2. To obtain the input and the output water temperatures from the water jacket, two thermocouples are used. More details of experimental facilities describe in [26]. Table 3 lists the detailed specifications and operating parameters of the TPCT.

\subsection{Experimental methods and data reduction}


The experiments are performed with a TPCT in the vertical orientation. During the tests, the heat input to the evaporator and the temperatures are monitored. An energy balance is performed to obtain a confidence in the measured values of heat transfer rate. Energy balances between the applied heat flux in the evaporator section (the electrical heaters, $Q_{i n}=V I$ ) and the removed heat flux (the heat sink, $\left.Q_{\text {out }}=\dot{m} C_{p}\left(T_{\text {out }}-T_{\text {in }}\right)\right)$ are monitored to ensure an energy balance of at least 90 percent at steady state operation, as evidenced in Fig. 3. Where $T_{\text {in }}$ is the temperature of the inlet and $T_{\text {out }}$ is the outlet temperature of cooling water and $\dot{\mathrm{m}}$ is cooling mass flow rate.

The heat transfer capacity of evaporator section is determined by the evaporation heat transfer coefficient $\left(h_{e}\right)$ of the TPCT. From the measured data of wall temperature and vapor temperature (equivalent to the wall temperature of the adiabatic section), the heat transfer coefficient in the evaporator can be evaluated using the following equation:

$h_{e}=\frac{Q_{a v}}{\pi D_{i} L_{e}\left(T_{e, a v e}-T_{v}\right)}$

Where

$Q_{a v}=\frac{Q_{\text {in }}+Q_{\text {out }}}{2}$

The heat transfer capacity of the condenser section is also reflected through condensation heat transfer coefficient $\left(h_{c}\right)$ for TPCTs. This is associated with conduction through the liquid film inside the thermosyphon and related to the average wall temperature of condenser section which can be evaluated using the following equation:

$h_{c}=\frac{Q_{a v}}{\pi D_{i} L_{c}\left(T_{v}-T_{c, a v e}\right)}$

In the evaporator and condenser regions, respectively, thermal resistances is calculated by

$$
R_{e}=\frac{T_{e, a v e}-T_{v}}{Q_{a v}}
$$


$R_{c}=\frac{T_{v}-T_{c, a v e}}{Q_{a v}}$

where $T_{e, a v e}$ and $T_{c, a v e}$ are the average wall temperatures in the evaporator and condenser, respectively, and $T_{v}$ is the saturated vapor temperature taken here as the adiabatic wall temperature. The experimental uncertainty of the measurement is calculated by the uncertainty in the temperature measurements at different applied powers, increasing from a higher power to lower one as indicated for total thermal resistance in Table 4.

\section{Results and discussion}

The purpose of experimental results is to understand the condensation and evaporation heat transfer of TPCTs. The performance of the thermosyphon is examined in detail to understand how the system operates in pool boiling mode at a high filling ratio ( $\mathrm{FR}=100 \%)$ and how to operate under a combination of film convection and pool boiling (FR<100\%). Before discussion on the evaporation and the condensation heat transfer, a sample of steady state and transient operation of thermosyphon is presented.

\subsection{Temperature distribution analysis}

A typical example of external wall temperature distributions along the thermosyphon at heat transfer rates of $30 \mathrm{~W}, 100 \mathrm{~W}$ and $200 \mathrm{~W}$ for filling ratios of $35 \%$ and $100 \%$ under steady state operation is shown in Fig. 4. Obviously, the wall temperatures and the total temperature differences increase with increasing input powers and the wall temperature of the evaporator and condenser sections are approximately uniform for each respective power level tested. The temperature rise of the evaporator section in the filling ratio of $100 \%$ is more than the filling ratio of $35 \%$. The temperature of lower part of the evaporator section in the filling ratio of $35 \%$ is similar to that of filled evaporator (filling ratio of 
$100 \%$ ) where the maximum temperature is observed as occupied by the liquid pool. The maximum wall temperature is approximately equal to $39^{\circ} \mathrm{C}$ and $41{ }^{\circ} \mathrm{C}$ for filling ratio of $35 \%$ and $100 \%$, respectively at heat transfer rate of $200 \mathrm{~W}$.

In some cases the heat flow rate is high, the thermosyphon can dry out. Fig. 5 shows the transient wall temperature variation for filling ratio of $16 \%$ at the heat flux ranged: $350 \mathrm{~W}$ to $900 \mathrm{~W}$ which the maximum heat transfer rate is detected. It is found that the normal operation continues up to heat transfer rate of $800 \mathrm{~W}$. Another observation is local dryout at first stage of operation in which evaporator temperature sharply increases to about $140^{\circ} \mathrm{C}$, and then decreases, much more than steady state operation which is about $43{ }^{\circ} \mathrm{C}$. This phenomenon can be explained by considering the condensate film response. This observation strongly recommends that to avoid an excessive temperature rise in the evaporator section for small filling ratios the input heat should be applied gradually. It should be noticed that when dryout occurs, the measurement is skipped from the heat transfer analysis described in following sections.

\subsection{Heat transfer analysis of the TPCT}

To evaluate the condensation and the evaporation heat transfer, different filling ratios of $16 \%, 35 \%$, $50 \%$ and $100 \%$ is tested. Fig. 6 shows the relationship between experimentally obtained evaporation and condensation heat transfers for filling ratio of $100 \%$ and lower than $100 \%(16 \%, 35 \%$ and $50 \%)$. As it appears, a general trend of both is increasing together for-with the inlet cooling temperature of 25

${ }^{\circ} \mathrm{C}$, at reasonably similar values. However, for the inlet cooling temperature of $55{ }^{\circ} \mathrm{C}$ the results are less clear.

Based on applied filling ratios, the evaporator section divides a region of the liquid pool $\left(L_{p}\right)$ in which nucleate pool boiling is occurring as well a region of the liquid film where evaporation is occurring across a thin liquid film. The evaporation and condensation heat transfers are predicted by the 
correlations listed in Table 1 and Table 2. Accordingly, the thermal resistance of the evaporator section obtains by Eq. 12 and Eq. 13 based on filling ratio and condenser section thermal resistance obtains by Eq. 1.

\subsubsection{Condensation heat transfer}

Dimensionless numbers are often used for a general characterization of heat transfer. The heat transfer in the condenser section is verified by a relation between Nusselt number, $N u$, and the film Reynolds number, $\operatorname{Re}_{f}\left(N u=h_{c} L_{c} / k_{l}\right)$. In Fig. 7, the experimental Nusselt numbers are presented as a function of the Reynolds number by the models of Nusselt, Hashimoto and Kaminaga [19] and Jouhara and Robinson [14] at filling ratios of $16 \%$ and $100 \%$. The Nusselt equation shows over prediction of experimental data at different heat fluxes; however, for the higher Reynolds numbers (higher heat transfer rates) a comparable agreement with the experimental data is observed. The similar agreement is observed at filling ratios of $35 \%$ and $50 \%$ (not shown). As it is evidenced in Fig. 7, the experimental results show a comparable agreement with the Hashimoto and Kaminaga [19] correlation while the best agreement with the experimental data is observed with Jouhara and Robinson [14] modification.

The variations of the thermal resistance in the condenser section with heat input power difference is shown in Fig. 8. As it is evidenced, the condenser thermal resistance remains constant over heat transfer rate of $400 \mathrm{~W}$ (see Fig. 8a). A very good agreement is observed in the comparison of experimentally thermal resistance in the condenser section and the correlation modified by (Jouhara and Robinson [14]).

\subsubsection{Evaporation heat transfer}


Complex fluid flow and heat transfer behaviors occur in the evaporator of TPCTs, as described in section 2; however, nucleate boiling could be dominant mechanism in the evaporator section $[7,16]$. The selected nucleate boiling correlations lists in Table 2 are chosen to compare with experimental data. Fig. 9 shows the evaporation heat transfer predictions by Rohsenow [8], Labuntsov [9], Imura et al. [10], Shiraishi et al. [11], Kutateladze [12] and Chowdhury et al. [13] correlations versus the experimental evaporation heat transfers at both filling ratio of $100 \%$ and lowers than $100 \%$. The most proposed correlations give similar results with the experimental evaporation heat transfer within a deviation of $\pm 30 \%$. As it is evidenced, the experimental data for filling ratio of $100 \%$ are in a good agreement with Rohsenow [8], Imura et al. [10] and Shiraishi et al. [11] correlations while underprediction of Labuntsov [9], Kutateladze [12] and Chowdhury [13] is observed. For filling ratio of $<100 \%$ there is a worse agreement between the sets of values. The Imura et al. [10], Shiraishi et al. [11] and Rohsenow [8] correlations show a better agreement for filling ratio of <100\% and underprediction of the experimental data at higher values for Imura [10] correlation while over-predict for Rohsenow [8] correlation. Agreement worsens for Kutateladze [12], Chowdhury et al. [13] and Labuntsov [9]. This suggests a combination of the liquid pool boiling and the film evaporation which would result in a better agreement.

The variations of the thermal resistance in the evaporator section with heat input power to compare the predicted and experimental thermal resistance values for filling ratio less than $100 \%$ (a combination of pool boiling and film evaporation occurs) are shown in Fig. 10. The lines indicate correlations for Shiraishi et al. [11], unfilled markers represent correlations for pool boiling correlations (Eq. 12, see Table 2) and filled markers represents the combination of pool boiling and film evaporation developed by Shiraishi et al. [11] (Eq. 13). As it is evidenced, the experiments and predictions show reasonable agreement with correlations of Imura [10], Shiraishi [11] and Rohsenow [8], together with the 
combination of nucleate pool boiling correlation of Imura [10], Kutateladze [12], Rohsenow [8], Labuntsov [9] and Chowdhury [13] with Shiraishi [11] for film evaporation, expect filling ratio of $8 \%$. At filling ratio of $8 \%$ dryout occurs due to a very low filling ratio (skipped from the following analysis). A general observation is that with increasing filling ratio the combination of pool boiling correlations and film evaporation [11] behaves as over/under-prediction of experimental measurements, thus this combination recommended for a low filling ratio. It is also noticed that applying the proposed correlation by Kutateladze [12], Labuntsov [9] and Chowdhury [13] yields poor results while its combination with film evaporation provides a very good prediction in comparison of experimental data. The proposed correlation by Shiraishi [11] and Rohsenow [8] show similar results with the experimental heat transfer within a deviation of $\pm 10 \%$ at filling ratio of $16 \%$ and high heat flux while applying these correlations at higher filling ratios (35\% and 50\%) yields comparable/underpredicted results in comparison of experimental data. The proposed correlation by Chowdhury [13] shows similar results at filling ratio and high heat flux, but at higher filling ratios Chowdhury [13] correlation gives comparable/over-predicted results in comparison of experimental data. Applying the proposed correlation by Labuntsov [9] and Kutateladze [12] yields worse results, over-prediction of experimentally obtained evaporation heat transfer. The combination of correlation proposed by Labuntsov [9] and Kutateladze [12] with Shiraishi [11] give a very good agreement in comparison of the experimental heat transfer within a deviation of $\pm 10 \%$ at filling ratio from $16 \%$ to $50 \%$ while the combination of Imura [10] and Rohsenow [8] with proposed film evaporation correlation provide a compare bale/under-prediction of experimental data within a deviation of $\pm 30 \%$.

Fig. 11 shows the variations of the thermal resistance in the evaporator section with heat input power to compare the predicted and measured thermal resistance values for filling ratio of $100 \%$ which the thermosyphon experience pool boiling. The thermal resistance is determined by calculating the heat 
transfer coefficient and then using Eq. 12. The proposed correlation by Imura [10] and Rohsenow [8] correlations give a good agreement in comparison of the experimental heat transfer within a deviation of $\pm 15 \%$. It is noticed that applying the proposed correlation by Shiraishi [11] yields comparable/under-prediction of experimental results at the inlet cooling temperature of $25^{\circ} \mathrm{C}$ (within a deviation of $\pm 30 \%$ ) while its prediction at the inlet cooling temperature of $55{ }^{\circ} \mathrm{C}$ shows a good agreement within a deviation of $\pm 10 \%$. The proposed correlation by Labuntsov [9] and Kutateladze [12] results in over-prediction of experimental results while applying the proposed correlation by Chowdhury [13] gives comparable/over-prediction of experimental data within a deviation of $30 \%$ at higher heat flux at both cooling temperatures. In all above correlation, it is observed that the proposed correlation by Shiraishi [11] seems to be sensitive to operating temperature. Based on the above presented results on evaporation and condensation heat transfers following a guideline to select appropriate heat transfer coefficients at different filling ratios and heat fluxes is presented.

\subsection{Summary of results and discussion}

In this section first the evaporation correlation is discussed in detail in comparison also with small tested thermosyphon $(6 \mathrm{~mm})$ using water as a working fluid at filling ratio of $135 \%$ in [14] to have a clear perspective for selection of appropriate heat transfer correlation for a particular application depending, diameter, filling ratio and applied heat input. Afterward, total thermal resistance is evaluated and discussed. Table 4-5 summarizes the agreement of selected nucleate pool boiling correlation at filling ratio of $100 \%$, together with their combination with film evaporation correlation [11] at filling ratios of $16 \%, 35 \%$ and $50 \%$. It is obvious that the proposed correlation by Shiraishi [11], Rohsenow [8], Kutateladze [12] and Chowdhury [13] gives almost similar results with the experimental heat transfer within a deviation of $\pm 20 \%$ at both small and large diameter thermosyphon at the inlet cooling temperature of $25{ }^{\circ} \mathrm{C}$, however, these correlationthese correlations show a better 
agreement at the inlet cooling temperature of $55^{\circ} \mathrm{C}$. Applying the proposed correlation by Imura [10] yields a deviation of $\pm 10 \%$ at large diameter thermosyphon while comparable/under-prediction of experimental results observes at small diameter thermosyphon (a deviation of $\pm 30 \%$ ). A discrepancy in experimental and predicted evaporation heat transfer proposed by Labuntsov [9] is observed in a comparison of small and large diameter thermosyphons. Applying the proposed correlation by Labuntsov [9] yields poor (over-prediction) results in present study for large diameter thermosyphon while at small diameter thermosyphon, Jouhara and Robinson [14] observed a good prediction in the comparison of experimental data within a deviation of $\pm 10 \%$ at low heat flux while comparable/underprediction of experimental results at high heat fluxes within a deviation of $\pm 30 \%$.

Table 4-5 also illustrates the agreement between the experimental values of the evaporation heat transfer coefficient and the prediction values of the correlation proposed by Imura [10], Rohsenow [8], Kutateladze [12], Chowdhury [13], Labuntsov [9] in combination of Shiraishi [11] to consider the effect of film evaporation at filling ratios of $16 \%, 35 \%$ and $50 \%$.

Imura [10] correlation- Based on presented results on evaporation heat transfer, the Imura [10] correlation can predict the pool boiling regime with a very good accuracy at filling ratios of more than $35 \%$ within a deviation of $\pm 10 \%$ while its combination with Shiraishi [11] correlation to consider film evaporation shows under-prediction of experimental data. A good agreement with the experimental heat transfer at filling ratio of $16 \%$ only observes at high heat fluxes. Therefore, the proposed correlation by Imura [10] is suggested to predict the thermal performance of thermosyphons at filling ratio of more than $30 \%$.

Shiraishi [11] correlation- Applying the proposed correlation by Shiraishi [11] yields comparable/under-prediction of experimental results at different filling ratios and the inlet cooling temperature of $25{ }^{\circ} \mathrm{C}$ (within a deviation of $\pm 30 \%$ ) while good agreement observes at inlet cooling 
temperature of $55^{\circ} \mathrm{C}$. Among them, the prediction result of filling ratio of $16 \%$ at high heat flux is the best with an error of lower than $10 \%$.

Rohsenow [8] correlation- From the analysis of data, it is observed that the proposed correlation by Rohsenow [8] is sensitive to both filling ratio and cooling temperature. As of filling ratio increases, the agreement of experimental evaporation improves from a deviation of $\pm 30 \%$ at a lower filling ratio to a deviation of $\pm 10 \%$ for the higher filling at low heat fluxes. However, a comparable/under-prediction of experimental results observes for higher filling ratios at higher heat fluxes while as the inlet cooling temperature increases from $25^{\circ} \mathrm{C}$ to $55^{\circ} \mathrm{C}$, an agreement within a deviation of $\pm 10 \%$ is observed. The combination of nucleate pool boiling correlation of Rohsenow [8] and Shiraishi et al. [11] correlation for film evaporation shows a better agreement only at low filling ratios and higher heat fluxes. Therefore, the combination of Rohsenow [8] and Shiraishi et al. [11] correlation is not suggested.

Kutateladze [12] correlation- Applying the proposed correlation by Kutateladze [12] to predict pool boiling heat transfer regime yields poor results (over-predicted) at different filling ratios while its combination with film evaporation (Shiraishi et al. [11] correlation) provides a very good prediction (within a deviation of $\pm 10 \%$ ) at filling ratio of $16 \%$ and $35 \%$ and a comparable/cover-prediction of experimental data at filling ratio of $50 \%$. It seems that for a thin film region it would be reasonable to apply Shiraishi [11] correlation for evaporation, thus, a combination of Kutateladze [12] and Shiraishi [11] correlations is suggested to predict evaporation heat transfer at filling ratios of lower than $35 \%$ within an accuracy of $\pm 10 \%$.

Labuntsov [9] correlation- The proposed pool boiling correlation by Labuntsov [9] gives overprediction of experimental heat transfer at different filling ratios, similar to that of Kutateladze [12] correlation. A combination of Labuntsov [9] and Shiraishi [11] correlations improves the prediction of evaporation heat transfer at filling ratios of $16 \%, 35 \%$ and $50 \%$ within an accuracy of $\pm 10 \%$ at high heat transfer rates, $\pm 10 \%$ and $\pm 20 \%$, respectively. Thus, applying Labuntsov [9] correlation is not 
suggested to predict pool boiling heat regime in large diameter thermosyphon application while the combination of this correlation with Shiraishi [11] is suggested at filling ratio ranges from $15 \%$ to $50 \%$.

Chowdhury [13] correlation- The experimental evaporation heat transfers and predictions show good agreement with the correlation of Chowdhury [13] at filling ratio of $16 \%$ (within an accuracy of $\pm 20 \%$ ) while as the filling ratio increases the predictions give over-prediction of experimental heat transfer. However, comparable/over-prediction of experimental results observes at filling ratio of $100 \%$ at high heat flux within an accuracy of $\pm 30 \%$. Its combination with film evaporation correlation of Shiraishi [11] provides a good prediction in comparison of experimental data at filling ratio of $16 \%-50 \%$ within a deviation of $\pm 10 \%$. Therefore, the combination of Chowdhury [13] and Shiraishi [11] correlations is suggested to predict evaporation heat transfer of thermosyphons at low filling ratios (15\%-50\%). The above suggestion would help modeling and prediction of the heat transfer process in TPCTs as well as their integration in industrial applications.

The total thermal resistance of the thermosyphon is determined by a combination of the evaporation and condensation thermal resistance $\left(\mathrm{R}_{t}=\mathrm{R}_{\mathrm{e}}+\mathrm{R}_{\mathrm{c}}\right)$. Fig. 12 shows comparisons of the experimental and predicted overall thermal resistance at different filling ratios $(16 \%, 35 \%, 50 \%$ and $100 \%)$. The most appropriate pool boiling correlations as well as their combinations is applied to predict evaporation heat transfer and modified correlation by Jouhara and Robinson [14] is used to predict heat transfer in the condenser section. The measured and predicted thermal resistance curves agree well. Therefore the applied set of correlations recommends predicting heat transfer in a TPCT for a wide range of filling ratios and heat fluxes.

At the end, it worth to notice that there is an interest to approximate the heat transfer capacity of a heat exchanger systems incorporating two-phase closed thermosyphons in various industrial applications (e.g. a simple thermal network approach). Therefore, the results of this study describe the most 
accurate evaporation and condensation heat transfer coefficients to characterize and analyze two-phase closed thermosyphons to be applied in a real system.

\section{Conclusions}

Experiments on the evaporation and condensation heat transfer of a two-phase closed thermosyphon (TPCT) are carried to have a clear perspective for selection of appropriate heat transfer correlation for a particular application depending filling ratio and applied heat input. The thermosyphon with an inner diameter of $33 \mathrm{~mm}$ is tested at heat transfer rate of $30 \mathrm{~W}$ to $900 \mathrm{~W}$. The pure water is used as the working fluid at filling ratios of $8 \%, 16 \%, 35 \%, 50 \%$ and $100 \%$. The filmwise model containing liquid entrainment affects in the condenser section shows good agreement with experimental results to predict condensation heat transfer. The available nucleate boiling correlations, together with their combination with a film evaporation correlation are evaluated to predict the evaporation heat transfer. From the analysis of data, the sensitivity of the pool boiling correlation as well as their combination to the heat flux, filling ratio and cooling temperature is described in details. The experimental results show an agreement with the most of the selected correlations with tolerance $\pm 30 \%$ and the proper sets of correlations are suggested to predict the heat transfer in the evaporator section as well as condensation heat within a deviation of $\pm 10 \%$. The applied approach is found to predict evaporation and condensation heat transfer of thermosyphons with a good agreement with experimental results. A join of our recent paper [26] and current study would enable the readers to design a TPCT for a specific application at different operating parameters, specifically, when a low filling ratio, a low heat flux and a low to medium temperature is a matter of interest (e.g. solar applications).

\section{References}

[1] A. Faghri, Heat Pipe Science and Technology, Philadelphia, PA: Taylor \& Francis, (1995). 
[2] D. Jafari, A. Franco, S. Filippeschi, P. Di Marco, Two-phase closed thermosyphons: A review of studies and solar applications, Renewable \& Sustainable Energy Reviews 53 (2016) 575-93.

[3] H. Shabgard, M.J. Allen, N. Sharifi, S.P. Benn, A. Faghri, Bergman TL, Heat pipe heat exchangers and heat sinks: Opportunities, challenges, applications, analysis, and state of the art, International Journal of Heat and Mass Transfer 89 (2015) 138-58.

[4] L.L. Vasiliev, S. Kakaç, Heat Pipes and solid sorption transformations Fundamentals and Practical Applications, Ed. CRC Press- Taylor \& Francis Group (2013).

[5] T. He, C. Mei, J.P. Longtin, Thermosyphon-assisted cooling system for refrigeration applications, International Journal of Refrigeration (2016), http://dx.doi.org/doi: 10.1016/j.ijrefrig.2016.10.012.

[6] A.A. Eidan, S.E. Najim, J.M. Jalil, Experimental and numerical investigation of thermosyphone performance in HVAC system applications, Heat Mass Transfer 52 (2016) 2879-93.

[7] M.S. EL-Genk, H H. Saber, Heat transfer correlations for small, uniformly heated liquid pools, International Journal of Heat and Mass Transfer 41 (1998) 261-74.

[8] W.M. Rohsenow, A method of correlating heat transfer data for surface boiling of liquids, Transactions of the ASME 74 (1952) 969-976.

[9] D.A. Labuntsov, Heat transfer problems with nucleate boiling of liquids, Thermal Engineering 19 (1972) 21-28.

[10] H. Imura, H. Kusada, J. Oyata, T. Miyazaki, N. Sakamoto, Heat transfer in two-phase closed-type thermosyphons, Transactions of Japan Society of Mechanical Engineers 22 (1977) 485-493.

[11] M. Shiraishi, K. Kikuchi, T. Yamanishi, Investigation of heat transfer characteristics of a twophase closed thermosyphon, Heat Recovery Systems 1 (1981) 287-297.

[12] Kutateladze, Heat Transfer and Hydrodynamic Resistance, Energoatomizdat Publishing House, Moscow, Russia, 1990. 
[13] F.Md. Chowdhury, F. Kaminaga, K. Goto, K. Matsumura, Boiling heat transfer in a small diameter tube below atmospheric pressure on a natural circulation condition, Journal of Japan Association for Heat Pipe 16 (1997) 14-16.

[14] H. Jouhara, A.J. Robinson. Experimental investigation of small diameter two phase closed thermosyphons charged with water, FC-84, FC-77 and FC-3283, Applied Thermal Engineering 30 (2010) 201-11.

[15] T. Kiatsiriroat, A. Nuntaphan, J. Tiansuwan, Thermal performance enhancement of thermosyphon heat pipe with binary working fluids, Experimental Heat Transfer 13(2) (2000) 137-52.

[16] Y.J. Park, H.K. Kang, C.J. Kim, Heat transfer characteristics of a two phase closed thermosyphon to fill charge ratio, International Journal of Heat and Mass Transfer 45 (2002) 4655-61.

[17] S. H. Noie, Heat transfer characteristics of a two-phase closed thermosyphon, Applied Thermal Engineering 25(4) (2005) 495-506.

[18] W. Guo, D.W. Nutter, An experimental study of axial conduction through a thermosyphon pipe wall, Applied Thermal Engineering 29 (2009) 3536-41.

[19] H. Hashimoto, F. Kaminaga, Heat transfer characteristics in a condenser of closed two-phase thermosyphon: effect of entrainment on heat transfer deterioration, Heat Transfer-Asian Res 31(3) (2002) 212-25.

[20] J.C.Y. Wang, Y. Ma, Condensation heat transfer inside vertical and inclined thermosyphons, Journal of Heat Transfer 113 (1991) 777-80.

[21] H.M.S. Hussein, M.A. Mohamad, A.S. El-Asfouri, Theoretical analysis of laminar-film condensation heat transfer inside inclined wickless heat pipes flat-plate solar collector, Renewable Energy 23 (2001) 525-35.

[22] M. H. M. Grooten, C. W. M. van der Geld, Predicting Heat Transfer in Long R-134a Filled Thermosyphons, Journal of Heat Transfer 131 (2009) 51501. 
[23] M. Shanbedi, S. Z. Heris, M. Baniadam, A. Amiri, M. Maghrebi, Investigation of Heat-Transfer Characterization of EDA-MWCNT/DI-Water Nanofluid in a Two-Phase Closed Thermosyphon, Industrial \& Engineering Chemistry Research 51 (2012) 1423-8.

[24] S. Z. Heris, M. Fallahi, M. Shanbedi, A. Amiri, Heat transfer performance of two-phase closed thermosyphon with oxidized CNT/water nanofluids, Heat Mass Transfer 10 (2015) 1007.

[25] E. Gedik, Experimental investigation of the thermal performance of a two-phase closed thermosyphon at different operating conditions, Energy and Buildings (127) 2016 1096-107.

[26] D. Jafari, S. Filippeschi, A. Franco, P. Di Marco, Unsteady experimental and numerical analysis of a two-phase closed thermosyphon at different filling ratios, Experimental Thermal and Fluid Science 81 (2017) 164-74.

[27] W.M. Rohsenow, J.P. Harnett, E.N. Ganic, Handbook of Heat Transfer Fundamentals. $2^{\text {nd }}$ ed. New York: McGraw-Hill (1985).

[28] I.L. Pioro, W. Rohsenow, S.S. Doerffer, Nucleate pool-boiling heat transfer II: assessment of prediction methods, International Journal of Heat and Mass Transfer 23 (2004) 5045-57.

\section{Figures}

Fig. 1 Schematic view of a TPCT at filling ratio of (a) $100 \%$ and (b) $<100 \%$ and (c) its thermal resistances as well as highlighted major ones

Fig. 2 schematic view of experimental apparatus as well as locations of thermocouples [26]

Fig. 3 Comparison of measured heat flow rates at evaporator and condenser side of the TPCT

Fig. 4 Axial wall temperature distribution for filling ratio of (a) $35 \%$ and (b) $100 \%$

Fig. 5 Transient wall temperature variation 
Fig. 6 Experimental condensation and evaporation heat transfer coefficients

Fig. 7 Predicted and experimentally determined Nusselt number $(\mathrm{Nu})$ versus the film Reynolds number $\left(R e_{f i l m}\right)$ values for the condenser section of the thermosyphon at filling ratio of (a) $16 \%$ and (b) $100 \%$

Fig. 8 Predicted and experimentally determined thermal resistance of the condenser section of the thermosyphon at filling ratio of (a) $16 \%$ and (b) $100 \%$

Fig. 9 Predicted evaporation heat transfer coefficients versus the experimental evaporation heat transfer coefficient values at the filling ratio of (a) $<100 \%(16 \%, 35 \%$ and $50 \%)$ and (b) $100 \%$

Fig. 10 Predicted and experimentally determined thermal resistances of the evaporator section of the thermosyphon (combination of pool boiling and film evaporation)

Fig. 11 Predicted and experimentally determined thermal resistances of the evaporator section of the thermosyphon (pool boiling)

Fig. 12 Predicted and experimentally determined total thermal resistances of the thermosyphon for filling ratios of (a) $16 \%$, (b) $35 \%$, (c) $50 \%$ and (d) $100 \%$.

(a)

(b)

(c) 
Thermal resistances in the condenser

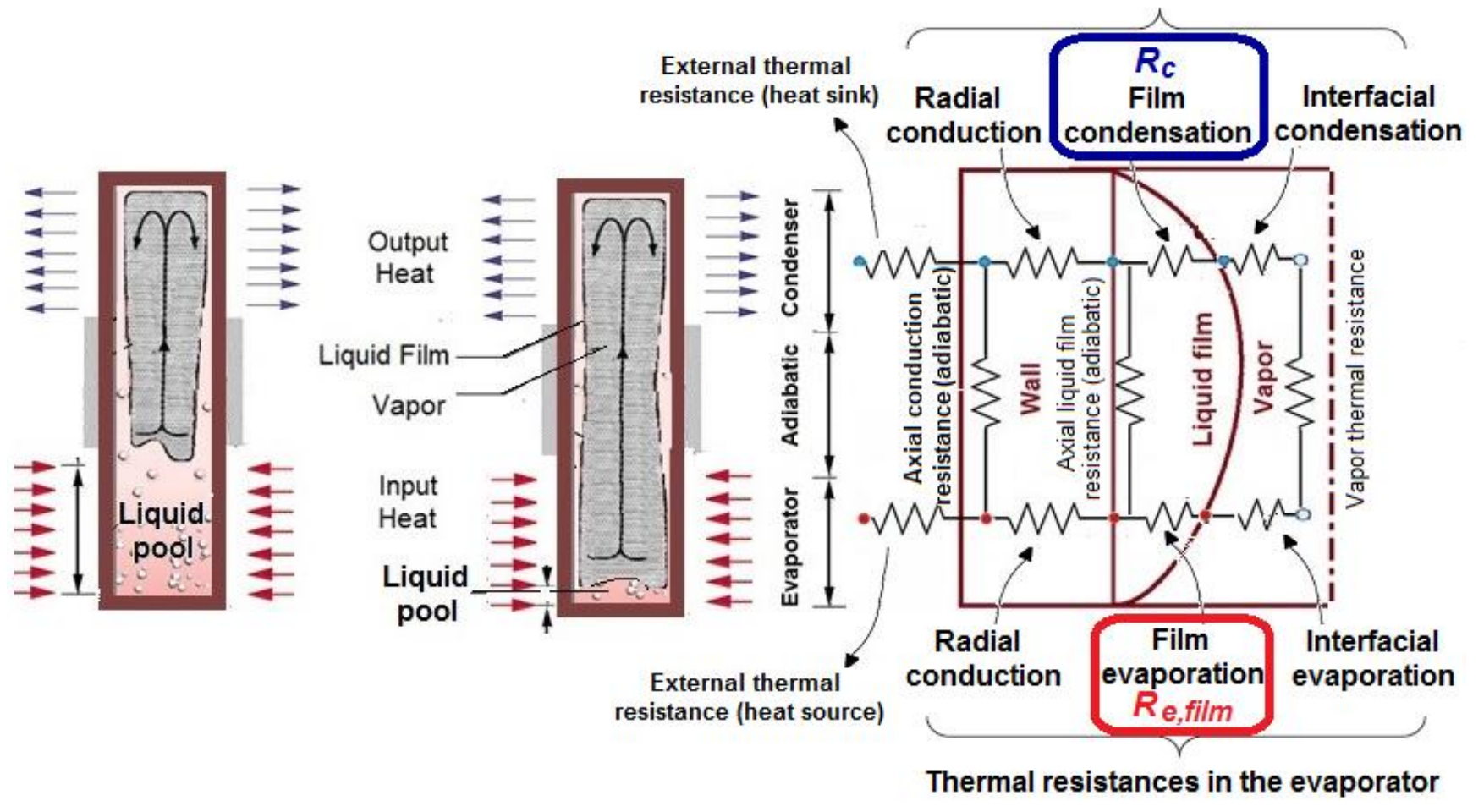

Fig. 1

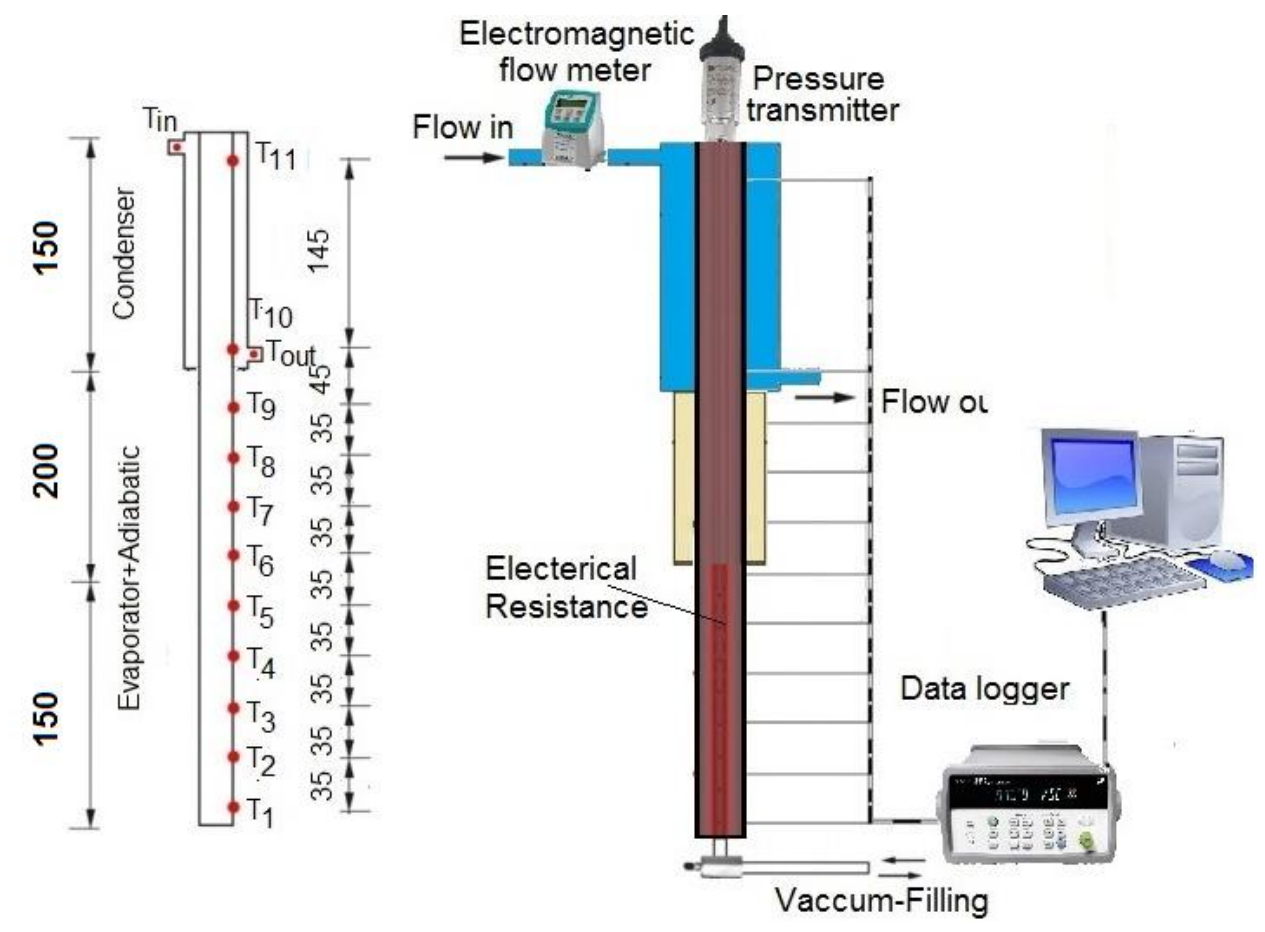

Fig. 2 


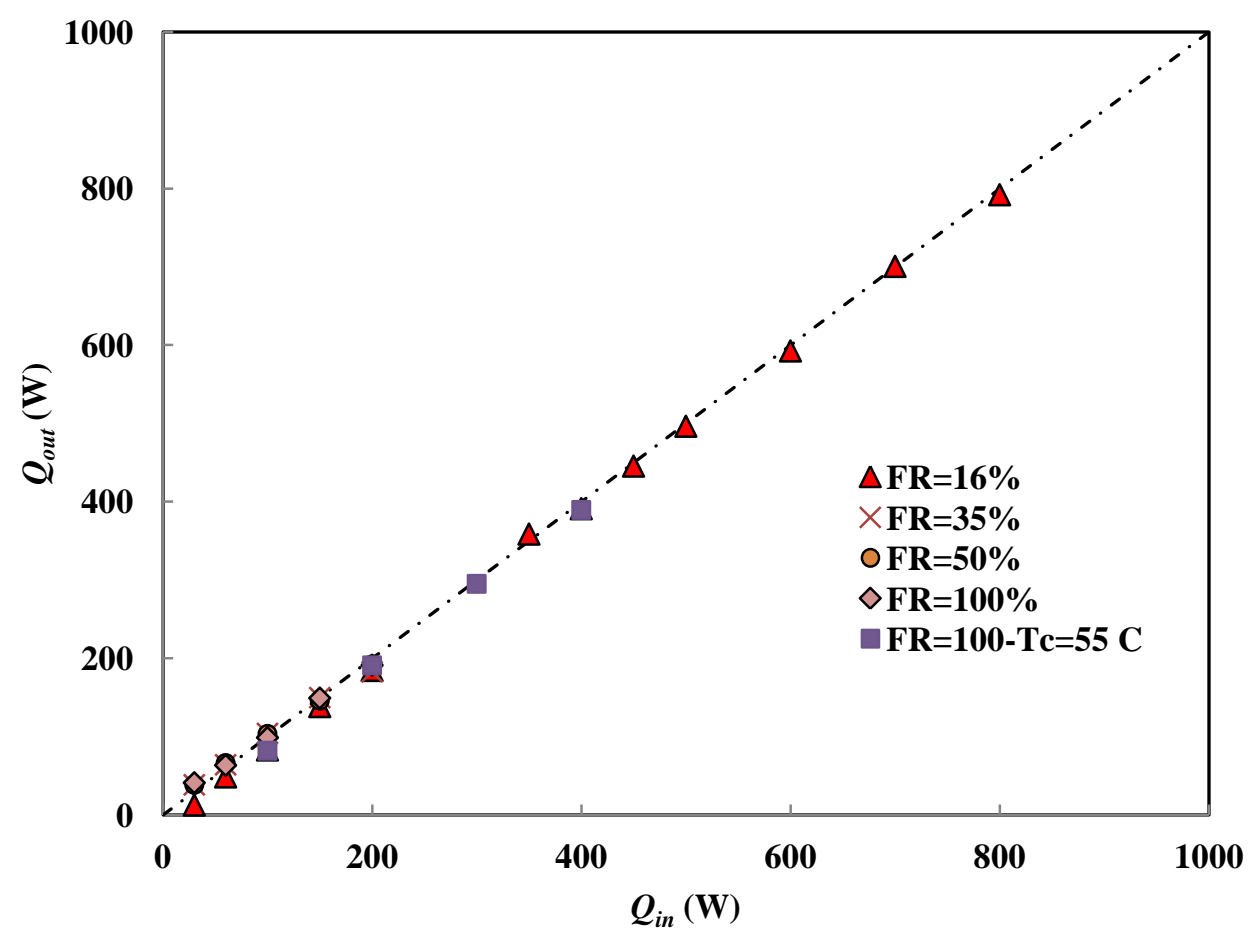

Fig. 3

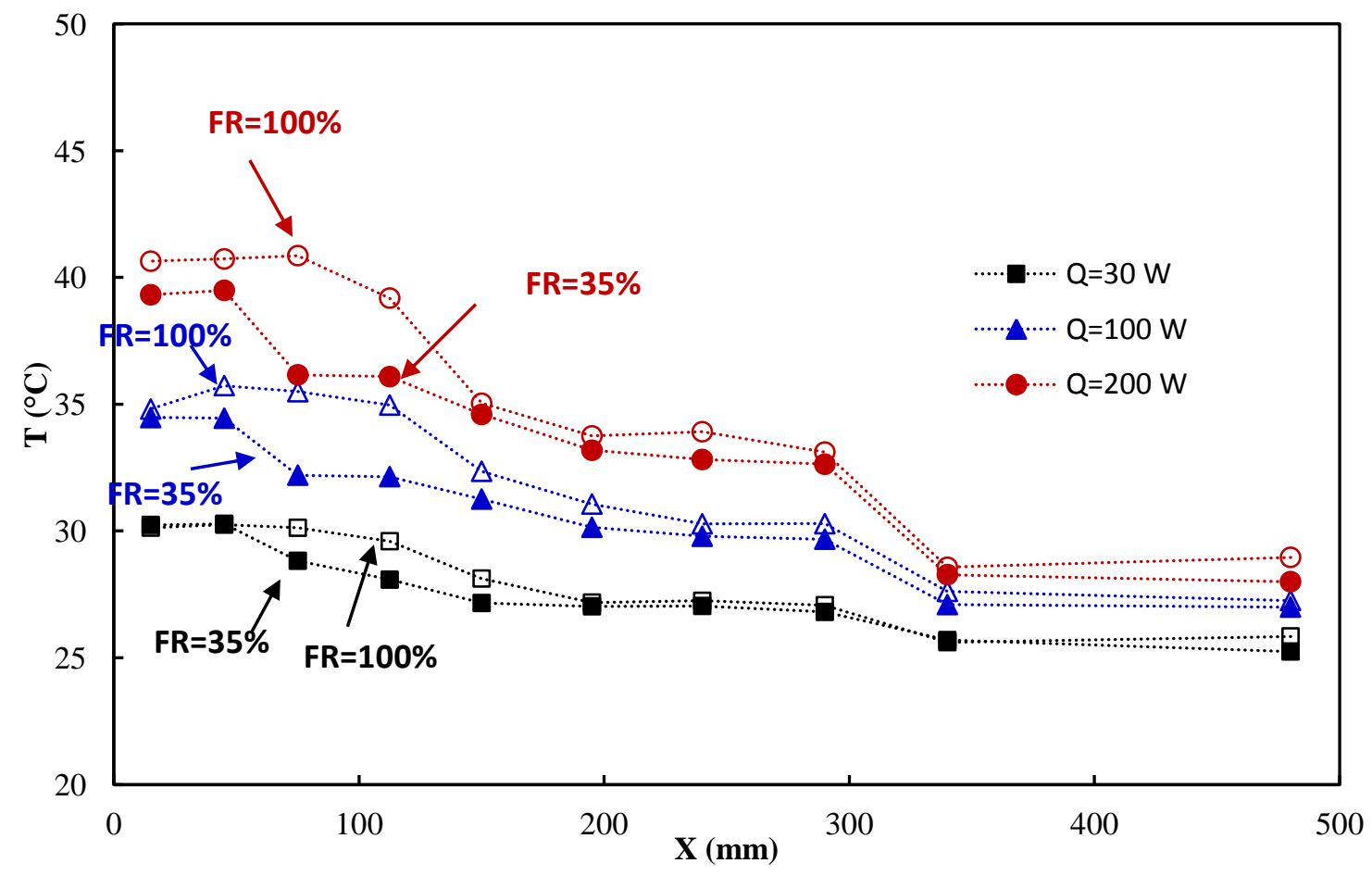

Fig. 4 


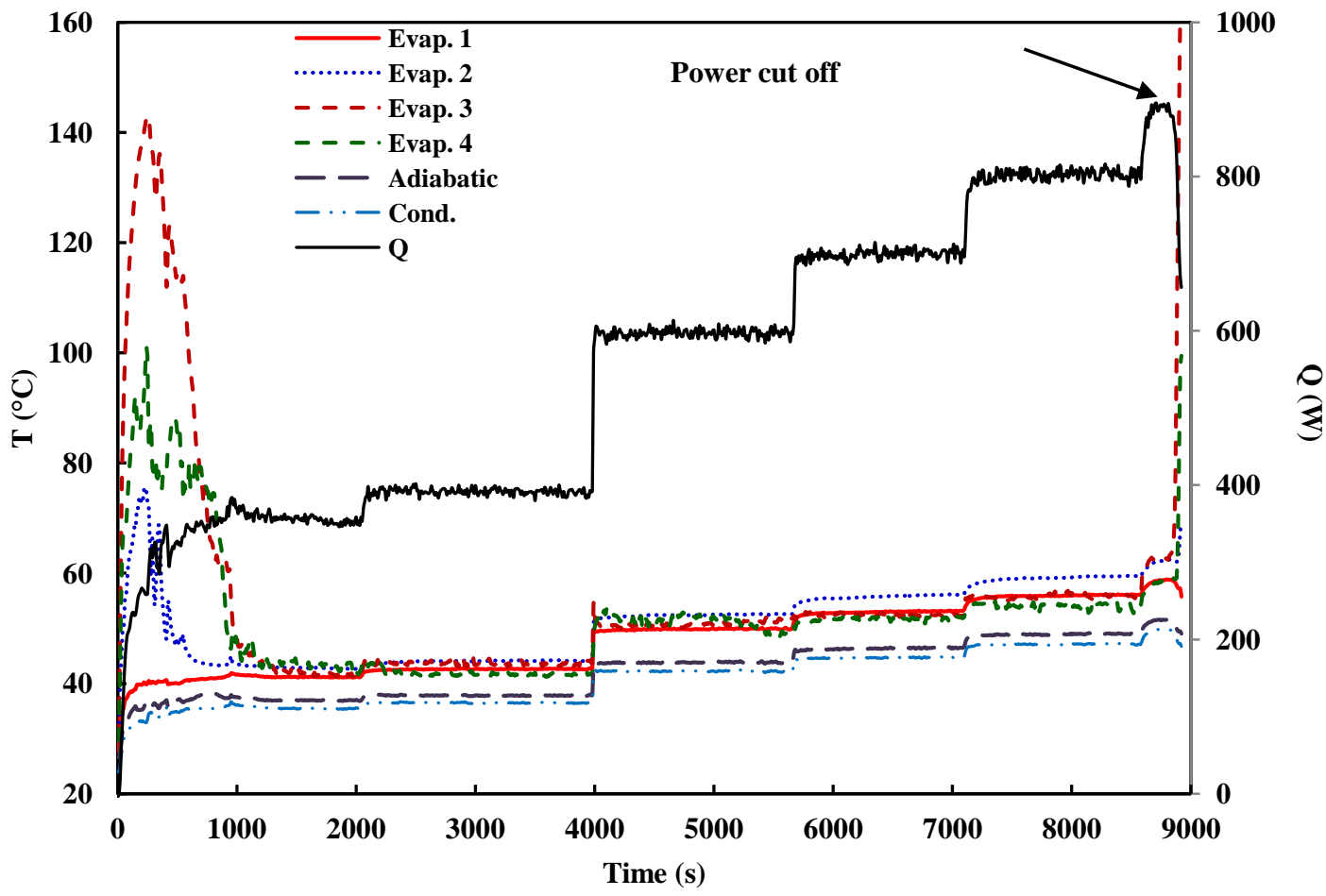

Fig. 5

$\square$ Filling ratio $<100 \% *$ Filling ratio $=100 \%$

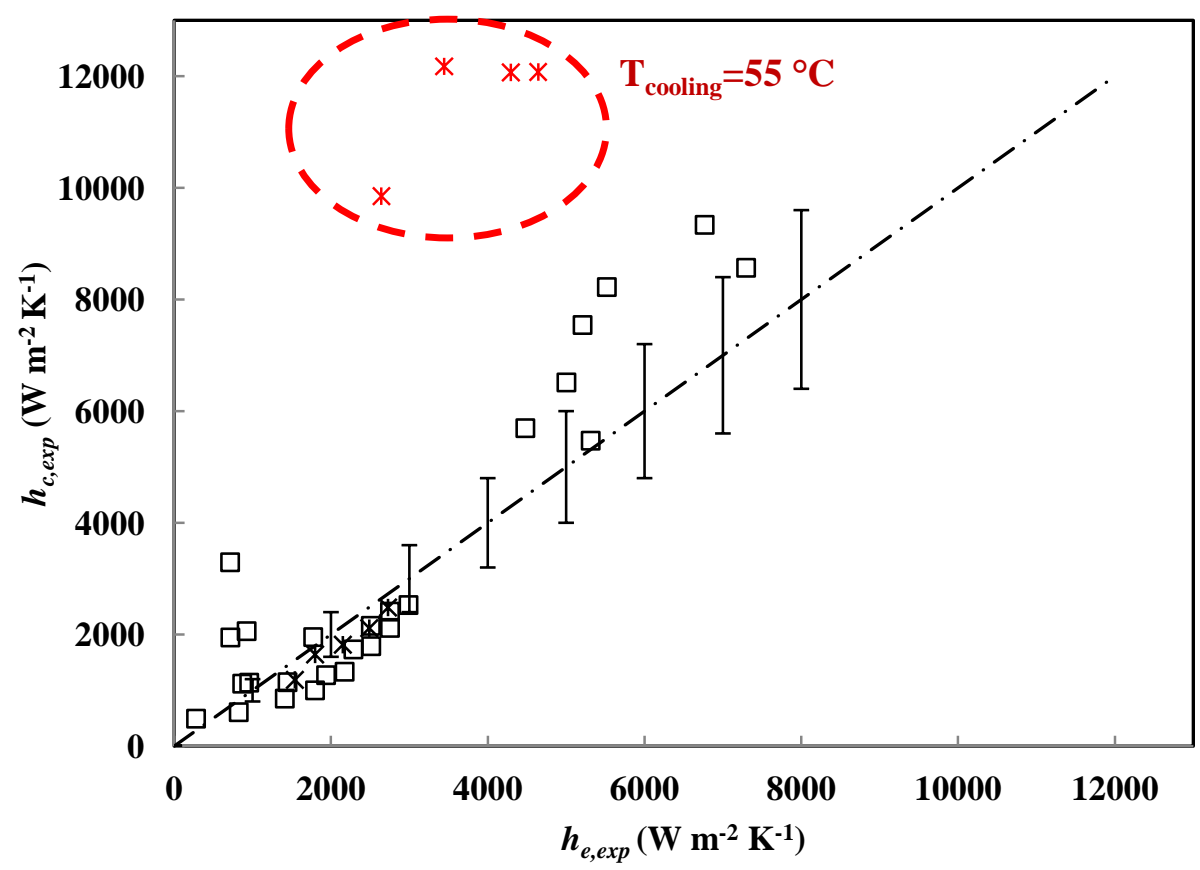

Fig. 6 

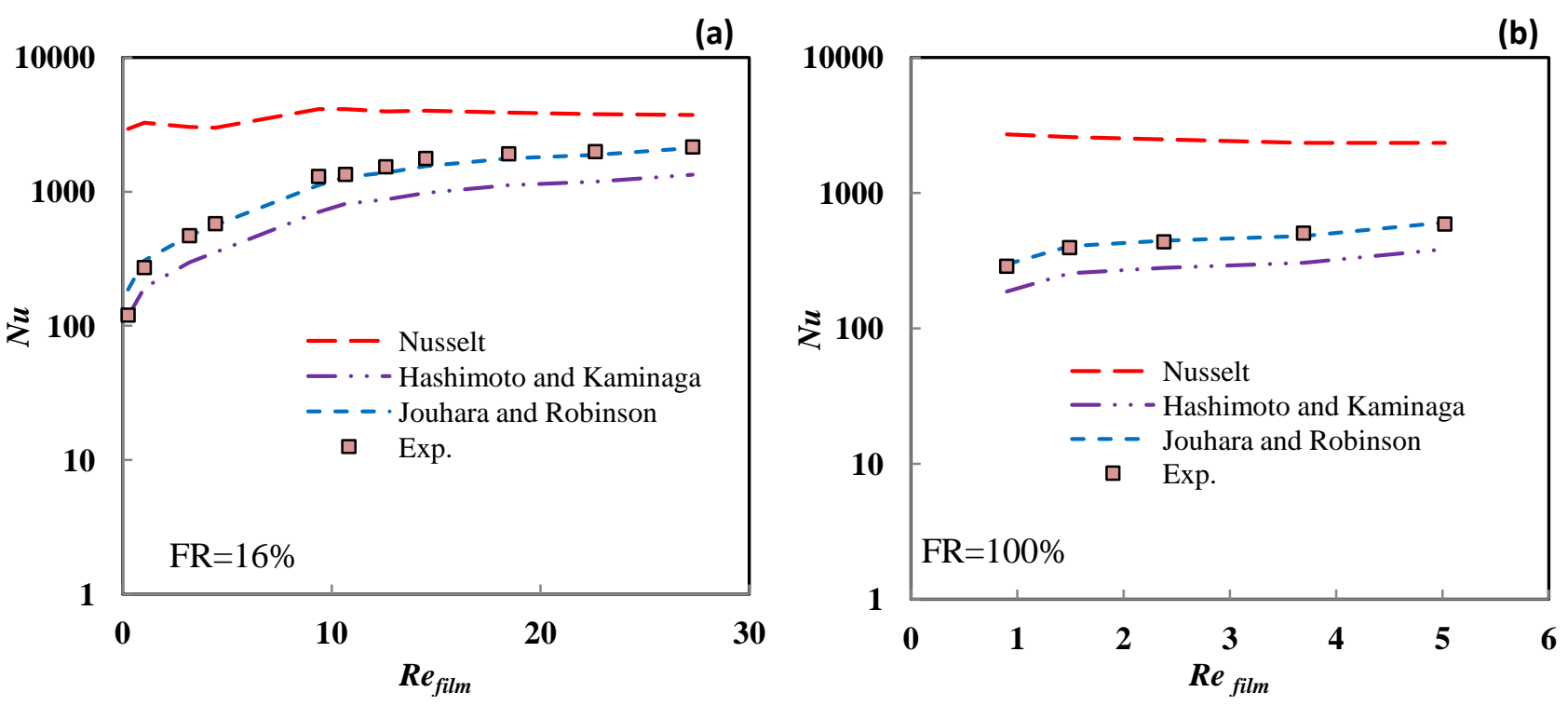

Fig. 7
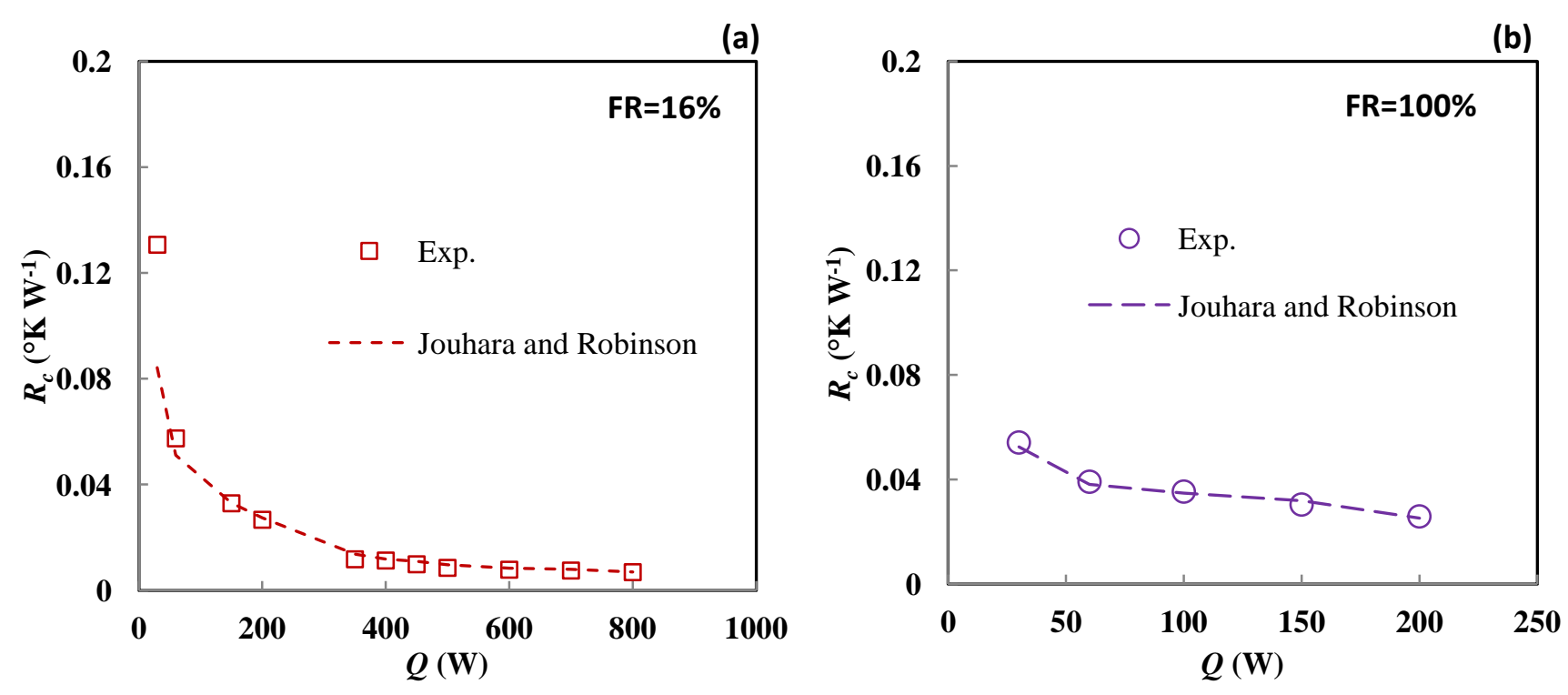

Fig. 8 


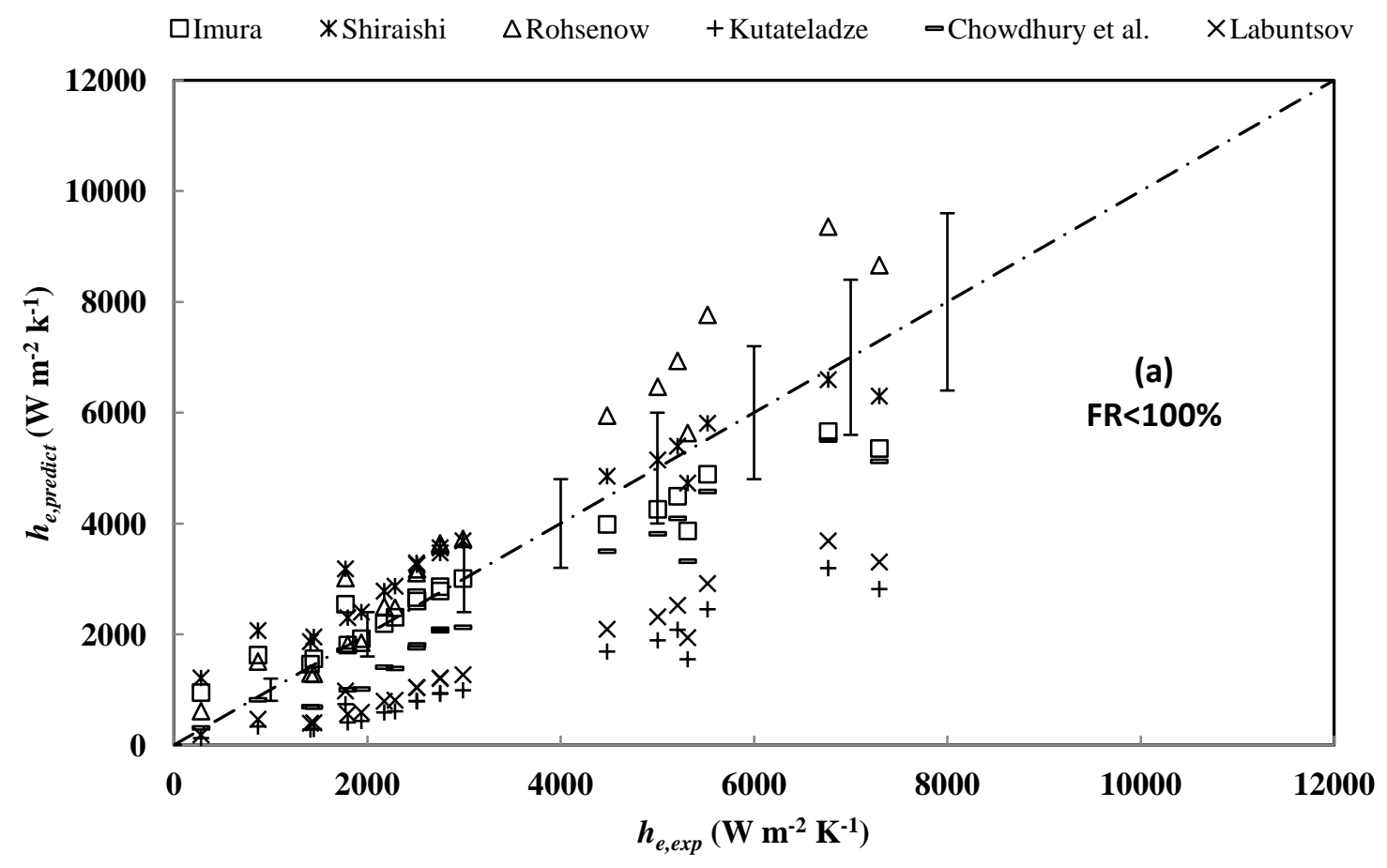

口Imura $*$ Shiraishi $\Delta$ Rohsenow +Kutateladze $=$ Chowdhury et al. $\times$ Labuntsov

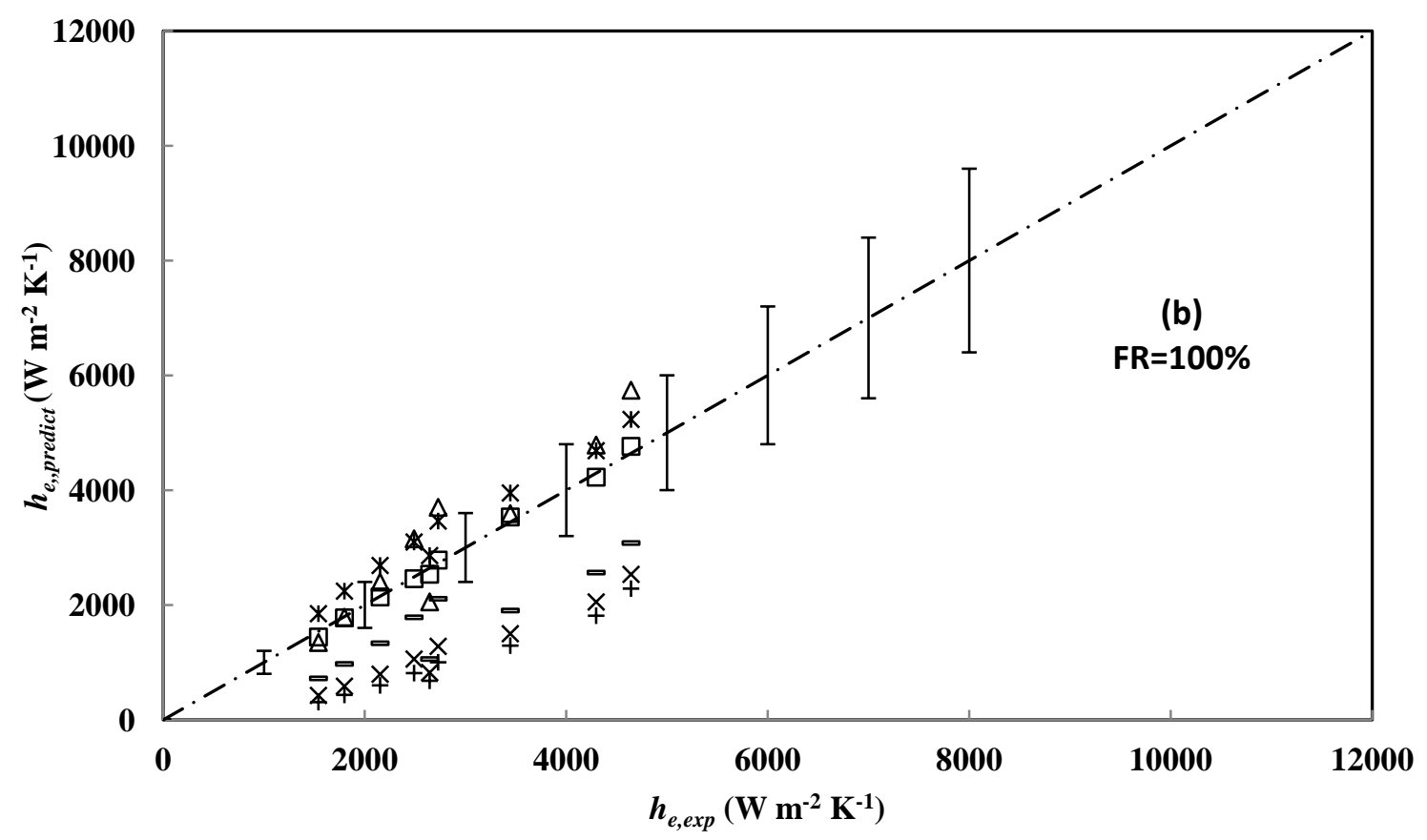

Fig. 9 

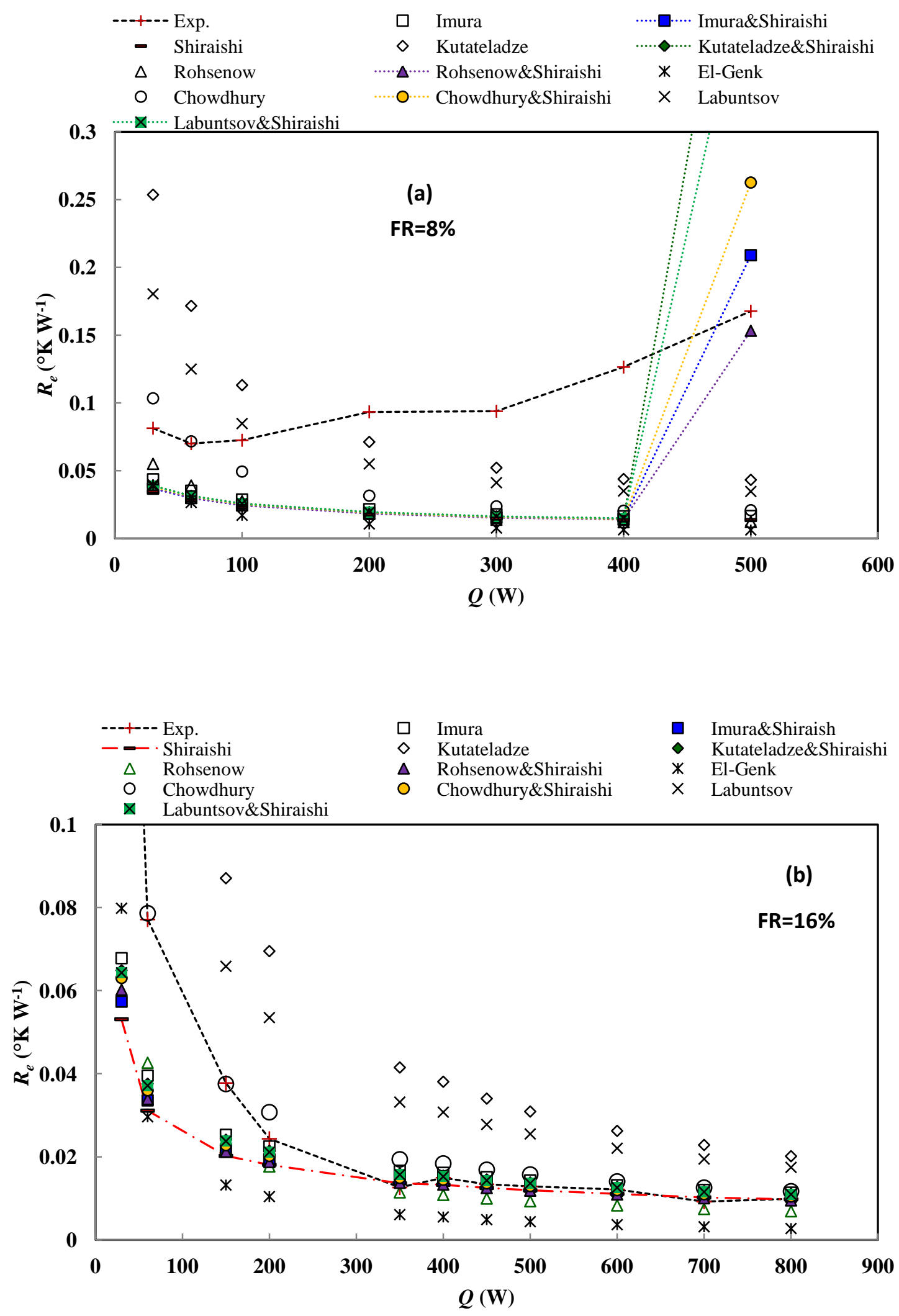


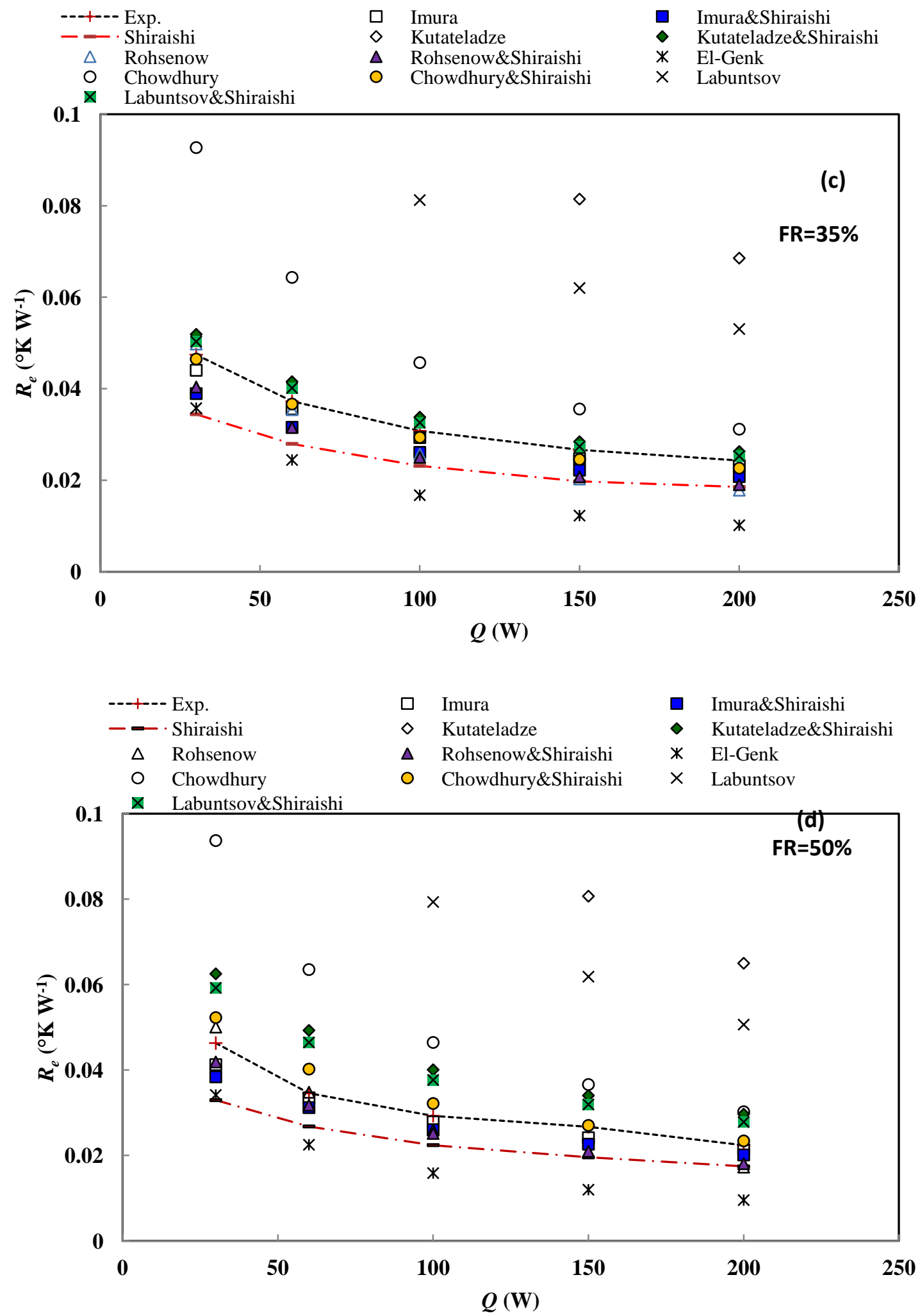

Fig. 10 

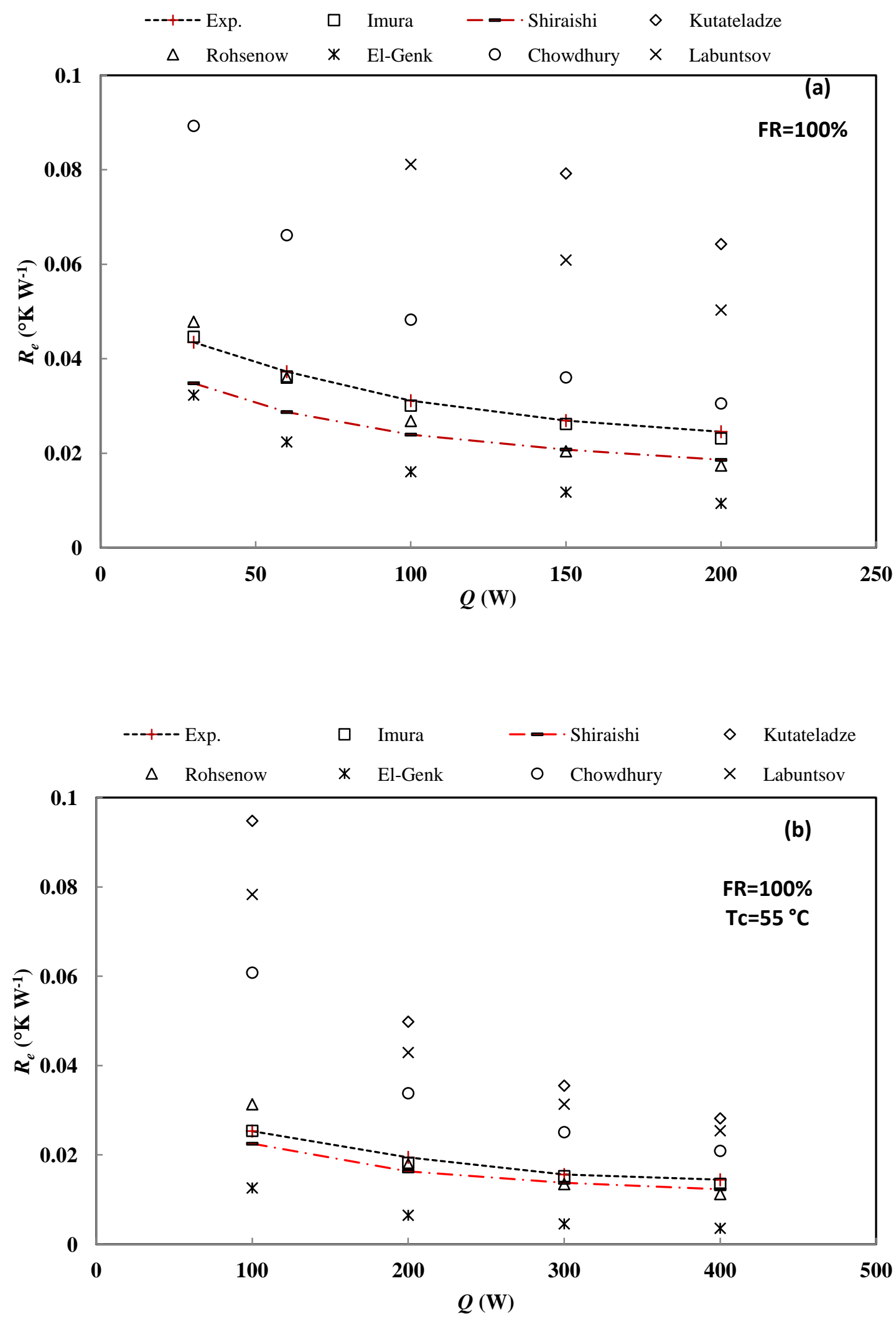

Fig. 11 

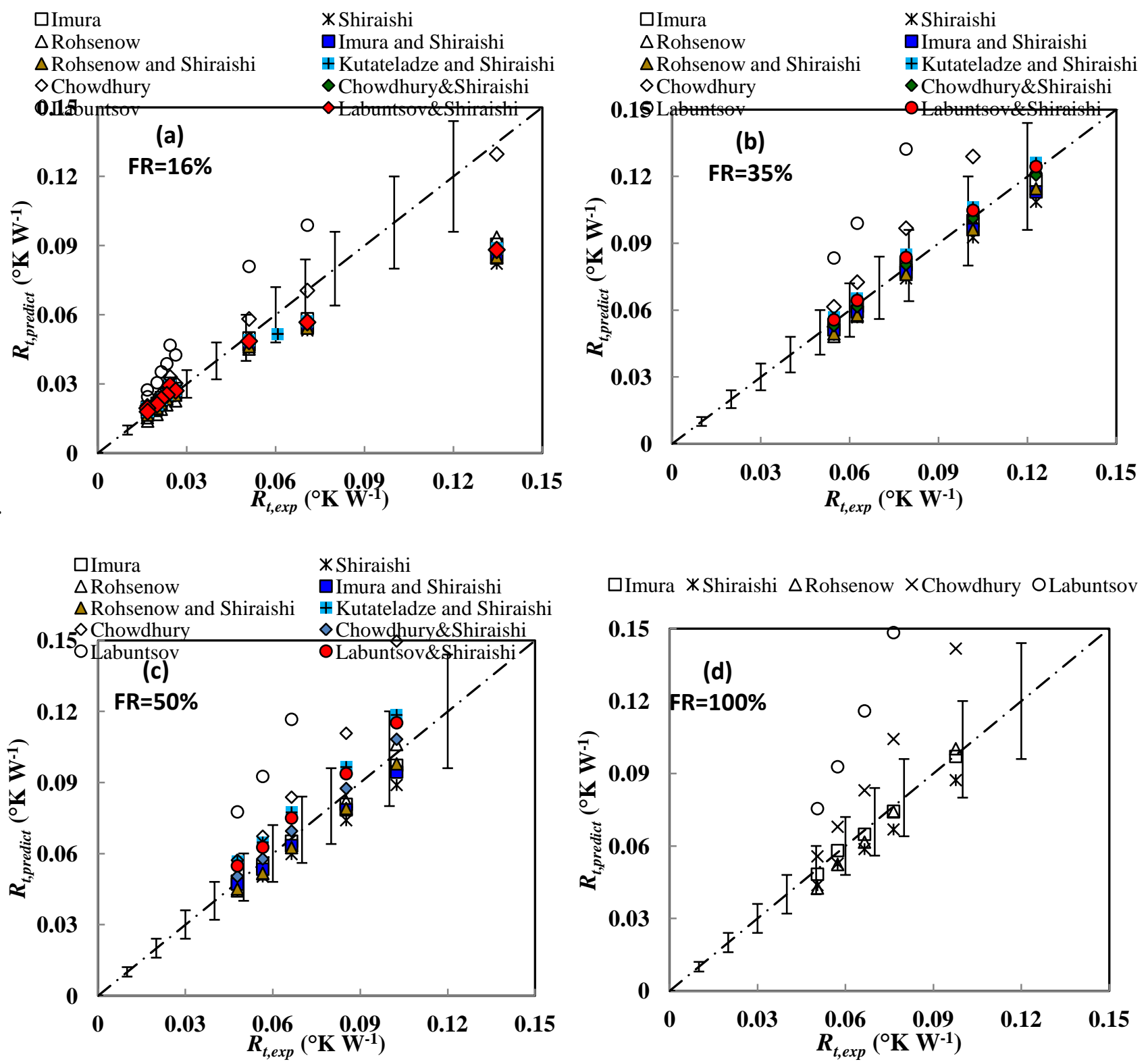

Fig. 12 


\section{$\underline{\text { Tables }}$}

Table 1 A list of some correlations provided for the calculation of condensation heat transfer

Table 2 A list of some correlations provided for the calculation of the evaporation heat transfer

Table 3 Design summery of the TPCT

Table Uncertainty of experimentally measured total thermal resistance (filling ratio of 50\%)

Table 4-5 The agreement of nucleate pool boiling correlations and their combination with film evaporation correlation [11] with experimental data

\section{Table 1}

\begin{tabular}{lll}
\hline Correlations & References \\
\hline$h_{\text {Nusselt }}=1.47 \operatorname{Re}_{f}{ }^{-1 / 3}\left[\frac{\rho_{l}\left(\rho_{l}-\rho_{v}\right) g k_{l}^{3}}{\mu_{l}^{2}}\right]^{1 / 3}$ & & Rohsenow [27] \\
$h_{c}=0.85 \operatorname{Re}_{f}^{0.1} \exp \left(-0.000067 \frac{\rho_{l}}{\rho_{v}}-0.6\right) h_{\text {Nusselt }}$ & (4) & Hashimoto and Kaminaga [19] \\
\hline
\end{tabular}




$$
h_{c}=0.85 \operatorname{Re}_{f}^{0.1} \exp \left(-0.000067 \frac{\rho_{l}}{\rho_{v}}-0.14\right) h_{\text {Nusselt }}
$$

Table 2

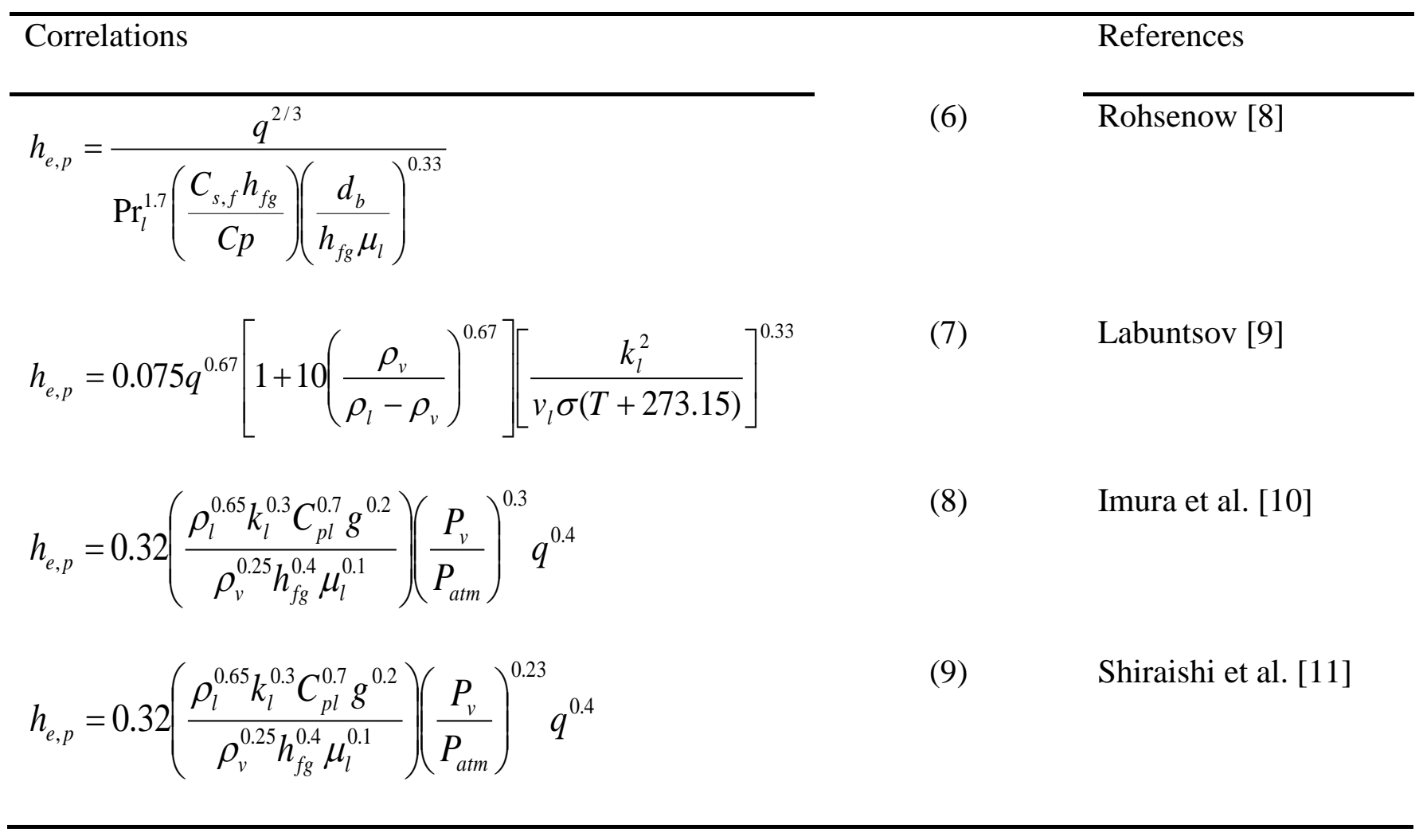




$h_{e, p}=0.44 \operatorname{Pr}^{0.35}\left(\frac{k_{l}}{L_{b}}\right)\left(\frac{\rho_{l}}{\rho_{l}-\rho_{v}} \frac{q P \times 10^{-4}}{\rho_{v} g h_{f g} \mu_{l}}\right)^{0.7}$
$h_{e}=11.43\left(\operatorname{Re}_{b}\right)^{0.72}\left(\operatorname{Pr}_{l}\right)^{0.42}\left(\frac{\rho_{v}}{\rho_{l}}\right)^{0.5}\left(\frac{d_{b}}{d_{i}}\right)\left(\frac{k_{l}}{d_{b}}\right)$

\section{Table 3}

\begin{tabular}{ll}
\hline Parameters & Copper \\
\hline Wall Material & 35 \\
Outer radius, $(\mathrm{mm})$ & 1 \\
Thickness, $(\mathrm{mm})$ & 500 \\
Total length, $(\mathrm{mm})$ & 150 \\
Evaporator length, $(\mathrm{mm})$ & 150 \\
Condenser length, $(\mathrm{mm})$ & 0.038 \\
Cooling mass flow meter, $\left(\mathrm{kg} \mathrm{s}^{-1}\right)$ & 25 and 55 \\
Inlet cooling temperature, $\left({ }^{\circ} \mathrm{C}\right)$ & $30-900$ \\
Input heat flux, $(\mathrm{W})$ & $8,16,35,50$ and 100 \\
Filling ratio (working fluid volume/evaporator volume), $(\%)$ & \\
\hline
\end{tabular}

Table 4

\begin{tabular}{llllll}
\hline Heat transfer rate $(W)$ & 30 & 60 & 100 & 150 & 200 \\
\hline
\end{tabular}




\begin{tabular}{llllll}
\hline Uncertainty in overal thermal resistance (\%) & 7.2 & 6.5 & 5.9 & 5.8 & 5.4
\end{tabular}

Table 4-5

\begin{tabular}{|c|c|c|c|c|c|c|}
\hline \multirow[t]{2}{*}{ Correlations } & \multicolumn{5}{|c|}{ Present study } & Jouhara and \\
\hline & $\begin{array}{l}\mathrm{FR}=16 \% \\
T_{c}=25^{\circ} \mathrm{C}\end{array}$ & $\begin{array}{l}\mathrm{FR}=35 \% \\
T_{c}=25^{\circ} \mathrm{C}\end{array}$ & $\begin{array}{l}\mathrm{FR}=50 \% \\
T_{c}=25^{\circ} \mathrm{C}\end{array}$ & $\begin{array}{l}\mathrm{FR}=100 \% \\
T_{c}=25^{\circ} \mathrm{C}\end{array}$ & $\begin{array}{l}\mathrm{FR}=100 \% \\
T_{c}=55^{\circ} \mathrm{C}\end{array}$ & $\begin{array}{l}\mathrm{FR} \approx 130 \% \\
T_{c}=25^{\circ} \mathrm{C}\end{array}$ \\
\hline Imura [10] & $\begin{array}{l}\text { Very Good } \\
\text { at high HF, } \\
\text { UP low }\end{array}$ & Good & Very Good & Very Good & Very good & $\begin{array}{l}\mathrm{Co} / \mathrm{UP} \text { at high } \\
\text { heat Flux }\end{array}$ \\
\hline Shiraishi [11] & $\begin{array}{l}\text { Very Good } \\
\text { at high HF, } \\
\text { UP at low } \\
\text { HF }\end{array}$ & $\mathrm{Co} / \mathrm{UP}$ & $\mathrm{Co} / \mathrm{UP}$ & $\mathrm{Co} / \mathrm{UP}$ & Good & $\begin{array}{l}\text { Co/UP at high } \\
\text { heat Flux }\end{array}$ \\
\hline Rohsenow [8] & $\begin{array}{l}\mathrm{Co} / \mathrm{UP} \text { at } \\
\text { high } \mathrm{HF}, \\
\mathrm{UP} \text { at low } \\
\mathrm{HF}\end{array}$ & $\mathrm{Co} / \mathrm{UP}$ & $\begin{array}{l}\text { Very Good } \\
\text { at low HF; } \\
\text { Co/UP at } \\
\text { high HF }\end{array}$ & $\begin{array}{l}\text { Very Good } \\
\text { at low HF; } \\
\mathrm{Co} / \mathrm{UP} \text { at } \\
\text { high HF }\end{array}$ & Very good & $\begin{array}{l}\mathrm{Co} / \mathrm{UP} \text { at high } \\
\text { heat flux; good } \\
\text { at low heat flux. }\end{array}$ \\
\hline Kutateladze [12] & OP & $\mathrm{OP}$ & $\mathrm{OP}$ & OP & $\mathrm{OP}$ & $\begin{array}{l}\text { Good at high } \\
\text { heat flux, OP at } \\
\text { low heat flux }\end{array}$ \\
\hline Chowdhury [13] & Good & $\begin{array}{l}\mathrm{OP} \text { at low } \\
\mathrm{HF}, \mathrm{Co} / \mathrm{OP} \\
\text { at high } \mathrm{HF}\end{array}$ & $\mathrm{OP}$ & $\begin{array}{l}\mathrm{OP} \text { at low } \\
\mathrm{HF}, \mathrm{Co} / \mathrm{OP} \\
\text { at high } \mathrm{HF}\end{array}$ & $\begin{array}{l}\mathrm{OP} \text { at low } \\
\mathrm{HF} \text {, } \\
\mathrm{Co} / \mathrm{OP} \text { at } \\
\text { high } \mathrm{HF}\end{array}$ & $\mathrm{Co} / \mathrm{OP}$ \\
\hline Labuntsov [9] & $\mathrm{OP}$ & $\mathrm{OP}$ & $\mathrm{OP}$ & $\mathrm{OP}$ & $\mathrm{OP}$ & $\begin{array}{l}\begin{array}{l}\text { Good at low } \\
\text { heat } \\
\text { CO/UP } \\
\text { heat flux. }\end{array} \\
\text { high }\end{array}$ \\
\hline
\end{tabular}




\begin{tabular}{|c|c|c|c|c|c|}
\hline $\begin{array}{l}\text { Imura } \quad[10] \& \\
\text { Shiraishi [11] }\end{array}$ & $\begin{array}{l}\text { Very Good } \\
\text { at high HF; } \\
\text { UP at low } \\
\text { HF }\end{array}$ & $\mathrm{Co} / \mathrm{UP}$ & $\mathrm{Co} / \mathrm{UP}$ & - & - \\
\hline $\begin{array}{l}\text { Rohsenow [8]\& } \\
\text { Shiraishi [11] }\end{array}$ & $\begin{array}{l}\text { Very Good } \\
\text { at high HF, } \\
\text { UP at low } \\
\text { HF }\end{array}$ & $\mathrm{Co} / \mathrm{UP}$ & $\mathrm{Co} / \mathrm{UP}$ & - & - \\
\hline $\begin{array}{l}\text { Kutateladze [12]\& } \\
\text { Shiraishi [11] }\end{array}$ & $\begin{array}{l}\text { Very Good } \\
\text { at high HF }\end{array}$ & Very Good & $\mathrm{Co} / \mathrm{OP}$ & - & - \\
\hline $\begin{array}{l}\text { Chowdhury [13]\& } \\
\text { Shiraishi [11] }\end{array}$ & $\begin{array}{l}\text { Very Good } \\
\text { at high HF }\end{array}$ & Very Good & Good & - & - \\
\hline $\begin{array}{l}\text { Labuntsov [9]\& } \\
\text { Shiraishi [11] }\end{array}$ & $\begin{array}{l}\text { Very Good } \\
\text { at high HF }\end{array}$ & Very Good & Good & - & - \\
\hline
\end{tabular}

$\boldsymbol{H F}$ : heat flux; $\boldsymbol{U P}$ : Under-Predict, $\boldsymbol{O P}$ : Over-Predict, $\boldsymbol{C o}$ : comparable,

Comparable: when experiments and predictions in an agreement of $\pm 20 \%- \pm 30 \%$

Good: when experiments and predictions in an agreement of $\pm 10 \%-20 \%$

Very Good: when experiments and predictions in an agreement of lower than $\pm 10 \%$ 


\section{UNIVERSITY OF TWENTE.}

Engineering Technology Faculty

Department of Design,

Production and Management

P.O. Box 217,

7500 AE Enschede,

The Netherlands

23 March 2017

Object: Detailed respond to reviewers (ETFS-D-17-00122)

\section{Reviewer \#1}

Thank you for your suggestions and comments. Following your suggestions, we have considered your comments. In the attached highlighted version of the manuscript, you can find the added parts according to your comments and our modification with blue and deleted phrases with red. You can also find the detailed response to your comments and related added or deleted phrases as follow:

\section{COMMENT 1:}

In abstract, the sentence of "The performance of the thermosyphon with predictions of the pool boiling (filling ratio of $100 \%$ ) and a combination of the pool boiling and film evaporation models in the evaporator section (filling ratio<100\%) and also filmwise condensation model in the condenser section are compared with available predictive correlations and theories" is very long. Please restate it and use shorter sentences.

\section{ANSWER:}

Thank you for your comment. We consider your comments and re-written the sentence as follow.

\section{Removed sentences:}

The performance of the thermosyphon with predictions of the pool boiling (filling ratio of $100 \%$ ) and a combination of the pool boiling and film evaporation models in the evaporator section (filling ratio $<100 \%$ ) and also filmwise condensation model in the condenser section are compared with available predictive correlations and theories Added and revised sentences:

The performance of the thermosyphon with predictions of the pool boiling (filling ratio of 100\%) and a combination of the pool boiling and film evaporation models in 
the evaporator section (filling ratio $<100 \%$ ) are compared with available predictive correlations and theories. The experimentally obtained condensation heat transfers also evaluate by available filmwise condensation model in the condenser section.

\section{COMMENT 2:}

Why did you use Qav? Qin is mostly used as the amount of heat for calculating R. For example Energy Conversion and Management 2015, 92, 322-330 and etc. used Qin for their experiments.

\section{ANSWER:}

Thank you for your comment. It is quite correct that it is possible to use Qin to calculate the heat transfer coefficients as well as thermal resistance. However, characterizing the transferred heat transfer is a complicated task because of difficulty in obtaining accurate energy losses to the ambient surroundings. In addition, as it is evidenced in Fig. 2 the input and output heat fluxes are close to each other. Thus, to have a confidence in the measured value of transferred heat flux, the average input and output heat fluxes is considered. We hope, our answer convincing you.

\section{COMMENT 3:}

It can be useful if you calculate the performance of TPCT in different filling ratio.

\section{ANSWER:}

Once again thank you for indication to improve the manuscript. The evaluation the thermal performance of current document, very recently experimentally and numerically have evaluated the thermal performance of the thermosyphon at the different filling ratio. This manuscript is the second part of our study, thus this would be a repetition and it is out of the scope of this study. 
P.0. Box 217,

7500 AE Enschede,

The Netherlands

23 March 2017

\section{$\underline{\text { Reviewer \#2 }}$}

Thank you for your suggestions and constructive comments. Following your suggestions, we have considered your comments. In the attached highlighted version of manuscript, you can find the added parts according to your comments and our modification with blue and deleted phrases with red. You can also find the detailed response to your comments and related added or deleted phrases as follow:

\section{COMMENT 1:}

Since TPCTs have been applied in many energy and thermal processing applications, many researchers have conducted the corresponding experimental works and compared them with available correlations and theories. What's the difference between this paper's work and other researchers'? Are the experimental working conditions of this paper typical? Can the conclusions of this paper be applicable for other experimental research work? Maybe an available correlation having a good agreement with this paper has not a good agreement with other research.

\section{ANSWER:}

Thank you very much for your comments. Actually, it is correct that there are a lots of studies to evaluate the evaporation and condensation heat transfer of thermosyphons. Howevere, most of the published literature on the thermal behaviour of thermosyphons involves the use of heat transfer in liquid pool, there are rare study to evaluate heat transfer characteristic of thermosyphon considering the combined heat transfer coefficients associated with the liquid pool and annular liquid film in the evaporator section. Also, in the condenser section, Jouhara and Robinson (2010) used the same approach for the condesation section, but at very small diameter 
(7 mm). Thus, the obove discussion motivates a new study to evalute thermal behaviour of thermosyphons considering predective heat transfer correlations to be aplied in simple simulation e.g. Lumped capacitane models applicble to a variety of applications. Regarding your latter comment that "the conclusions of this paper be applicable for other experimental research work?", we considered another study at small dimater using wter as a working fluid in section 4 to clarify for reader to select an appropriate corrlation depending diamter, filling ratio and heat flux. Howevere, for another working fluid the results might be different.

\section{COMMENT 2:}

What's the accuracy of measuring devices? And please give the corresponding error analysis, especially the calculation of heat transfer coefficients.

\section{ANSWER:}

Thank you very much for your comment. As we mentioned in section 2, the details of experimental facilities describe in our recent paper [26]. Howevere, the corresponding error analysis for the calculated heat transfer coefficients are added accordingly.

\section{Added part:}

The experimental uncertainty of the measurement is calculated by the uncertainty in the temperature measurements at different applied powers, increasing from a higher power to lower one as indicated for total thermal resistance in Table 4.

\section{Table 4}

Uncertainty of experimentally measured total thermal resistance (filling ratio of 50\%)

\begin{tabular}{llllllll}
\hline Ieat transfer rate $(\mathbf{W})$ & & $\mathbf{3 0}$ & $\mathbf{6 0}$ & $\mathbf{1 0 0}$ & $\mathbf{1 5 0}$ & $\mathbf{2 0 0}$ \\
\hline Jncertainty in & \multirow{2}{*}{ overal } & thermal & 7.2 & 6.5 & 5.9 & 5.8 & 5.4 \\
\hline
\end{tabular}




\section{COMMENT 3:}

On Page 4, according to the literature review, it seems that previous studies mainly focused on pool boiling or film evaporation heat transfer. What's the reason? Also, they are related to higher filling ratios. Is it because that the higher filling ratio has a better performance and there is no need to figure out the performance of low filling ratio? Maybe there is an optimal filling ratio for a typical TPCT.

\section{ANSWER:}

Thank you again for your indication. Obviously, there is an optimal filling ratio. If it is considered that the optimal filling ratio means that a condensate film extending from the condenser end cap to the evaporator end cap at steady-state for a given heat input without any liquid at the bottom the device, in our recent publication and in the other studies in the litterature, it is confirmed that to ensure optimal and stable steadystate operation, an optimally filled thermosyphon is recommended with a small amount of additional working fluid to prevent breakdown of the liquid film. Therfore, it is important to study the thermal performance of thermosyphon at low filling ratio 20-50\% which the liquid pool and film evaporation can be considered.

\section{COMMENT 4:}

On Page 6, Eq. (2) gives the definition of the film Reynolds number. Please make it clear. Maybe $<$ mu $>1$ should be replaced by the dynamic viscosity of the vapor.

\section{ANSWER:}

Thank you for your note. We considered your comment to make clear the reynolds film number and the $\mu_{1}$ in our calculations is written correctly. 


\section{$\underline{\text { Revised sentence: }}$}

The film Reynolds number $\left(\operatorname{Re}_{f}\right)$ for this study is defined as

\section{COMMENT 5:}

On Page 7, in Eq. (13), the hfilm should be replaced by he,film.

\section{ANSWER}

Thank you for your comment. It is revised accordingly.

\section{COMMENT 6:}

On Page 9, Eq. (16) gives the definition of condensation heat transfer coefficient, which is related to the average wall temperature of condenser regions. However, according to Figure 2, there are just two temperature sensors. Why? It's insufficient to obtain more accurate wall temperature.

\section{ANSWER:}

Thank you for your comment. We revised the sentence as follow. Also for the number of thermocuples in the condenser section, besed on on the arrange of thermocuples and short condenser section, we considered 2 thermocuples.

\section{$\underline{\text { Added and revised sentences: }}$}

The heat transfer capacity of the condenser section is also reflected through condensation heat transfer coefficient $\left(h_{c}\right)$ for TPCTs. This is associated with conduction through the liquid film inside the thermosyphon and related to the average wall temperature of condenser section which can be evaluated using the following equation:

\section{COMMENT 7:}

In the Results and discussion, many results are related to the cooling temperature. It is the inlet temperature of cooling water? Please make it clear. 
P.0. Box 217,

7500 AE Enschede,

The Netherlands

23 March 2017

\begin{abstract}
ANSWER:
we revised the phrases accordingly.
\end{abstract}

\title{
COMMENT 8:
}

On Page 11, "4.2.2 Condensation hat transfer" is mistake.

\section{ANSWER:}

Thank you for your comment. It is revised.

\section{COMMENT 9:}

In Figure 10 (a), the tendency of experimental data is different with other research work, why?

\section{ANSWER:}

Thank you for your comment. This is because of this fact that at a very low filling ratio, the thermosyphon is not working under normal operation. As indicated in the manuscript: "At filling ratio of $8 \%$ dryout occurs due to a very low filling ratio (skipped from the following analysis)".

\section{COMMENT 10:}

Table 1 and 2 give some correlations form other research works. What's the applicable range of them? Please make sure that they can be applied for this experiment.

\section{ANSWER:}

Thank you for your comment. All the selected correlations are applicable for our experiments in terms of heat flux, working fluid, etc. and we selectd the correlations which appear frequently in thermosyphon publications to obtain a sense of their applicability for the situation under study. 
